\title{
The Implications of Future Building Scenarios for Long-Term Building Energy Research and Development
}

W. T. Flynn

December 1986

Prepared for the U.S. Department of Energy under Contract DE-AC06-76RLO 1830

Pacific Northwest Laboratory Operated for the U.S. Department of Energy by Battelle Memorial Institute 


\title{
DISCLAIMER
}

This report was prepared as an account of work sponsored by an agency of the United States Government. Neither the United States Government nor any agency thereof, nor Battelle Memorial Institute, nor any of their employees, makes any warranty, expressed or implied, or assumes any legal liability or responsibility for the accuracy, completeness, or usefulness of any information, apparatus, product, or process disclosed, or represents that its use would not infringe privately owned rights. Reference herein to any specific commercial product, process, or service by trade name, trademark, manufacturer, or otherwise, does not necessarily constitute or imply its endorsement, recommendation, or favoring by the United States Government of any agency thereof, or Battelle Memorial Institute. The views and opinions of authors expressed herein do not necessarly state or reflect those of the United States Government or any agency thereof, or Battelle Memorial Institute.

\author{
PACIFIC NORTHWEST LABORATORY \\ operated by \\ BATTELLE \\ for the \\ UNITED STATES DEPARTMENT OF ENERGY \\ under Contract DE-AC06-76RLO 1830
}

\begin{tabular}{|c|c|}
\hline \multirow{2}{*}{\multicolumn{2}{|c|}{ Printed in the United States of America }} \\
\hline & \\
\hline \multicolumn{2}{|c|}{$\begin{array}{l}\text { Available from } \\
\text { National Technical Information Service }\end{array}$} \\
\hline \multicolumn{2}{|c|}{ United States Department of Commerce } \\
\hline \multicolumn{2}{|c|}{5285 Port Royal Road } \\
\hline \multicolumn{2}{|c|}{ Springfield, Virginia 22161} \\
\hline \multirow{2}{*}{\multicolumn{2}{|c|}{$\begin{array}{l}\text { NTIS Price Codes } \\
\text { Microfiche A01 }\end{array}$}} \\
\hline & \\
\hline \multicolumn{2}{|c|}{ Printed Copy } \\
\hline & Price \\
\hline Pages & Codes \\
\hline 001-025 & $\mathrm{A} 02$ \\
\hline 026-050 & $\mathrm{A} 03$ \\
\hline 051-075 & $\mathrm{A} 04$ \\
\hline $076-100$ & A05 \\
\hline $101-125$ & A06 \\
\hline $126-150$ & $\mathrm{~A} 07$ \\
\hline $151-175$ & $\mathrm{~A} 0 \mathrm{~B}$ \\
\hline $176-200$ & A09 \\
\hline 201-225 & A010 \\
\hline $226-250$ & A011 \\
\hline $251-275$ & A012 \\
\hline $276-300$ & A013 \\
\hline
\end{tabular}


THE IMPLICATIONS OF FUTURE BUILDING SCENARIOS FOR LONG-TERM BUILDING ENERGY RESEARCH AND DEVELOPMENT

W.T. Flynn

December 1986

Prepared for the U.S. Department of Energy under Contract DE-AC06-76RLO 1830

Pacific Northwest Laboratory Richland, Washington 99352 


\section{EXECUTIVE SUMMARY}

This report presents a discussion of alternative future scenarios of the building environment to the year 2010, and assesses the implications these scenarios present for long-term building energy R\&D needs. Two panels of professionals with expertise in building energy R\&D, representing a national cross-section of government, private industry, and academic interests, provided expert opinion in developing the scenarios and assessing the scenario implications for R\&D needs. The topic for this analysis was determined by the panel members as:

Develop scenarios describing the factors that affect

the characteristics of residential and commercial buildings, their construction, and their use, including institutional

factors, and the consequent impacts on building energy consumption in the U.S. through the year 2010 .

\section{Building Scenarios}

Three alternative building scenarios are presented in this report: 1) the base scenario, essentially a continuation of the current state of the world; 2) the "A" scenario, characterized by high GNP growth and a high rate of technological progress in the economy; and, 3) the "B" scenario, characterized by a low GNP growth and a low rate of technological progress in the economy. The $A$ and $B$ scenarios were presented to the panel members to derive the implications for building energy R\&D needs. These scenarios were chosen because they encompass the base scenario and provided the bounds within which to examine the interaction of forces that will shape the future building environment.

\section{"A" Scenario: High Growth, High Technology}

The macro-environment under this scenario is characterized by a very rapid rate of technological progress in the economy and a high rate of GNP growth. The economy has increasingly shifted towards a "services" economy. Real interest rates are high, while inflation is projected to be low. Energy 
prices are high, with oil, gas, and electricity all in their highest real cost projections.

Population is growing according to the census highest projections, and immigration into the country is above trend, adding to the higher native growth rate. U.S. population is projected to increase from 239.9 million people in 1985 to 310 million people in 2010. However, the rate of population growth increases until 1995, and then steadily declines, although remaining positive, thereafter.

The proportion of the population in the older age groups is increasing in this scenario. The percentage of the population 65 years of age or older increases from $11 \%$ in 1985 to almost $14 \%$ in 2010, while those 45-64 years of age increases of $18 \%$ in 1985 to $26 \%$ in 2010 . The age group 18-44, the prime childbearing age group, declines from $42 \%$ of the total in 1985 to $35 \%$ in 2010 . The rate of household formation in this scenario is expected to be above trend. The increase is due primarily to the increased proportion of the population that is aging, and the increased number of immigrants.

The proportion of the population living in the "Sunbelt" is above trend, more than $45^{\circ}$ of the population in this scenario. [The Sunbelt is divided into two climatic zones: low heating/high cooling (less than 4,000 HDD and greater than 2,000 CDD), and low heating/low cooling (less than 4,000 HDD and less than 2,000 CDD)]. This shift implies reduced energy demands due to reduced need for space heating, as well as a possible shift to more electricity relative to fossils fuels.

The trend towards suburbanization and away from central cities continues in this scenario. However, the increasing suburbanization, as well as the increasing demand for space in the Sunbelt, will put upward pressure on land prices. Coupled with high interest rates and increasing energy costs, the affordability of new homes, especially single-family homes will decline. The decreased affordability of new housing will lead to increased demand for cheaper housing in the form of smaller new units, more manufactured housing, the conversion of buildings from other uses to residential uses, increased retrofit of existing buildings, and an increased demand for multi-family units, especially among the more elderly portions of the population. Imingrant families will also have a high demand for multi-family housing, predominantly 
in the center cities, thus leading to an overall decline in the share of single family houses in the building stock. The increased percentage of multi-family housing will raise building densities in both the center city and suburban areas.

The rate of growth of commercial floor space is expected to grow at a rate greater than $2 \%$, compared to a trend rate of $1.5-2 \%$ per year. This high growth rate reflects the shift towards a more services oriented economy, increasing the demand for office space, as well as the continued dispersion of residences in the suburban areas, calling for more retail and other buildings to serve this population, especially health clinics for the elderly.

Higher energy prices are expected to maintain demand for relatively energy efficient buildings, although only at the current trend. The shift to the Sunbelt will reinforce the trend.

\section{"B" Scenario: Low Growth, Low Technology}

The macro-environment under this scenario is characterized by a low rate of technological progress and a low rate of GNP growth. The economy is still increasingly a services economy, while real interest rates are lower, and inflation is higher. 0il, gas, and electricity prices are all in their lowest real cost projections. Population is growing according to the census lowest projections, and immigration into the country is below trend. The U.S. population is projected to increase from 237.6 million people in 1985 to 261.5 million in 2010. The rate of population growth increases until 1990, and steadity declines thereafter.

The proportion of the population in the various age groups is approximately the same as in Scenario $A$ in $2010-14 \% 65$ or over, 29\% 45-64, 32\% 18-45 but the absolute numbers of people is substantially smaller. In addition to the smaller number of people, the rate of household formation in each age group is expected to decline in this scenario. The primary reason for the decline is the lower income implied by the low rate of GNP growth. The shift of the population to the Sunbelt is reversed in this scenario, so that less than $42 \%$ of the population resides in the Sunbelt by 2010 . This reversal of trend implies more heating degree days relative to cooling degree days, and more reliance on fossil fuel for space heating. 
The trend towards suburbanization is also reversed in this scenario as more of both the youngest and oldest households choose to live in the centra? cities. This trend gives rise to an increased demand for multi-family housing in the cities, but with lower densities than historically due to the relatively smaller population. The lower densities imply a larger size per unit (sq. ft.). The move into central cities relieves the pressure on housing costs in the suburbs, leading to a decline in the price of new units. However, incomes are also lower due to the low rate of GNP growth so that overall housing affordability declines, leading to a lower rate of new construction. The new single family units that are built tend to be larger, catering to the demands of the more affluent who can afford to buy them.

The lower rate of GNP growth also reduces the demand for new commercial building space. The new commercial buildings that are built are bujt in the central cities where prices are higher, leading to construction of more large buildings.

Energy prices are low so that overall building energy consumption increases. Furthermore, in an attempt to reduce costs and make buildings more affordable, new units are constructed at a lower level of themal efficiency, leading to a general decline in the themal efficiency of the building stock.

\section{Summary of R\&D Recommendations}

Although the A and B scenarios described different future societies in terms of economic, demographic, and spatial distributions, there is a commonality to the research recommendations made by the panel. This outcome is encouraging in that the recommendations are applicable over a wide range of possible building futures.

The recommended areas of research can be broadly classified into five nonexclusive groups: 1) the quality of the building environment; 2) the fabric of the building environment; 3 ) the construction of the building environment;

4) the maintenance of the building environment; and 5) the form of the building environment. Two more areas, building diagnostics and technology transfer, are germane to each of the other five. 


\section{Quality of the Building Environment}

In both scenarios maintenance of the quality of the internal building environment was deemed necessary for the safety and health of occupants. It is also necessary for the introduction of new materials, new construction practices, and energy efficient designs. Research in this area centers primarily about air and environmental control research:

- development of air quality sensors and controls;

- development of improved sealants and air barriers;

- research on improved air cleaning and humidification technologies;

- research on materials, controls, or designs to enhance day lighting;

- development of inexpensive air heat exchangers.

Fabric of the Building Environment

Research in this area pertains to the need for new materials. This need was thought necessary to increase the affordability of housing; to increase design flexibility in new construction and retrofits; to improve air and environmental quality; and to improve energy efficiency through systems integration. Recommendations for materials research were:

- non-toxic super insulations;

- switchable/phase change surfaces and glazings;

- thermal storage materials;

- high temperature absorbents for heat pumps;

- new chemistries for sensing materials and fire resistance;

- research on composites;

- designs for pre-cast roof panels;

- research on new adhesives and fasteners.

\section{Construction of the Building Environment}

The manner in which building components are assembled at the site or in the factory has a large role in the ultimate energy efficiency of a building. It also significantly affects building cost. Quality control was seen by the panel to be of major importance. Recommended research areas in building construction technology are:

- robotic construction techniques; 
- cad/cam systems;

- design simulation models;

- modular/flexible design construction techniques.

\section{Maintenance of the Building Environment}

Maintenance of the building environment is concerned with the operating efficiency of buildings and their relationship to the suppliers of energy, in particular the electric utilities. Systems integration research was seen as the mechanism whereby the interaction of all building components, including mechanical systems, could be examined. This research will indicate the most effective combinations of active and passive energy utilization techniques for various building types and climatic regions. The results of this research are seen as contributing to building design flexibility, flexibility in electric utility management, and lowering that portion of building operating cost attributable to energy use, thereby increasing building affordability. Recommended areas of research are:

- thermal storage;

- HVAC equipment efficiency;

- passive solar/photovoltaics;

- computer controls/expert systems;

- operable devices (louvers, awnings, etc.);

- improved lighting (daylighting, lighting control);

- load management research (time-of-day rates, load control);

- cogeneration and district heating;

- human factors research.

Form of the Building Environment

The form of the building environment is a function of both land use patterns and the uses for which buildings are intended to serve. Alternative lifestyles can give rise to many different building types and uses, ranging from building space serving as both a residence and work place to self-contained urban villages. Some research ares implied by the alternative lifestyles considered by the panel are:

- energy generation from bio-technological waste recycling;

- on-site processing and reclamation of waste; 
- equipment integration (e.g., cooling, water heating, HVAC)

- cogeneration/district heating;

- utility ownership of energy using building components.

\section{Building Diagnostics}

Research into the diagnostics of energy use in buildings requires accurate data bases and analytical methods. This information is necessary to identify the most effective combinations of building components and also to show proof of concept for new components. Quality information is required for all areas of building research. Panel recomnendations include:

- improved data base;

- improved diagnostic/simulation models.

\section{Technology Transfer}

Transferring the results of building research to those who can apply the results in actual practice is critical to the success of programs designed to improve building/utility energy efficiency, increase the affordability of housing, and maintaining the global competitiveness of the building industry. As an intermediate step, it is also critical to have the results of proven research accepted by the bodies that prepare building codes and standards and by the ultimate purchasers of buildings. Some possible ways to facilitate the technology transfer process recommended by the panel are:

- development/improvement of technology centers;

- improve the engineering and technological basis for codes and standards;

- enhance government/industry cooperation. 

. 


\section{ACKNOWLEDGMENTS}

The preparation of this report required the cooperative efforts of a large number of people without whose support this document could not have been completed. A special appreciation is extended to the panel members listed in Appendices $A$ and $B$ who volunteered their time and expertise. Their efforts were fundamental in developing the scope and conclusions of this study. Thanks is also extended to Dr. Fred Abel of the office of Buildings and Community Systems, U.S. Department of Energy, who as the project monitor provided the technical guidance and support for this project.

Space does not permit identification of all the researchers at Pacific Northwest Laboratory who provided assistance during the various phases of this project. However, the contributions of several staff members warrants special mention. Rafael Rivera provided the vision and impetus for this project; Richard Scheer provided the managerial support. Dr. Gary Stacy (Battelle Columbus) was instrumental in organizing and conducting the group sessions and in providing analytical support in the operation of the computer programs. Or. David Belzer, Dr. John Reilly, and Dr. Joseph Roop provided invaluable analytical assistance throughout the conduct of this project, as well as providing critical conments and suggestions for improvement to an earlier draft of the report. The preparation of this report was greatly facilitated by the typing of various drafts by Jackie Jenkins, while Jodi Kohlman handled the administrative details. 


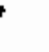


EXECUTIVE SUMMARY $\cdot$ •

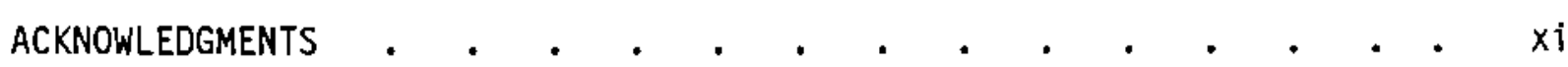

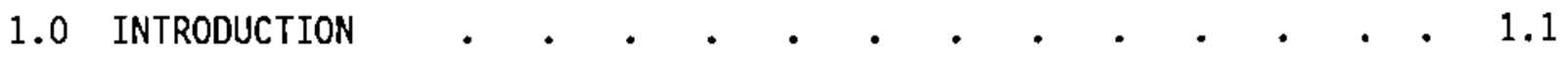

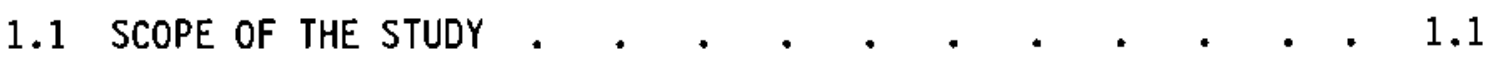

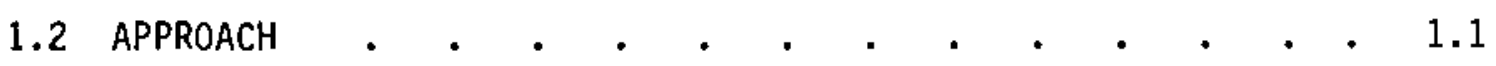

1.3 BACKGROUND ANO RATIONALE.$\quad \cdot \quad \cdot \quad \cdot \quad \cdot \quad \cdot \quad \cdot \quad \cdot \quad \cdot 1.3$

1.3.1 Introduction . . . . . . . . . . . 1.3

1.3.2 Historical Perspective . . . . . . . . 1.4

1.3.3 Rationale . . . . . . . . . . . 1.6

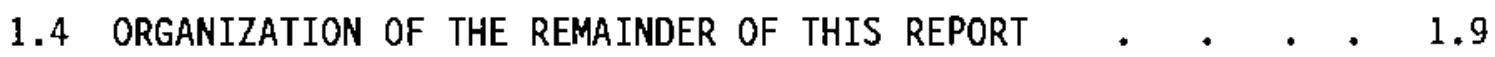

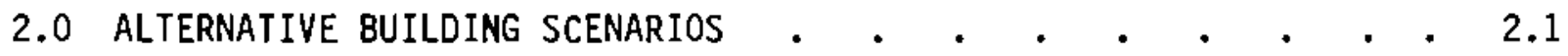

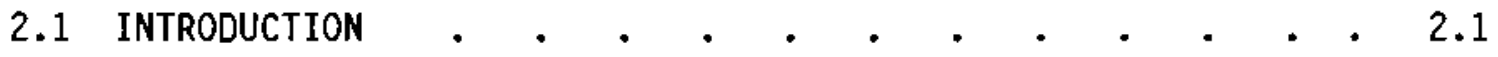

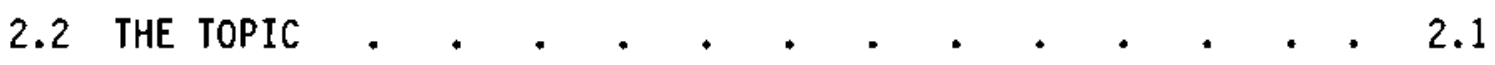

2.3 STRUCTURE OF THE SCENARIOS

2.4 Base SCENARIO

2.5 "A" SCENARIO: HIGH ECONOMIC GROWTH, RAPID RATE OF
TECHNOLOGICAL CHANGE

2.6 "B" SCENARIO: LOW ECONOMIC GROWTH, SLOW RATE OF
TECHNOLOGICAL CHANGE...
.

3.0 SCENARIO IMPLICATIONS FOR BUILDING ENERGY R\&D $\quad . \quad$. $\quad . \quad$. $\quad . \quad 3.1$

3.1 INTRODUCTION $\cdot$ •

3.2 APPROACH . . . . . . . . . . . . . . . . . . 3.1

3.3 R\&D RECOMMENDATIONS FROM THE "A" SCENARIO-HIGH GROWTH,

3.4 R\&D RECOMMENDATIONS FROM THE "B" SCENARIO-LOW GROWTH,
LOW TECHNOLOGY . . 3.9 


\section{CONTENTS}

3.5 SUMMARY OF R\&D RECOMMENDATIONS . . . . . . . . . 3.10

3.5.1 Quality of the Building Environment . . . . . 3.15

3.5.2 Fabric of the Building Environment . . . . 3.15

3.5.3 Construction of the Building Environment . . . . 3.15

3.5.4 Maintenance of the Building Environment . . . . 3.16

3.5.5 Form of the Building Environment . . . . . . 3.16

3.5.6 Building Diagnostics . . . . . . . . . . 3.17

3.5.7 Technology Transfer . . . . . . . . . . 3.17

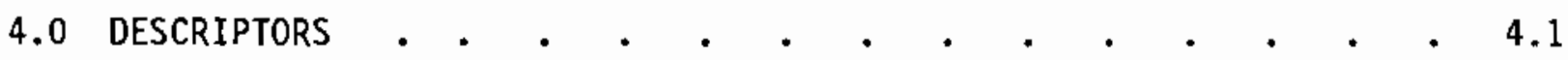

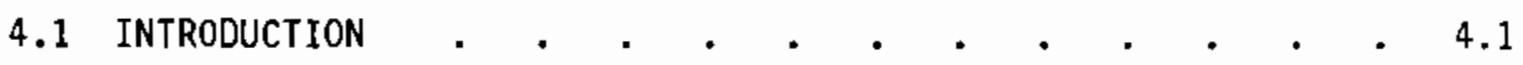

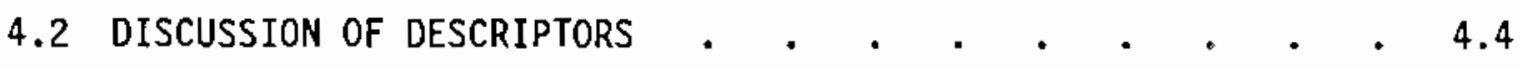

4.2 .1 Fuel Prices . . . . . . . . . . . 4.4

4.2.2 Interest Rates . . . . . . . . . . 4.10

4.2.3 Technological Process . . . . . . . . 4.16

4.2.4 Household Formation . . . . . . . . . . 4.19

4.2.5 Geographic Distribution of the Population . . . 4.23

4.2.6 Percent Single Family Homes . • • . • • . 4.27

4.2.7 Residential Energy Use Intensity . . . . . . 4.30

4.2.8 Commercial Floor Space . . . . . . . . . 4.35

4.2.9 Commercial Construction Cost . . . . . . . 4.44

4.2.10 Building Type (Large Commercial Buildings) . . . 4.47

REFERENCES

APPENDIX A - PANEL MEMBERS + • • • • • • • • • • • A-1

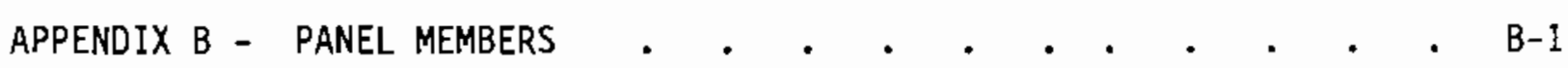

APPENDIX C - METHODOLOGY AND COMPUTER RESULTS . . • . . • . • c c-1 


\section{TABLES}

3.1 R\&D Recommendations from the "A" Scenario . . . . . . . . 3.5

3.2 R\&D Recommendations from the "B" Scenario . . . . . . . . 3.11

4.1 Descriptors, Descriptor States, and $\underline{A}$ Priori Probabilities. . . 4.2

4.2 Population Per Household-U.S. Total, 1960-1984 . . . . . . 4.21

4.3 Estimated 1983 Stocks and Growth Rates by Building Type . . . 4.36

4.4 Percentage Increase in Floor Space . . . . . . . . . . 4.37

4.5 Projections of 2010 Floor Space . . . . . . . . . . . . 4. 43

4.6 Percentage of Floor Space in New Buildings

Over 100,000 Square Feet (Million Sq. Ft.) . . . . . . . 4.51

4.7 Percentage of Building Stock in Bufldings

Larger than 100,000 Square Feet . . . . . . . . . 4.52

C.1 Macro-Environment . . . . . . • • . . . . . c.7

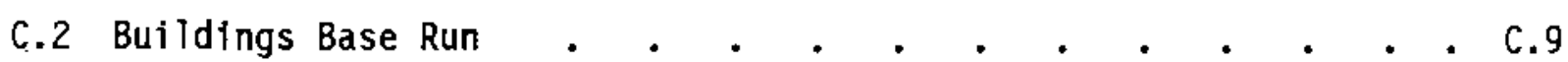

C.3 Buildings "A" Scenario. . . . . . . . . . . . . C.12

C.4 Buildings "B" Scenario. . . . . . . . . . . . . . C.15 


\section{FIGURES}

1.1 Scenarios Development Process . . . . . . . . . . 1.2

4.1 Average End-Use Distillate Prices (1984 Dollars). . . . . 4.5

4.2 Average End-Use Gas Prices (1984 Dollars) . . . . . . . 4.6

4.3 Average End-Use Electricity Prices (1984 Dollars). . . . . 4.7

4.4 Prime Rate, Inflation and Real Growth in the U.S., 1950-1984, With Forecasts To 1995 . . . . . . . . . . . 4.13

4.5 Productivity Measures for the Private Business Sector 1948-1981 . . . . . . . . . . . . . 4.17

4.6 Sun Belt States and Heating and Cooling Degree Days . . . . 4.24

4.7 Sun Belt Population, Share of U.S. Population . . . . . . 4.25

4.8 Residential Energy Use Intensity EUI

(millions of BTU's per household) . . . . . . . . . 4.32

4.9 Floor Space per Employee . . . . . . . . . . . . 4.39

4.10 Floor Space-Commercial (Trade \& Office) . . . . . . . 4.39

4.11 Floor Space per Capita (Population age 5-15) . . . . . . 4.40

4.12 Floor Space - Education . . . . . . . . . . . 4.40

4.13 Floor Space per Capita (Weighted Population) . . . . . . 4.41

4.14 Floor Space - Health . . . . . . . . . . . . 4.41

4.15 Floor Space per Capita . . . . . . . . . . . 4.42

4.16 Floor Space - Other Buitdings . . . . . . . . . . 4.42

4.17 New Nonresidential Structures, Relative Price . . . . . . 4.46

4.18 Percent Floor Space in Large Buildings Large Buildings: $>100,000 \mathrm{Sq}$. Ft. . . . . . . . . . 4.50 


\subsection{INTRODUCTION}

\subsection{SCOPE OF THE STUDY}

This report presents a discussion of alternative future scenarios of the building environment to the year 2010 and assesses the implications these scenarios present for long-term building energy R\&O. The scenarios and energy R\&D implications derived from them are intended to serve as the basis from which a strategic plan can be developed for the management of R\&D programs conducted by the Office of Buildings and Community Systems, U.S. Oepartment of Energy. The scenarios and analysis presented here have relevance not only for government R\&D programs; on the contrary, it is hoped that the results of this effort will be of interest and useful to researchers in both private and public sector organizations that deal with building energy R\&D.

Making R\&D decisions today based on an analysis that attempts to delineate the nexus of events 25 years in the future are clearly decisions made in the face of uncertainty. Yet, the effective management of R\&D programs requires a future-directed understanding of markets, technological developments, and environmental factors, as well as their interactions. The analysis presented in this report is designed to serve that need. Although the probability of any particular scenario actually occurring is uncertain, the scenarios to be presented are sufficiently robust to set bounds within which to examine the interaction of forces that will shape the future building environment.

\subsection{APPROACH}

An analysis of alternative futures for the building environment to the year 2010 for the purposes of identifying R\&D needs is a broad and complex undertaking. The approach used in this study to narrow the analysis to manageable proportions was to combine the expert opinion of professionals in the building energy field with a structured computer program that manipulated the expert opinion to generate scenarios. The scenarios development process is depicted in Figure 1.1. 


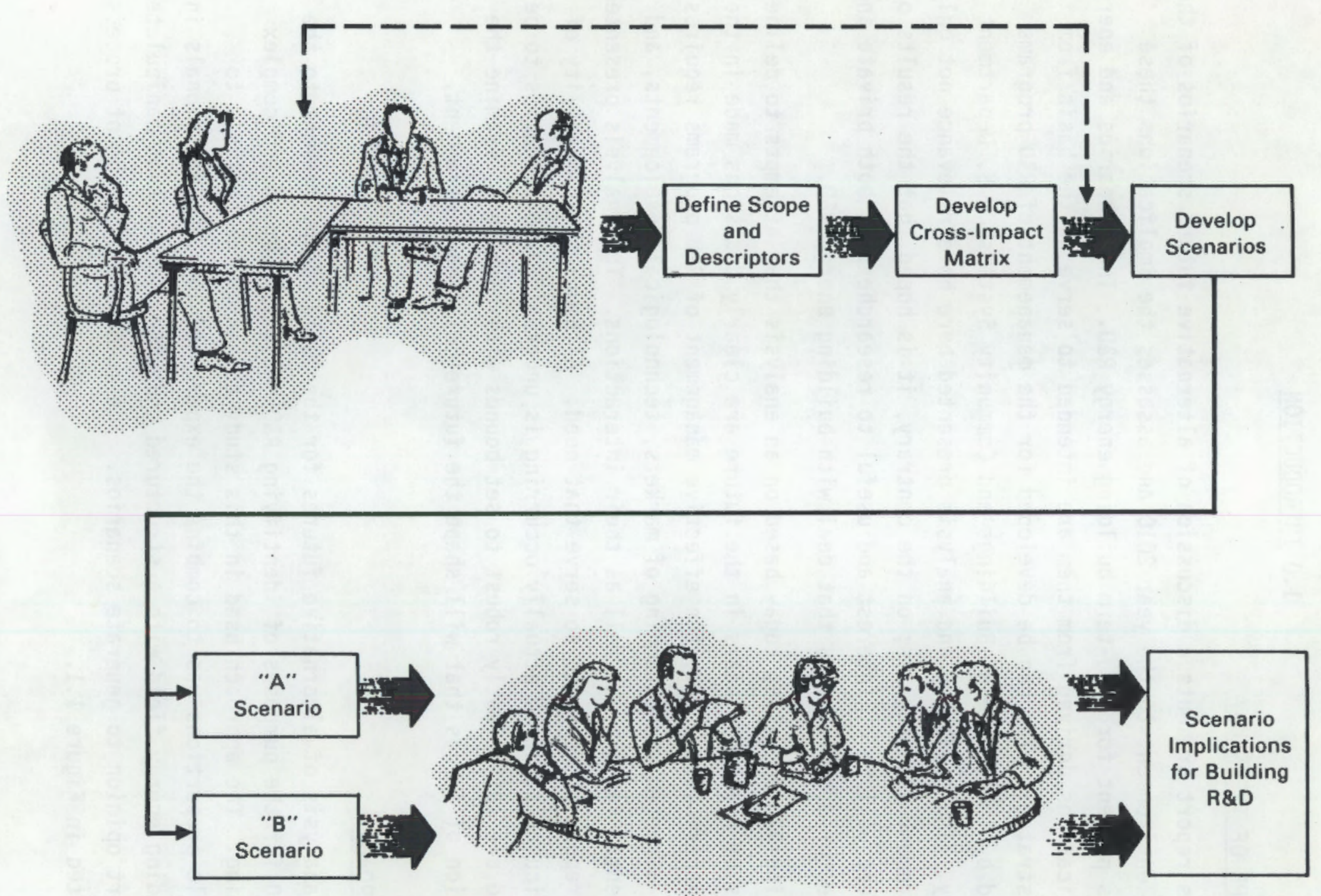

FIGURE 1.1. Scenarios Development Process 
A panel of experts was convened to define the scope of the study and to identify the descriptors, or variables, that were necessary to conduct the analysis (the panel members for this part of the process are listed in Appendix A. Further detail on the descriptors is contained in Chapter 4.0). The topic for this analysis was determined by the panel members as:

Develop scenarios describing the factors that affect the characteristics of residential and commercial buildings, their construction, and their use, including institutional

factors, and the consequent impacts on building energy

consumption in the U.S. through the year 2010 .

The next step in the process was to develop the cross-impact matrix. The cross-impact matrix records the panel members judgments as to the strength of the interrelationships among the descriptors. As Figure 1.1 shows, developing the cross-impact matrix was an iterative procedure until consensus was reached. The scenarios were generated from the cross-impact matrix using a computer program named BASICS. (The scenarios are presented in Chapter 2.0. Appendix $C$ describes the methodology and presents the computer results).

Two scenarios that were felt to represent the bounds of the building future were presented to another panel of building energy R\&D experts to derive the scenario implications for long-term building R\&D needs (The panel members for this part of the process are listed in Appendix B. Chapter 3.0 presents the R\&D recommendations). The "storyboard" creative thinking approach was used to elicit the R\&D recommendations from the panel members.

The strength of this approach is that it provides a procedure for combining quantitative and qualitative information in a structured framework of analysis. Furthermore, by incorporating the expert opinion of two different panels with slightly different expertise, a built-in cross-check of the analysis was provided, as well as involving a larger number of professionals in the process.

\subsection{BACKGROUND AND RATIONALE}

\subsubsection{Introduction}

Great strides have been made in the U.S. economy to overcome the adverse impacts of the energy crisis of the 1970's. Indeed, much of the concern these 
days centers on the effects the worldwide glut of oil is having on oil prices, with their consequent impact on the debt burden of the oil-exporting developing countries, (for example Mexico), petroleum/banking industry profitability, long-term domestic petroleum supply, and employment in the petroleum producing states (Business week 1986). Ironically, the prescription for curing these i11s is higher oil prices that would be maintained through production quotas and tariffs--a prescription not very different from the energy situation of the 1970 's.

It would be unwise, however, to forget the lessons learned over the past thirteen years, form the time of the first Arab oil embargo in 1973. Although the past is not necessarily prologue, especially when looking 25 years hence, it certainly can serve as a first reference by which to judge the validity of an analysis of the future. An historical overview of the salient points follows.

\subsubsection{Historical Perspective}

What has been the magnitude of the domestic economy's response to the energy price shocks of the last decade? U.S. GNP grew from 2.7 trillion dollars (\$1982) in 1973 to 3.6 trillion dollars $(\$ 1982)$ in 1985 , a $33 \%$ increase. In contrast, over the same period energy consumption per dollar of GNP dropped 24\%, from 27.1 thousand Btu per 1982 dollar in 1973 to 20.7 thousand Btu per 1982 dollar in 1985 (EIA 1986). This reduction in energy input per dollar of output has been the result of conservation (increases in end-use efficiencies), changes in product mix (moving production from more to less energy intensive goods and services), substitution of energy with a higher "form value" (e.g., gas or electricity substituted for coal), and "doing without" (an undesired lower level of energy service).

These trends, in turn, wrought changes in end-use energy consumption $\left(^{*}\right)$ by economic sector (i.e., residential, commercial, industrial, and

$\left.{ }^{*}\right)$ End-use energy consumption excludes energy used to generate and distribute electricity. By convention, only energy losses associated with electricity generation are excluded from the end-use total. Other fuels used in the process of delivering energy to final consumers are distributed to either the transportation or industrial sectors. primary, or total, energy consumption includes all generation and distribution losses. 
transportation). End-use energy consumption increased by nearly $45 \%$ from 1960 to 1970 , but grew only about $7 \%$ between 1970 and $1980--$ from 54.8 quads in 1970 to 58.5 quads in 1980. Furthermore, end-use energy consumption declined sharply after the second oil price shock in 1979 such that end-use consumption was 52.9 quads in 1983, a level $10 \%$ lower than in 1980 and $3.5 \%$ lower than in 1970 (EIA 1984). On the other hand, primary energy consumption ${ }^{*}$ ), has increased by about 6\% over the 1970 to 1983 period, from 66.4 quads to 70.5 quads. This increase reflects the economy's increasing reliance on electricity, particularly in the residential and commercial sectors. In fact, the post1980 decline in total energy consumption has resulted almost entirely from reduced energy use in the industrial sector (EIA 1984).

Residential and commercial buildings have accounted for a relatively constant share of 33-36\% of primary energy consumed in the U.S. since 1970, and a share of $27 \%$ of end-use energy. The absolute magnitudes show an increase in primary energy consumption from 21.7 quads in 1970 to 25.5 quads in 1983 , reflecting the increasing use of electricity in these two sectors. End-use consumption has actually declined slightly over the period, from 14.9 quads in 1970 to 14.3 quads in 1983 (EIA 1984).

The decline in end-use energy consumption, however, has taken place at the same time that the number of households in the U.S. increased by $32.3 \%$ from 1970 to $1983,63.4$ million to 83.9 million, and the growth rate of square feet of commercial buildings was estimated to be $2.3 \%$ per year. clearly, the end-use energy "productivity" of these two sectors has been increasing.

The price-induced U.S. (and worldwide) responses of conservation, changes in product mix, energy substitution, and, in some cases, doing without have exerted strong pressures in the energy market. After a steady increase through most of the period after 1973, average imported oil prices peaked in 1980 at 39.6 dollars per barrel (\$1982), but have since fallen $62 \%$ to 15.2 dollars per barrel (\$1982) (EIA 1986). U.S. dependence on petroleum imports has declined from $46.5 \%$ of total oil requirements in 1977 to $27.2 \%$ in 1985, $7.6 \%$ lower than imports of $34.8 \%$ in 1973. Furthermore, only $3 \%$ of petroleum imports came from the Arab OPEC countries in 1985, down from the peak of $17.3 \%$ in 1977 and 16.5\% in 1979. In addition, the U.S. has stored approximately 500 million barrels of oil in the Strategic Petroleum Reserve (EIA 1986). The 
U.S. has also taken legislative action to eliminate the rigidities that existed in U.S. energy markets in the $1970^{\prime} \mathrm{s}$ and earlier, as evidenced by the deregulation of domestic oil and natural gas prices.

\subsubsection{Rationale}

This picture shows a response that has had the desired outcome. Aside from some adjustment problems in the oil industry, domestic economic growth has been restored while the use of energy has become increasingly efficient. Indeed, a legitimate question has been raised as to the value of long-term building energy R\&D given the economic adjustments already achieved. The answer is that long-run complacency could be even costlier than the short-run crises already experienced.

Research and development programs provide the knowledge base that leads to technical innovations in methods of production and new products that have been the main source of increases in productivity in the U.S. Interest in building energy R\&D grew out of the 1970's energy crisis and rapid increases in energy prices. Technological improvements offered the opportunity to save energy and reduce costs while providing a high level of energy services to residential and commercial users. The pay-off to R\&D is relatively long-term, however. Development, testing, marketing and significant market penetration of new technologies takes about ten years, and for major technologies up to 25 years or more. Thus, the R\&D efforts of the 1970's are now beginning to payoff even as the world focuses on the oil glut and falling energy prices. In fact, the reduced demand due to the penetration of efficient technologies is a major cause of the oil glut and falling energy prices.

The "short-run" costs of the transition form scarcity to glut, however, were by no means insignificant. There were recessions in 1973-75, 1979-80, and in 1981-83, during which unemployment exceeded $10 \%$ for the first time since the great depression. Each of these recessions was related to the energy price shocks of the period or in an attempt to fight the inflation that was created in large part by energy price increases. From 1953 to 1973, real GNP grew at an average annual rate of $3.6 \%$ per year, while real GNP per capita grew at an average annual rate of 2.1\% per year. From 1973 to 1983, however, real GNP growth fell to an average annual rate of $1.9 \%$ per year, while real GNP per capita fell to an average annual growth rate of $0.9 \%$ per year (Dornbusch 
1984, p. 580). One way to appreciate the difference in the growth rates between the two periods is to notice that at an average annual growth rate of $2.1 \%$ per year, GNP per capita will double in 33 years, while at an average annual growth rate of $0.9 \%$ per year it will take 76 years for GNP per capita to double. In 1972, direct annual energy expenditures had declined to only $7 \%$ of GNP, or about $\$ 960$ per year per capita $(\$ 1982)$. By 1980 the figure had more than doubled to over $\$ 2,000$ per person $(\$ 1982$ ), or about $15 \%$ of GNP (Sant et al. 1984 p. 11). The economic loss implied by these numbers, moreover, are permanent losses to the U.S. economy.

Even more ominous for the long-term vitality of the U.S. economy has been the sharp decline in the rate of productivity growth since 1973, with its consequent impact on the rate of growth of potential output. From 1960 to 1973 , productivity grew at an average annual rate of $2.9 \%$, while potential output grew at an average annual rate of $3.6 \%$. In the 1973-79 period, however, the average annual rate of productivity growth fell to $0.8 \%$ per year; in the 1979-82 period it fell even farther to $0.5 \%$ per year. For those same two periods, the average annual growth rate of potential output fell to $3.3 \%$ and $2.6 \%$, respectively (Dornbusch 1984, p. 594).

The reasons for the decline in the growth of productivity have been puzzling and are the subject of continuing research. It appears less than coincidental, however, that the decline in productivity growth coincided with the two major oil price shocks of the $1970^{\prime} \mathrm{s}$. The few studies that have examined the energy-productivity link have provided estimates of the effect on potential output ranging from less than one to over four percent (Denison 1979, Tatom 1982, and the sources cited therein). A recent study states that "... a $10 \%$ rise in the relative price of energy reduces output, productivity, and the capital-labor ratio by 1.22 percent. From the third quarter of 1973 to the third quarter of 1974, and again from the first quarter of 1979 to the second quarter of 1980 , the relative price of energy rose 40 percent. Given the estimates above, each shock reduced productivity and potential output by 3.6 percent in the short-run and 4.9 percent... in the long-run." (Tatom 1982, p.8). Regardless of the precise magnitudes, it is quite clear that adjustment to the energy price shocks of the 1970's imposed substantial current and future costs on the U.S. economy. 
With the uncertainty that characterizes the world market in oil, there is no guarantee that the massive transfers of wealth from the oil-importing to the oil-exporting nations that took place over the last decade will not be repeated. As was mentioned previously, the decline in energy consumption in the U.S. since 1980 has been almost entirely because of reduced energy consumption in the industrial sector, due in large part to the severe worldwide recession of 1981-83. It should be remembered that $60 \%$ of the worlds proven oil reserves are in areas adjacent to the Persian Gulf, and this region is probably no more stable today than it was during the 1970's. Also, if the "OPEC multiplier" is true, then a small percentage increase in world oil demand results in a large percentage increase in demand for OPEC oil (the converse also holds under this postulate), and conceivably the energy situation extant in the 1970's could repeat itself (Mossavar-Rahmani 1986). Falling oil prices could induce producers and consumers to increase energy consumption to the level of earlier trends, potentially subjecting the economy to the costs of continual adjustment shocks.

The buildings sector not only accounts for a large share of energy consumption in the U.S., slightly more than one-third of the primary energy consumed, and is therefore an important component of energy markets in and of itself, but also offers the opportunity for large gains in the productivity of energy use. Citing members presented in Sant, et. al. (1984 p. 19), of the 78 quads of primary energy consumed in the U.S. in 1980, only 33 quads, $42 \%$, were actuality consumed in the form of useful energy - that is, the heat that comes out of the register to warm a building or the lumens generated by a light bulb. Eighteen quads of energy were lost in the fuel conversion process, predominately electricity generation, and the other 27 quads lost in end-use conversion. Buildings consume approximately $60 \%$ of the electricity generated in the U.S., and their share is growing, so the potential for productivity gains is obvious. Of the 33 quads of useful energy consumed, about $40 \%$ goes for the space heating, cooling, and lighting of buildings. End-use conversion improvements, both equipment and shell, therefore, also offer substantial potential for increasing the productivity of energy use.

The energy not consumed in the buildings sector is available for productive uses elsewhere in the economy. The money not spent on energy is also available 
for productive investments elsewhere in the economy. One final note on this point. When expenditures are calculated on the useful energy actually consumed basis, space heating and cooling in buildings alone accounted for $\$ 629$ of the average persons energy expenditure in 1980 . This is more than industrial manufacturing (\$517) and feedstock $(\$ 103)$ expenditures combined (Sant, et. al. 1984 p. 21).

Buildings are a long-lived assets, with average lives exceeding 50 years. Structures built now and in the recent past will have energy impacts well into the next century. Most analysts agree that U.S. domestic supply of oil will be declining by the turn of the century, thereby contributing to an expected long-term decline in oil availability, with its consequent oil price increase. Most analysts also agree that the "easy" improvements to the energy efficiency of buildings and building equipment, such as caulking, storm windows, high-efficiency furnaces, etc., have been made or shortly will be to the stock of existing buildings, and that under plausible assumptions the energy consumption of the buildings sector will once again be increasing sometime in the 19g0's.

If the productivity gains of the past are to be maintained and improved upon, new methods and technologies must be available for future applications. Providing the knowledge base for the development of future technologies is the function of building energy R\&D programs. The future course of events in energy markets are, of course, highly uncertain; but the costs of adjusting to the energy disruptions of the 1970 's should provide enough incentive to be prepared for future contingencies. It is this uncertainty for which alternatives need to be developed, for it just might be that "since the first price explosion of 1973, we have learned that the energy crisis is not a mere problem of transitional adjustment; it is a grave challenge to the potential and economic structure of the free world." (Kissenger, in Ebinger 1982). The R\&D recommendations derived from the scenarios presented in this report are an attempt to provide these alternatives.

\subsection{ORGANIZATION OF THE REMAINDER OF THIS REPORT}

The next chapter, Chapter 2.0, presents three alternative building futures: a base scenario, and high and low growth alternatives. The high and low growth 
scenarios were used as the reference "boundaries" of the building future by a panel of energy experts to make recommendations for buildings related R\&D. Their recommendations are presented in Chapter 3.0 . Section 3.3 presents R\&D recommendations from the high growth scenario, and Section 3.4 presents the results derived from the low growth scenario. The summary of the panel's R\&D recommendations are given in Section 3.5. In Chapter 4.0 a detailed discussion of several of the key variables used in this analysis is presented. Appendix $C$ gives the methodology and computer results, while Appendices $A$ and $B$ list the panel members whose expert opinion was instrumental in conducting this study. 


\subsection{ALTERNATIVE BUILDING SCENARIOS}

\subsection{INTRODUCTION}

This chapter presents three alternative building futures: 1) the base scenario, essentially a continuation of the current state of the world; 2) the "A" scenario, characterized by high GNP growth and a high rate of technological progress in the economy; and, 3) the "B" scenario, characterized by low GNP growth and a low rate of technological progress in the economy. The scenarios were developed by combining the expert opinion of a panel composed of professionals representing a cross-section of government and private industry interests (see Appendix A for the list of panel members) with a computer program that examined the interaction of all the variables and their likelihood of occurrence as specified by the panel members (see Appendix $C$ for a discussion of the methodology and computer results).

\subsection{THE TOPIC}

The topic for this analysis was determined by the panel members as:

Develop scenarios describing the factors that affect the characteristics of residential and commercial buildings, their construction, and their use, including institutional factors, and the consequent impacts on building energy consumption in the U.S. through the year 2010 .

\subsection{STRUCTURE OF THE SCENARIOS}

The scenarios of the future building environment were analyzed in the context of five major elements:

- the macro-environment;

- demographics;

- residential buildings;

- commercial buildings; and

- energy consumption. 
The macro-environment is defined in terms of variables $\left(^{*}\right)$ such as GNP, interest and inflation rates, productivity, economic structure, government fiscal policy, and energy prices. Demographics is comprised of population projections; household formation, and the spatial distribution of the population.

Residential and commercial buildings were analyzed in terms of the number of buildings, building costs, the mix of building types, building densities, and building regulations. The thermal integrity of buildings, materials and HVAC technology, and the role of utilities were the variables determining energy consumption.

These elements, and the variables that comprise them, are clearly interdependent and need to be examined simultaneously. It is just as clear that each variable can individually take on a wide range of values. It is the interaction of the variables across their range of values that the three scenarios to be presented in the following sections are intended to analyze.

\subsection{BASE SCENARIO}

\section{Macro-Environment}

The macro-environment in the base scenario is, for the most part, a continuation of the current state of the world. Growth in GNP is moderate to. sluggish, typically growing at the lower end of the 2-4\% per year range; government fiscal policy is counter-cyclical, but deficits remain. There is modest inflation of $3-5 \%$, restoring the historic interest rate-inflation differential of $2-3 \%$, so that interest rates (prime rate) are $6-9 \%$. The share of manufacturing as a proportion of GNP has stabilized at 22-25\%, lower than the peak of $30 \%$ in 1953 but halting the decline in share that took place over the last decade, bottoming out at about $21 \%$ in 1985.

The pace of technological change, and hence productivity, will improve over the record of the 1970 's, achieving a moderate average annual growth rate of

$\left.{ }^{*}\right)$ The variables, or descriptors, used in this study were determined by the panel members. A list of the variables, the process by which they were chosen, and a discussion of some key descriptors is presented in Chapter 4.0. 
$2-3 \%$. Most of the growth in productivity occurs in the manufacturing sector, however, implying a continued slow rate of growth of personal income for the increasing proportion of the labor force employed in the service industries, with the consequent drag on GNP.

There is a great deal of volatility of fossil fuel prices in this scenario. It is highly unlikely that the world price of oil will be in the $\$ 20-30 / b b 1$ (constant dollars) range. The most likely case is that oil will exceed $\$ 30 / \mathrm{bbl}$; it is only slightly less likely, though, that the price of oil will be below $\$ 20 /$ bbl. Similarly, in the most likely case the price of natural gas will be greater than $\$ 9 / \mathrm{mmbtu}$, but only slightly less likely that the price will be below $\$ 7 / \mathrm{mmb}$ tu. The variability reflects the uncertainty surrounding supply constraints in the next century, as well as the impact of moderate to slow GNP growth on fossil prices. Electricity prices, however, are projected to remain constant - $\$ 17-20 / m m b t u$ (constant dollars) due to the slow growth in GNP and moderate interest rates.

\section{Demographics}

Population is growing according to the census highest projections in the base scenario, and immigration into the country is above trend, adding to the native growth rate. U.S. population is projected to increase from 239.9 million people in 1985 to $310 \mathrm{milli}$ ion people in 2010 , an increase of almost $30 \%$. The rate of population growth, however, increases until 1995, and then steadily declines, although remaining positive, thereafter. By way of comparison, population growth averaged 1.3\% between 1955 and 1980 . In this scenario, population growth will average $1.1 \%$ until 1995, and then average $0.9 \%$ from 1995 to 2010.

A pervasive trend in all U.S. population projections is the overall aging of the population. Because of the high growth rate, the aging of the population is slowest in this scenario. But even at that, the median age in 2010 will be 36.7 years, compared to a median age in 1982 of 30.6 years. The percentage of the population 65 years or older increases from $12 \%$ in 1985 to almost $14 \%$ in 2010, while those aged 45-64 increases from $18 \%$ to $26 \%$ over the period. The 18-44 age group, the prime child-bearing group, declines from $42 \%$ of the total in 1985 to $35 \%$ in 2010 . 
The proportion of the population living in the Sunbelt states in this scenario shows a continuation of the general share of about $42-44 \%$ of the population. 0lder people and imnigrants still prefer to migrate to the sunbelt states, but the sluggish economy and slow growth in personal income inhibit acceleration of the trend. There is an absolute increase in the number of people living in the Sunbelt, however, because of the large population base.

\section{Residential Buildings}

The two primary determinants of the quantity and type of residential buildings that will be demanded are the headship rate and the affordability of units. Headship rates (the number of household formations per hundred people in an age cohort) in this scenario are projected to maintain trend. With the high population growth, there is strong demand for housing, especially during the latter part of this century when population growth is highest. The housing type of preference is single-family.

The affordability of single-fanily houses (the ratio of price plus operating cost to income), however, is not projected to improve. Although the cost of single-family houses is projected to remain relatively constant (constant $\$ ' s$ ) and interest rates are modest, tending to improve affordability, the moderate growth in personal income will preclude a significant portion of the population from owning their own homes. Sales of single-family homes will be restricted to those with higher incomes and those that aiready own a home. Furthermore, the low inflation reduces the capital gains/speculative component of housing demand, providing less incentive for existing homeowners to purchase new homes. Those who can't afford single-family houses will mainly live in multi-family housing, with a smaller proportion choosing manufactured housing.

Thus, the share of single-family housing in the stock is not expected to increase from its proportion of 60-64\%. The volume of new starts will be sufficient to meet the demand of the more affluent, generally older segment of the population, 0.9-1.0 million units per year. Since the number of people per household in this group is generally smaller than the population average, the demand will be for moderately sized houses, typically averaging 1,500 sq. ft. or less. 
The majority of the remainder of the population will seek multi-family housing. Instead of increasing suburban expansion, however, the trend in this scenario is for the multi-family units to be provided in older central city and suburban neighborhoods, some of which will require rehabilitation. This tendency will bring about an increasingly urban and higher density settlement pattern.

There are several reasons for this development. With only moderate GNP growth, there will be less business expansion. Instead, businesses will attempt to improve the efficiency of existing plants or offices. Workers, especially those with lower incomes, will prefer to live close to their jobs, exerting pressure for affordable units in existing neighborhoods and adjacent areas, thereby "filling in" vacant parcels and raising densities. There will be new construction as well as subdivision of larger single-family houses into multifamily units and the conversion of formerly non-residential buildings into multi-family units.

Another factor is that the infrastructure is already in place in existing metropolitan areas, thus avoiding the costly expansion of services to farther out, undeveloped parcels. Immigrants have historically settled in the central cities because of the centralized availability of services, cheap housing, and existing network of those of their own ethnic background who have settled before them. The increasingly elderly portion of the population also will want access to conveniences and facilities in close proximity to each other, in this scenario best served by expansion within existing metropolitan areas of transportation networks, medical facilities, restaurants, etc. The influx of people back to the metropolitan areas will expand the tax base so that the infrastructure can be maintained and expanded as needed.

\section{Commercial Buildings}

The growth in square feet of commercial floor space is projected keep pace with the growth in GNP, and in particular with the growth in the service sector of the economy. In this scenario, commercial floor space is projected to grow $1.5-2 \%$ per year, for a total of $70-80 \mathrm{million} \mathrm{sq.} \mathrm{ft}$. in 2010 . There is little change from current construction practices and productivity, so the cost of these buildings is expected to increase at about the same rate as the historical trend -- $0.5-1.5 \%$ per year. 
Approximately $61 \%$ of the floor space will be for offices, retail, warehouse, and service establishments. Educational and health buildings will account for $12 \%$ and $4 \%$, respectively, while the remaining $23 \%$ of floor space will consist of motels/hotels, assembly buildings, and other miscellaneous buildings.

Reflecting the trend towards urbanization by the population, new commercial construction will also tend to be built in the central cities and existing suburban areas. Due to the competition for space, an increasing percentage of new commercial buildings will be large, high-rise buildings over 100,000 sq. ft. Over 37\% of new floor space in this scenario falls into this category. Hospitals and health care facilities, serving the older population, and office buildings, due to the number of people employed in the service sector of the economy, will account for the majority of the large buildings.

\section{Energy Consumption}

The high fossil fuel prices in this scenario will provide incentives for consumers to switch to alternative fuels, primarily electricity, improve the thermal integrity of their buildings, and purchase more energy efficient equipment. The incentive to switch to electricity is even stronger because the real price of electricity is projected to remain constant. Offsetting these incentives is the modest growth in income. Capital intensive system conversion, building retrofits, or equipment purchases won't be made unless they have a relatively quick payback.

The net effect is that there will be small, incremental improvements in energy efficiency in the existing stock of buildings. New residential and commercial buildings will increasingly use electricity as a fuel source, but with steady prices there is little incentive to pay for substantial improvements in thermal integrity or equipment efficiency.

The increasing share of electricity in building energy consumption is reinforced by the number of people residing in the Sunbelt states. Although the proportion of the population living in the Sunbelt is expected to remain as today in this scenario, the absolute number of people will be larger because of the high population projection. Air cooling is the dominant load in the sunbelt, and the cooling requirement will be met with electricity. 
The overall consequences of the base scenario on building energy consumption can be summarized as a gradual decrease in energy consumption per unit due to incremental efficiency improvements, and an increasing use of electricity at the expense of fossil fuels. Consequently, primary energy consumption by the buildings sector will steadily increase. The increasing demand for electricity will ease the financial burden of many of the nation's electric utilities. However, the electric utilities will still conduct conservation programs to ease the peaking problems caused by the increased number of large buildings and the increased air conditioning loads.

\section{5 "A" SCENARIO: HIGH ECONOMIC GROWTH, RAPID RATE OF TECHNOLOGICAL CHANGE}

\section{Macro-Environment}

The macro-environment under this scenario is characterized by a high rate of GNP growth, averaging greater than $4 \%$ per year. Part of the growth in GNP is fueled by persistent government deficit spending. The deficit is debt financed so that interest rates are high, averaging over $9 \%$, while inflation is low, averaging $3 \frac{6}{6}$ or less. The economy has increasingly shifted to a services economy as manufacturing output is less than $21 \%$ of GNP.

There is a very rapid rate of technological progress in the economy, improving growth in productivity to better than $3 \%$ per year. Most of the productivity gains occur in the services sector, increasing the growth rate of personal income for the majority of the work force employed in this sector.

Energy prices are high in this scenario, with oil gas and electricity all in their highest real price projections. $0 i 1$ is projected to be greater than $\$ 30$ per barrel; natural gas is projected to be greater than $\$ 9 / \mathrm{mmbtu}$; and electricity is projected to be greater than $\$ 20 / \mathrm{mmbtu}$. The high energy prices don't impede the growth in GNP because the technological improvements in the economy have increased the productivity all input factors, implying higher end-use efficiencies. Furthermore, the shift away from manufacturing and towards services means that less energy is required to fuel the growth in GNP. 


\section{Demographics}

Population growth in this scenario is the same as in the base scenario; that is, it is growing according to the census highest growth projection. Also, as in the base scenario, immigration into the U.S. is above trend. To summarize the salient points, the population will grow by about 70 million people from 1985 to 2010 so that total population in 2010 will be 310 million people. overall, though, the U.S. population is increasingly aging, so that in 2010 $14 \%$ of the population will be 65 or older, and $26 \%$ will be $45-64$ years of age. The 18-44 age group will decline from $42 \%$ of the total in 1985 to $35 \%$ in 2010 .

Differing from the base scenario is the geographic shift to the Sunbelt states. In this scenario more than $44 \%$ of the population will live in the Sunbelt. Most immigrants will settle there, as will an increasing proportion of the elderly who will now have higher incomes and can afford to retire in the warmer climates. Job expansion will also take place in the Sunbelt states, attracted by the increasing proportion of the population living there and attracting more of the population to locate there. The expansion will be spurred by the income generating effects of the high energy prices in the $0 i 1$ and gas producing states.

\section{Residential Buildings}

The high income growth in this scenario will encourage the formation of more households in each of the relevant age cohorts, lowering the number of people per household. The young will leave their parents' homes earlier to set up their own households and the older segments of the population will increasingly form single households.

Housing, especially single family housing, is projected to be less affordable in this scenario. Most business expansion and new construction will take place in the suburban and outlying areas - a shift away from central cities. However, the increasing suburbanization as well as the increasing demand for space in the Sunbelt will put upward pressure on land prices. Rapid development witl also lead to increasingly strict enforcement of building and development regulations that will restrict building densities, in effect taking land out of production, adding additional pressure on land prices. These factors, in conjunction with high interest rates and high energy prices, 
will offset the growth in personal income and lower the affordability ratio of new housing.

The decreased affordability of new housing will lead to increased demand for cheaper housing in the form of smaller new units, more manufactured housing, and an increased demand for multi-family units. Immigrant families will also have a demand for multi-family housing, predominately in the central cities. Thus, the high demand for housing due to the high rate of household formation will increasingly be met less by single family houses so that they will be less than $60 \%$ of the total by 2010 , the difference being made up by a larger proportion of both multi-family and manufactured housing. Average housing size will be smaller, less than 1,500 sq. ft., and building density will rise because of the increased number of multi-family units.

\section{Commercial Buildings}

The high rate of growth of GNP and the shift towards a more services oriented economy will increase the demand for commercial floor space. The projection is for a growth rate of more than $2 \%$ per year in commercial floor space, compared to a trend of $1.5-2 \%$ per year in the base scenario.

There will be fewer very large (G.T. 100,000 sq. ft.) buildings built in this scenario, less than $33 \%$ of the total, reflecting the dispersion associated with suburban lifestyles. Compositional effects on building types will be more low to mid-rise buildings and relatively more growth in assembly, trade and food service buildings.

\section{Energy Consumption}

The high prices of all energy forms, which should lead to relatively less consumption, will be offset by the high growth in income, allowing consumers to maintain their desired proportion of energy consumption to total expenditure. The thermal integrity of structures and the efficiency of energy consuming equipment will generally improve, partly in an effort to reduce energy consumption and partly to lower operating cost, thereby increasing the affordability of structures. The smaller average size of residences as well as increasing proportion of multi-family units will lower energy consumption per unit. 
The above trend shift to the Sunbelt will significantly raise the demand for electricity used to provide space cooling. There will be a change in seasonal demand from winter to summer, and fossil fuels will provide less and less of the energy consumed in the buildings sector. Primary energy consumption will correspondingly also increase significantly. The high price of electricity and steady baseload demand for air conditioning will allow the electric utilities to provide as much service as needed without financial strain.

\section{6 "B" SCENARIO: LOW ECONOMIC GROWTH, SLOW RATE OF TECHNOLOGICAL CHANGE Macro-Environment}

In this scenario the macro-environments characterized by a low rate of GNP growth, averaging less than $2 \%$ per year. Government spending is persistently in deficit, but the debt is monetized so that inflation is high, greater than $5 \%$, and interest rates are 6-9\%, implying a low real rate of interest. The economy is increasingly a services economy as manufacturing output steadily declines as a proportion of GNP.

The rate of technological change in the economy is low, with increasing obsolescence of plant and equipment. Hence, productivity in both the manufacturing and service sectors is growing at a very low rate, as is the growth in personal income.

Energy prices are low in this scenario, with oil, natural gas, and electricity all in their lowest real cost projections. 0 il is projected to be less than $\$ 20$ per barre1; natural gas is projected to be less than $\$ 7 / \mathrm{mmbtu}$; and electricity is projected to be less than $\$ 17 / \mathrm{mmbtu}$. The Tow energy prices reflect the slack demand caused by the low growth in GNP and income.

\section{Demographics}

Population is growing according to the census lowest projection in this scenario, and immigration into the country is below trend. The U.S. population is projected to increase from $237.6 \mathrm{mitlion}$ people in 1985 to only $261.5 \mathrm{mi} 11$ ion in 2010. The rate of population growth increases until 1990, and steadily declines thereafter, actually turning negative in the years iminediately following 2010. The proportion of the population in the various age groups is 
approximately the same as in the base scenario - 14\% 65 or over, $29 \% 45-64$, and $37 \%$ 18-45 - but the absolute number of people is substantially smaller.

The shift of the population to the Sunbelt is reversed in this scenario, so that less than $42 \%$ of the population resides in the Sunbelt by 2010 . The shift is reversed due to the minimal lack of business expansion and job growth in any part of the country and the low growth in personal income.

\section{Residential Buildings}

In addition to the smaller number of people in this scenario, the rate of household formation in each age group is expected to decline. The primary reason is the lower income implied by the low rate of GNP growth. Of the new households that are formed, particularly among the young and elderly, the demand will be for multi-family housing because they don't have the income to afford single family units. The demand will be for existing units in the urban areas, but at lower densities than historically due to the relatively smaller population. The lower densities imply a larger size per unit.

The trend away from suburbanization in this scenario and the lower demand due to the smaller number of people puts downward pressure on housing costs in the suburbs, leading to a decline in the price of new units. But again, lower incomes reduce overall affordability, leading to a lower rate of new construction. The new single family units that are built tend to be larger, catering to the demands of the more affluent who can afford them.

\section{Commercial Buildings}

The low rate of GNP growth also reduces demand for commercial building space. There will be less than a $1.5 \%$ increase in commercial floor space per year as there is little expansion in new construction. The demand for floor space will be met primarily by refurbishing existing space in the central cities.

\section{Energy Consumption}

The low energy prices encourage consumption so that overall building energy consumption per unit increases. Furthermore, in an attempt to reduce costs and make buildings more affordable, new units are constructed at a lower level of themal efficiency, leading to a general decline in the thermal efficiency of the building stock. 
Heating demands are relatively large in this scenario because of the smaller proportion of people living in the Sunbelt states. As a result, fossil fuels, especially natural gas, will have a higher share of total energy consumption. Conversely, primary energy consumption will fall. 


\subsection{SCENARIO IMPLICATIONS FOR BUILDING ENERGY R\&D}

\subsection{INTRODUCTION}

The "A" scenario, describing a high economic growth, high technology future, and the "B" scenario, describing a future based on the opposite outcomes -- low economic growth and low technology -- were presented to a national panel of professionals with expertise in building energy R\&D (see Appendix B) to explore the implications of these two scenarios for long-term building energy R\&D needs. The A and B scenarios were chosen because they provided the bounds within which to examine the interaction of forces that will shape the future building environment.

The next section describes the process used to elicit the recommendations from the panel. The specific R\&D recommendations derived from the $A$ and $B$ scenarios is presented next. The last section, section 3.5, provides the overall summary of building energy $R \& D$ recommendations.

\subsection{APPROACH}

The "storyboard" creative thinking approach was used to elicit the recommendations for building energy R\&D from the panel members. The pane 1 members were first asked in a group discussion to separately list the major differences between the "A" scenario and the "B" scenario and the current building environment in terms of energy consumption, building construction, building uses, and any other issues that seemed relevant. After a list was prepared for each of the two scenarios, the panel members "voted" on the items of the most importance relative to the need for bujlding R\&D implied by the $A$ and $B$ scenarios. The items remaining on the lists were summarized and classified according to the components of the building environment with which they interacted. The broad areas of R\&D need were derived from these classifications.

The next step in the process was to divide the panel into two groups, one group being responsible for the detailed analysis of the R\&D areas derived from scenario $A$ and the other being responsible for the same thing for scenario $B$. Both groups examined their respective $R \& D$ areas in terms of problems, 
causes, and solutions. As was done previously, the groups voted on which of the items in the solutions list would be the recommendations for building energy R\&D. At the end of this step the groups reconvened for a discussion on the final recommendations.

\subsection{R\&D RECOMMENDATIONS FROM THE "A" SCENARIO - HIGH GROWTH, HIGH TECHNOLOGY}

Scenario A described a future characterized by a very rapid rate of technological progress in the economy and a high rate of GNP growth. Energy prices were high in this scenario but the effects of high prices were offset by the technological improvements in the economy. The growth in population was also in its highest projection.

The spatial distribution of buildings in this scenario was increasingly suburbanized and also increasingly shifting towards the sunbelt. These trends, however, put upward pressure on land and housing prices, leading to a decline in the affordability of new homes. The decreased affordability of housing led to increased demand for cheaper housing in the form of smaller new units; more manufactured housing; building conversions and retrofits; and an increased demand for multi-family units, especially among the elderly portion of the population. The increased percentage of multi-family buildings raised building densities in both the center city and suburban areas. The rate of growth of square feet of commercial floor space is high, but it is generally of low height and is dispersed throughout the suburban areas.

Five research areas were identified from this scenario by the panel members:

- improved energy efficiency and system integration;

- improved air and environmental control;

- research on standardized building construction;

- research on new materials for building construction; and

- research on alternative building patterns for alternative lifestyles.

The high energy prices of this scenario focused the panel's attention on improvements in energy efficiency. Improved energy efficiency was also felt to be important from the electric utility's perspective in order to meet the increased air conditioning loads due to the shift to the Sunbelt. Systems 
integration research was seen as the mechanism whereby both mechanical systems and building shell components could be simultaneously examined.

Consideration of the building shell components led to a recommendation for new building materials research. But energy efficiency is only one aspect of the need for new materials. The panel members felt that the high density, smaller living spaces in the scenario by a large proportion of the population would cause people to alter how they used their internal space as well as how it is constructed. In the first case, a given internal space would have to serve more than one function. This implies a modular approach to the internal structure of the space by changing wall configurations, outlets, lighting fixtures, etc. The panel saw a clear need for new materials to meet this need.

Modular use of internal building space requires flexibility in the design and construction of buildings. Coupled with the issue of housing affordability, the panel saw standardized building construction as a way to increase both the flexibility of the construction process and building affordability. It was postulated that in the future when people move or businesses change location they might take their already paid for modules with them, for example their kitchen module or a display module. This type of building use clearly requires new materials and new ways of constructing buildings.

The quality of the internal building environment becomes much more important when the internal spaces have multiple uses, new materials are introduced, and there is "tight" construction for energy efficiency purposes. Air and environmental control was therefore recommended as a research area by the pane1. The safety and health of building occupants has to be guaranteed prior to the introduction of new designs.

The high income by a large segment of the population in this scenario and the increasing proportion of the elderly in the population led the panel to consider R\&D to achieve alternative building patterns for alternative lifestyles. The different lifestyles could range from a self-sufficient vitlage pattern where people come and go with their modular buildings, to a "mall" concept where all the required amenities are provided under one roof. The provision of housing for low income households was also considered. 
Candidate R\&D needs for each of the five research areas derived from the A scenario through the storyboard technique are presented in Table 3.1. 
TABLE 3.1. R\&D Recommendations from the "A" Scenario

A. CANDIDATE R\&D NEEDS FOR IMPROVED ENERGY EFFICIENCY AND SYSTEM INTEGRATION

1. Thermal storage

a. Responsive controls (quicker, smarter)

b. Improved controls (microprocessors)

2. More efficient HVAC equipment

a. Room scale heating and cooling equipment

b. Better match of equipment to task

3. Zone control

a. Search for dynamic materials (selective transmission, absorptivity, etc.)

b. Operable devices (louvers, awnings, etc.)

4. Improved lighting (daylighting, lighting controls)

5. Improved diagnostic techniques (for quality control)

6. Research on cogeneration

7. Need to overhaul PUC/utility relationships

8. Load management (time-of-day rates, load shedding, etc.)

9. Continued research on passive solar photovoltaics

10. Federal support of demonstrations

B. CANDIDATE R\&D FOR IMPROVING AIR AND ENVIRONMENTAL CONTROL

1. New materials that are less or non-toxic

2. Improved HVAC designs to improve air quality

a. R\&D on air cleaning systems to remove pollutants in buildings

b. R\&D on air quality sensors and controls

c. Determination of acceptable levels of social risk

3. New materials, controls, or design that allows more daylighting 
TABLE 3.1. R\&D Recommendations from the "A" Scenario, cont.

4. Development of inexpensive air/heat exchanges

5. Development of economic temperature zone-control systems

6. Development of sealants and barriers to improve air quality in buildings

a. Develop nonvolatile adhesives

7. Establish building code to ensure construction quality

8. Provide diagnostics to assess site quality

a. Improve building diagnostics

9. Improved humidification technology

C. CANDidATE R\&D PERTAINING tO STANDARDIZED BUILDING CONSTRUCTION

1. Construction and design

a. Flexible design construction system

b. Innovative design

c. Robotic construction techniques

d. Modularized construction techniques

2. Materials

a. Quality control and uniformity

b. Substitute materials that provide design flexibility

3. Computer aid
a. Personalized design
b. Computer aided energy analysis
c. Simulation of design alternatives
d. CAD/management aid

4. Acceptance
a. Codes responsive to new technologies
b. Uniformity of codes
c. Marketing

5. Industry character 
TABLE 3.1. R\&D Recommendations from the "A" Scenario, cont.

a. Industry centralization (consolidation)

b. Industry/government cooperation

D. CANDIDATE R\&D NEEDS FOR NEW MATERIALS FOR BUILDING CONSTRUCTION

1. Super insulation

a. Quality control

b. Switchable outside surfaces and glazings

2. Thermal storage materials

a. High "R" glazing materials, plasma, lighting

b. Composites

c. Adhesives

- non-toxic

- mobile delivery systems

d. New fasteners - thermal break, fiber reinforced

3. New construction tools
a. High temperature absorbants for heat pumps
b. New chemistries, sensing materials, fire resistant codes for better design for existing pre-cast roof panels
c. Improved codes

E. CANDIDATE R\&D TO ACHIEVE ALTERNATIVE BUILDING PATTERNS FOR ALTERNATIVE LIFESTYLES

1. Cogeneration and district heating

2. Village energy self-sufficiency

3. On-site processing and reclamation of waste

4. Mall concept for community gathering and recreation

5. "People oriented" size of community

6. Biotechnology for waste recycling

7. Shared facilities 
TABLE 3.1. R\&D Recommendations from the "A" Scenario, cont.

8. Building construction liability

9. Reduced household responsibilities

10. Low income households

11. Income sharing

12. Change in government structure

13. No rent subsidized housing ownership/equity

14. Recycled water 


\subsection{R8D RECOMMENDATIONS FROM THE "B" SCENARIO - LOW GROWTH, LOW TECHNOLOGY}

Scenario B described a future characterized by a low rate of technological progress in the economy and a low rate of GNP growth. Energy prices are low, and the population is growing according to its lowest projections.

There is a shift away from the Sunbelt and back to central cities as more of both the youngest and oldest households choose to live there. This trend gave rise to an increased demand for multi-family housing in the cities, but at lower than historical densities. The move to the central cities relieves pressure on housing costs in the suburbs, but income growth is also low, so that overall housing affordability declines, leading to a lower rate of new construction. The single family units that are built tend to be larger, catering to the demands of the more affluent who can afford to buy them. The lower rate of GNP growth also reduces the demand for new commercial space. The new commercial buildings that are built are also built in the central cities.

Five research areas were identified from this scenario by the panel members:

- research on construction technology to make housing more affordable;

- research on the retrofit and rehabilitation of existing residential and commercial buildings;

- research in building computerization;

- research to facilitate building industry competitiveness; and

- building research in response to increases in income polarization.

As is evident by the nature of these research areas, low income and lack of affordability of housing in this scenario were the panel's overriding concern. Consequently, research into new construction technologies to improve the affordability of housing was a clear research recommendation.

The low rate of new construction implies that the stock of buildings will be increasingly older. This has ramifications for both energy consumption and the structural integrity of the building stock. Ways to cost-effectively rehabilitate and retrofit residential and commercial buildings were also seen by the panel as a clear research need. 
Building computerization seemed to the panel to be necessary to achieve cost-effective solutions to both the new construction and retrofit problems. In addition to providing design flexibility and assisting in the analysis of new materials and construction techniques, building computerization could also minimize building operating cost, thereby increasing incomes or profits.

A fear of the panel was that the low level of construction activity would seriously erode the competitiveness of the U.S. construction industry, leading to foreign domination of construction in the U.S. The panel felt that the fragmented nature of the U.S. building industry, with its myriad of builders and suppliers, would be ill-equipped in a low growth, low profit scenario to apply the most recent technological advances, and therefore be vulnerable to an organized foreign effort at market penetration. Research into ways to improve the efficiency of and eliminate structural barriers in the building industry was seen by the panel as a response to this condition.

Response to the potential income polarization implied by this scenario was seen as necessary by the panel to provide minimally adequate shelter for a large segment of the population. The panel felt that a return to the substandard housing conditions that existed earlier in this century could possibly create such social turmoil as to undermine our political system.

Candidate R\&D needs for each of the five research areas derived from the $B$ scenario through the storyboard technique are presented in Table 3.2 .

\subsection{SUMMARY OF R\&D RECOMMENDATIONS}

Although the $A$ and $B$ scenarios described different future societies in terms of economic, demographic, and spatial distributions, there is a commonality to the research recommendations made by the panel. This outcome is encouraging in that the recommendations are applicable over a wide range of possible building futures.

The recommended areas of research can be broadly classified into five nonexclusive groups: 1) the quality of the building environment; 2) the fabric of the building environment; 3 ) the construction of the building environment;

4) the maintenance of the building environment; and 5) the form of the building environment. Two more areas, building diagnostics and technology 
TABLE 3.2. R\&D Recommendations from the " $B$ " Scenario

A. CANDIDATE R\&D IN CONSTRUCTION TECHNOLOGY TO MAKE HOUSING MORE AFFORDABLE

1. Conduct research into exotic materials

a. composites

b. lightweight masonry

c. throw-away structures

2. Conduct research into exotic systems

a. utility energy services on-site (supply)

b. integrated utilities (end-use)

c. utility ownership of energy-using components

3. Conduct research into integrated equipment
a. cooking
b. water
c. space conditioning
d. lighting

4. Conduct research into more efficient equipment
a. eclectic solutions
b. sizing for end-use

B. CANDIDATE R\&D FOR REHABILITATION AND RETROFIT OF EXISTING RESIDENTIAL AND COMMERCIAL BUILDINGS

1. Conduct research on materials and techniques for retrofit and rehabilitation
a. commercial lighting
b. fenestration
c. masonry
d. roofs

2. Conduct research to identify technology needs for retrofit
a. commercial buildings
b. residential buildings

3. Provide for the effective transfer of R\&D results

a. establish behavioral baseline 
TABLE 3.2. R\&D Recommendations from the "B" Scenario, cont.

b. document audit results

c. centralization

4. Investigate feasibility (cost \& benefits) of stable political environment
a. legislation
b. tax incentives
c. land use

5. Investigate feasibility of utility financing and involvement

\section{CANDIDATE R\&D NEEDS IN BUILDING COMPUTERIZATION}

1. Develop low-cost, advanced technologies for:
a. design \& operation
b. controls
c. software
d. meters
e. heat storage, cooling storage
f. sensors
g. expert systems (building design)
h. CADD systems for energy efficient design

2. Conduct research to incorporate human factors into computer design
a. work place "quality of life"
b. control of immediate environment
c. flexible work space (part-time use)
d. compartmentalization of work space

3. Understand dynamics of energy use in buildings
a. improve simulation models
b. develop proof of concept (validation)
c. improved technical information on materials

4. Develop standards for control and automation protocols
a. standardization of energy analysis process 
TABLE 3.2. R\&D Recommendations from the "B" Scenario, cont.

D. CANDIDATE R\&D NEEDS TO FACILITATE BUILDING INDUSTRY COMPETITIVENESS

1. Investigate feasibility of a new technology center or improve existing ones
a. information dissemination
b. technology transfer
c. micro-electronics center
d. research and technical development
e. NIBS, CII-type organizations

2. Perform market segmentation/target study for buildings industry
a. U.S. markets
b. foreign markets
c. targeted R\&D
d. characterize the market
e. define federal role

3. Implement ways to enhance government industry cooperation
a. eliminate legal barriers
b. "MITI"-like organization
c. labor, builders, consumers, government, management

4. Improve the engineering and technology basis for codes and standards
a. uniformity
b. test procedures for appliances
c. coordinate local authorities
d. "U.L."-type approval for construction practice

E. CANDIDATE R\&D IN THE BUILDINGS AREAS IN RESPONSE TO INCREASES IN INCOME POLARIZATION

1. Investigate low-tech building solutions
a. paper house
b. styrofoan house
c. inflatable house

2. Conduct research to support code changes

a. safety 
TABLE 3.2. R\&D Recommendations from the "B" Scenario, cont.

b. health

c. multiple families in one unit

d. home business

3. Investigate possibilities of new living and working environments
a. day care
b. flexible use of work space
c. $\mathrm{CCC}$
d. cottage industries
e. use of home as office
f. transit alternatives

4. Conduct research on low-income weatherization
a. technology transfer
b. quality control
c. behavioral
d. improved audits
e. extend training
f. identify low-income sites 
transfer, are germane to each of the other five.

\subsubsection{Quality of the Building Environment}

In both scenarios maintenance of the quality of the internal building environment was deemed necessary for the safety and health of occupants. It is also necessary for the introduction of new materials, new construction practices, and energy efficient designs. Research in this area centers primarily about air and environmental control research:

- development of air quality sensors and controls;

- development of improved sealants and air barriers;

- research on improved air cleaning and humidification technologies;

- research on materials, controls, or designs to enhance day lighting;

- development of inexpensive air heat exchangers.

\subsubsection{Fabric of the Building Environment}

Research in this area pertains to the need for new materials. This need was thought necessary to increase the affordability of housing; to increase design flexibility in new construction and retrofits; to improve air and environmental quality; and to improve energy efficiency through systems integration. Recommendations for materials research were:

- non-toxic super insulations;

- switchable/phase change surfaces and glazings;

- thermal storage materials; .

- high temperature absorbents for heat pumps;

- new chemistries for sensing materials and fire resistance;

- research on composites;

- designs for pre-cast roof panels;

- research on new adhesives and fasteners.

\subsubsection{Construction of the Building Environment}

The manner in which building components are assembled at the site or in the factory has a large role in the ultimate energy efficiency of a building. It also significantly affects building cost. Quality control was seen by the panel to be of major importance. Recommended research areas in building 
construction technology are:

- robotic construction techniques;

- cAD/CAM systems;

- design simulation models;

- modular/flexible design construction techniques.

\subsubsection{Maintenance of the Building Environment}

Maintenance of the building environment is concerned with the operating efficiency of buildings and their relationship to the suppliers of energy, in particular the electric utilities. Systems integration research was seen as the mechanism whereby the interaction of all building components, including mechanical systems, could be examined. This research will indicate the most effective combinations of active and passive energy utilization techniques for various building types and climatic regions. The results of this research are seen as contributing to bujlding design flexibility, flexibility in electric utility management, and lowering that portion of building operating cost attributable to energy use, thereby increasing building affordability. Recommended areas of research are:

- thermal storage:

- HVAC equipment efficiency;

- passive solar/photovoltaics;

- computer controls/expert systems;

- operable devices (louvers, awnings, etc.);

- improved lighting (daylighting, lighting control);

- load management research (time-of-day rates, load control);

- cogeneration and district heating;

- human factors research.

\subsubsection{Form of the Building Environment}

The form of the building environment is a function of both land use patterns and the uses for which buildings are intended to serve. Alternative lifestyles can give rise to many different building types and uses, ranging from building space serving as both a residence and work place to self-contained 
urban villages. Some research ares implied by the alternative lifestyles considered by the panel are:

- energy generation from bio-technological waste recycling;

- on-site processing and reclamation of waste;

- equipment integration (e.g., cooling, water heating, HVAC)

- cogeneration/district heating;

- utility ownership of energy using building components.

\subsubsection{Building Diagnostics}

Research into the diagnostics of energy use in buildings requires accurate data bases and analytical methods. This information is necessary to identify the most effective combinations of building components and also to show proof of concept for new components. Quality information is required for all areas of building research. Panel recommendations include:

- improved data base;

- improved diagnostic/simulation models.

\subsubsection{Technology Transfer}

Transferring the results of building research to those who can apply the results in actual practice is critical to the success of programs designed to improve building/utility energy efficiency, increase the affordability of housing, and maintaining the global competitiveness of the building industry. As an intermediate step, it is also critical to have the results of proven research accepted by the bodies that prepare building codes and standards and by the ultimate purchasers of buildings. Some possible ways to facilitate the technology transfer process recommended by the panel are:

- development/improvement of technology centers;

- improve the engineering and technological basis for codes and standards;

- enhance government/industry cooperation. 


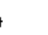




\subsection{DESCRIPTORS}

\subsection{INTRODUCTION}

Descriptors are trends, events, developments, variables, or attributes that serve to describe the topic. Their measurement may be quantitative or qualitative. Each descriptor consists of two or more descriptor states that represent mutually exclusive alternative possible future outcomes for that descriptor. At the end of a simulation each descriptor is characterized by one of its states occurring and the other state(s) not occurring.

Judgments must be made regarding the a priori probability of occurrence for each of the descriptor states independently of other external influences. One and only one of the states for a descriptor will ultimately occur at the end of one simulation, so the sum of the a priori probabilities for all states for a given descriptor witl always equal 1.0. That is, descriptor states are defined to be both mutually exclusive and exhaustive of the range of possible outcomes for a descriptor.

The descriptors, their states, and a priori probabilities that were used to derive the scenarios in this study were developed by combining forecasts of the variables with the expert opinion of a panel representing a crosssection of government and private industry interests (see Appendix A). A preliminary list of 164 descriptors was generated by the panel. The panel members then ranked each descriptor on the list based on its importance to the topic. This procedure resulted in paring the list to 34 descriptors.

The reduction process involved three main considerations. First, descriptors were retained based on the priority assigned to them by the panel members. Second, redundant descriptors were eliminated and closely related descriptors combined into one. Third, a balance of descriptors and their relative importance to the topic were retained subject to the time and resource constraints of this study.

After obtaining the final list of descriptors, the panel used an iterative process to determine the descriptor states and a priori probabilities for each state. These are presented in Table 4.1. 
IABLE 4.1. Descriptors, Descriptor States, and A Priori Probablities

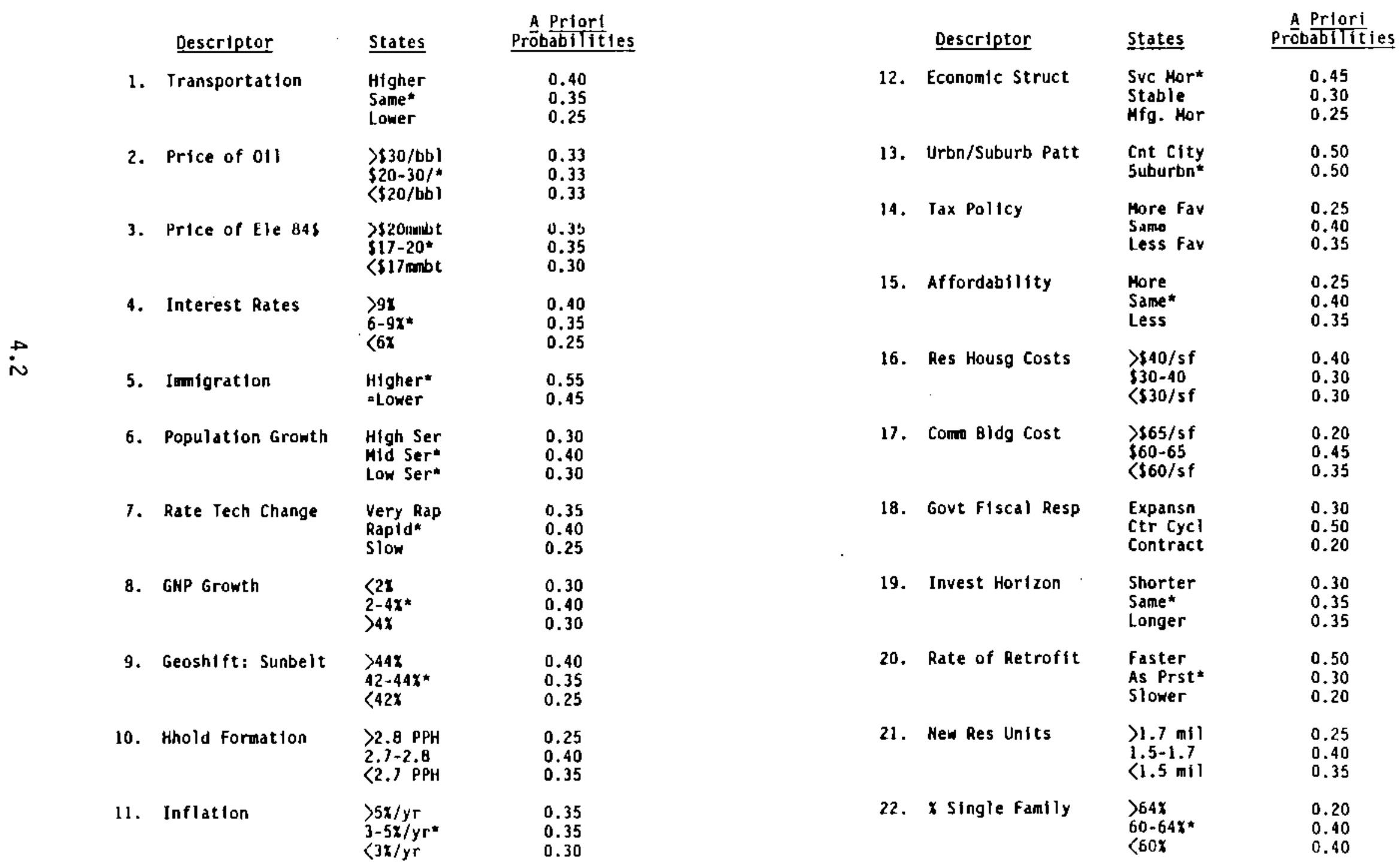


IABLE 4.1. Descriptors, Descriptor States, and A Prfori Probabilities, cont.

\begin{tabular}{|c|c|c|c|}
\hline & Descriptor & States & Prōbabillities \\
\hline 23. & $x$ Manuftrd Housg & $\begin{array}{l}\text { High } \\
\text { As Prst * } \\
\text { Low }\end{array}$ & $\begin{array}{l}0.35 \\
0.40 \\
0.25\end{array}$ \\
\hline 24. & Hsing Unit $512 e$ & $\begin{array}{l}>1500 s f \\
1-1500 s f \\
\text { c1000sf }\end{array}$ & $\begin{array}{l}0.25 \\
0.35 \\
0.40\end{array}$ \\
\hline 25. & x Incr Conm blag & $\begin{array}{l}>2 \pi \\
1.5=2 \pi \\
i 1.5 \pi\end{array}$ & $\begin{array}{l}0.35 \\
0.50 \\
0.15\end{array}$ \\
\hline 26. & $x$ Very Lrg Bldg & $\begin{array}{l}>37 x \\
33-37 x \\
\langle 33 x\end{array}$ & $\begin{array}{l}0.70 \\
0.20 \\
0.10\end{array}$ \\
\hline 27. & H/C Technology & $\begin{array}{l}\text { Rapld } \\
\text { Hoderate } \\
\text { Slow }\end{array}$ & $\begin{array}{l}0.30 \\
0.45 \\
0.25\end{array}$ \\
\hline 28. & Materials Techn & $\begin{array}{l}\text { Rapid } \\
\text { Hoderate } \\
\text { Slow }\end{array}$ & $\begin{array}{l}0.45 \\
0.30 \\
0.25\end{array}$ \\
\hline 29. & Bldg Code Enforc & $\begin{array}{l}\text { Relaxed } \\
\text { Ho Chng" } \\
\text { Increase }\end{array}$ & $\begin{array}{l}0.25 \\
0.45 \\
0.30\end{array}$ \\
\hline 30. & Enrgy Effic Bldg & $\begin{array}{l}\text { EUI }<1.5 \\
1.5-1.7 \\
\text { EUI }>1.7\end{array}$ & $\begin{array}{l}0.25 \\
0.50 \\
0.25\end{array}$ \\
\hline 31. & Ut 111 ty Role & $\begin{array}{l}\text { Ho reActy } \\
\text { As Prst* } \\
\text { LessActy }\end{array}$ & $\begin{array}{l}0.15 \\
0.45 \\
0.40\end{array}$ \\
\hline 32. & Bldg Density & $\begin{array}{l}\text { H1gher } \\
\text { Same* } \\
\text { Lower }\end{array}$ & $\begin{array}{l}0.40 \\
0.35 \\
0.25\end{array}$ \\
\hline 33. & Pref for Convenc & $\begin{array}{l}\text { Higher } \\
\text { Same* } \\
\text { Lower }\end{array}$ & $\begin{array}{l}0.40 \\
0.35 \\
0.25\end{array}$ \\
\hline
\end{tabular}




\subsection{DISCUSSION OF DESCRIPTORS}

Essays were prepared for a subset of the descriptors. The subset was chosen by the panel and, again, in consideration of time and resource constraints. The states and a priori probabilities for which essays were not prepared were determined by the panel members. The descriptor discussion follows.

\subsubsection{Fuel Prices}

The importance of fuel prices to building construction practices was amply demonstrated during the 1970's. Rapidly escalating prices caused a revolution in building practices. Insulation levels increased, passive conservation building designs were examined and variously applied, storm windows and doors became cominon features, heating systems changed, and features such as greenhouses and solar hot water heating equipment became common building options. While rising energy prices spurred changes in building practices, the channels of impact are varied.

The direct impact of fuel prices on building practices are those that are market driven, i.e., builders responding to increased interest on the part of building buyers in life cycle energy costs over the initial capital cost. Beyond this direct impact, rising energy prices, particularly price "shocks" of the variety encountered during the $1970^{\prime} \mathrm{s}$, caused federal and state governinents as well as private sources to actively encourage energy conservation. Energy conservation building codes were developed, consumers were informed of the potential cost savings from energy conserving building practices (through utility sponsored energy audits and other means), buildingsrelated $R \& D$ was sponsored and demonstrated, federal buildings were required to use new and renewable energy sources when feasible, and additional economic incentive was provided through tax codes. Energy prices are also recognized as having an impact on economic growth and, to the extent that economic growth affects construction of new buildings, this provides another indirect channel through which fuel prices affect building scenarios.

\section{Historical Trends}

Figures 4.1 to 4.3 show historical trends in fuel prices since 1970 and some fuel price projections (DOE 1983(a); DRI, Chase 1985). The fact that fuel 


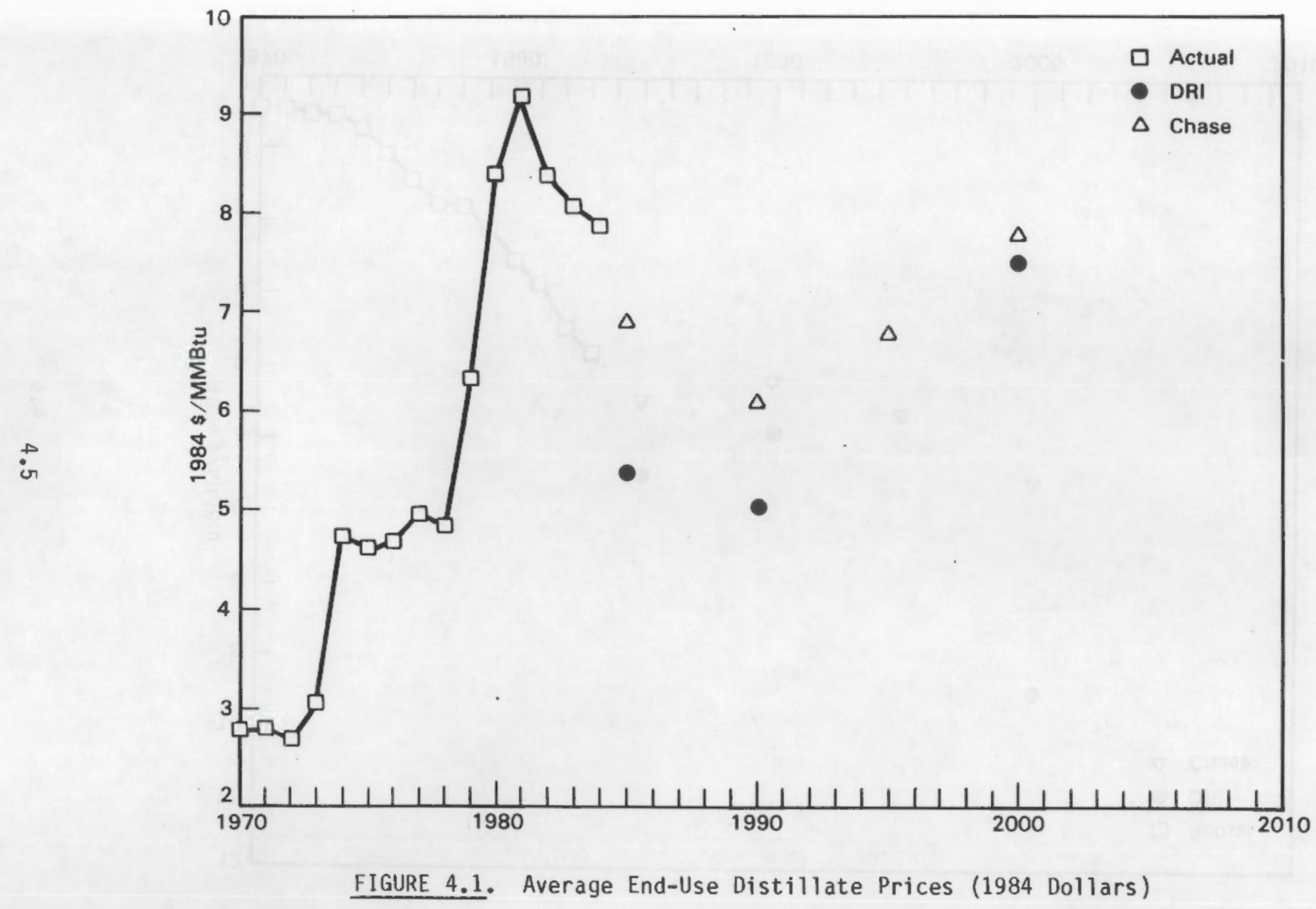




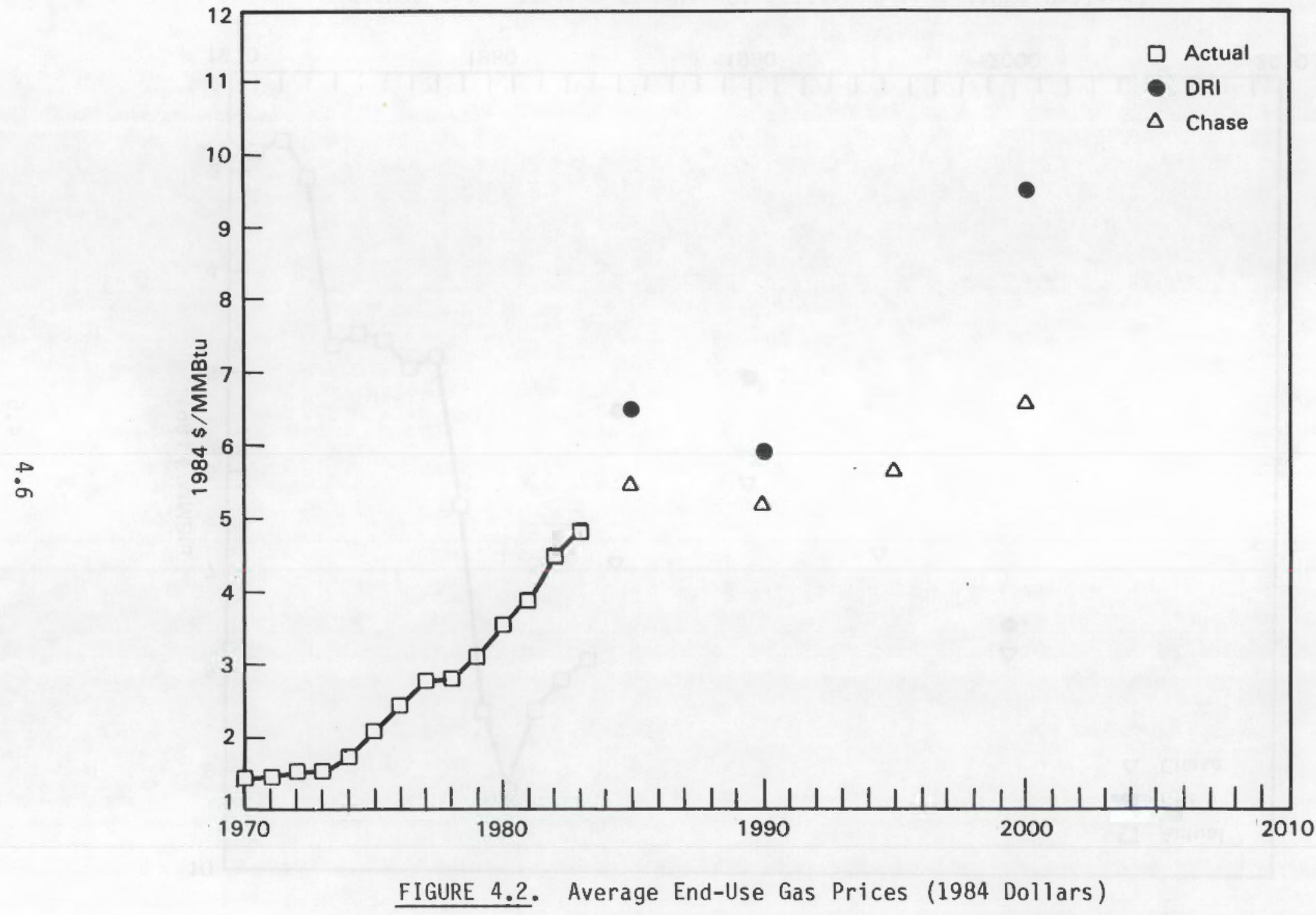




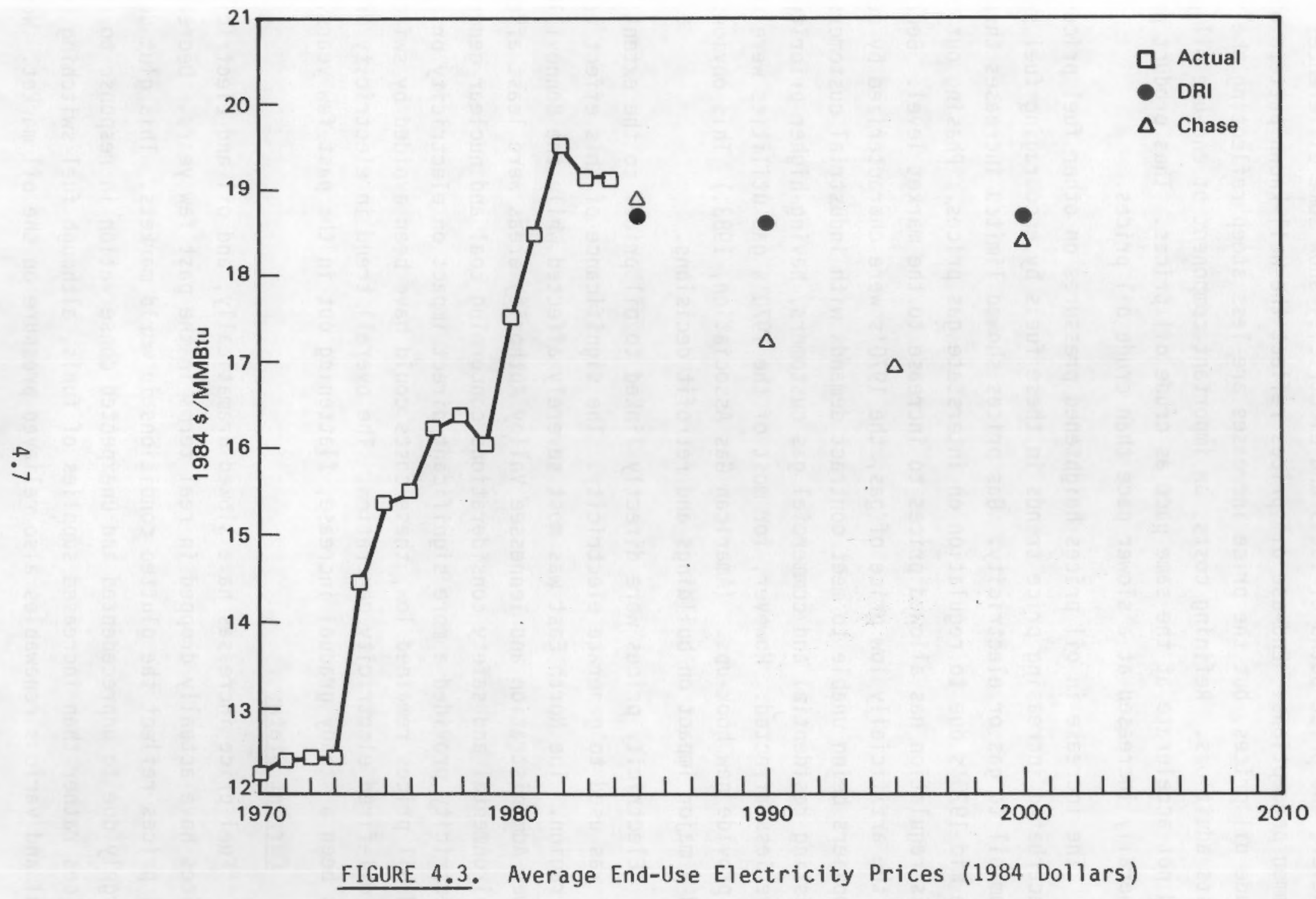


prices increased considerably during the past decade is hardly surprising. However, the price paths of fuels and electricity show some differences from common perceptions. End-use oil prices reflect the well-known pattern of crude oil prices, but the price increases are less steep reflecting the refining costs additions. Refining costs, an important component of end-use oil prices, did not accelerate at the same pace as crude oil prices. Thus product prices generally increased at a slower pace than crude oil prices.

The increase in oil prices heightened pressures on other fuel prices and exacerbated increasing price trends in these fuels by encouraging fuel switching from oil to gas or electricity. Gas prices showed limited increases through the mid 1970's due to regulation on interstate gas prices. Phasing out of this regulation has allowed prices to increase to the market level. Because of the artificially low price of gas, the 1970's were characterized by gas suppliers being unable to meet contract demands with industrial customers. Existing residential and commercial gas customers, having higher priority, were less affected. However, for most of the 1970's gas utilities were unable to provide new hook-ups. (American Gas Association, 1983.) This obviously had a major impact on buildings and retrofit decisions.

Electricity prices were directly linked to oil prices to the extent that oil was used to generate electricity. The significance of this effect varied by region. The North East was most severely affected while the Bonneville Power Administration and Tennessee Valley Authority areas were least affected. Environmental and safety considerations concerning coal and nuclear generated electricity provided a more significant direct impact on electricity prices. Had oil prices remained low, these costs could have been avoided by switching to oil-fired electricity generation. The overall trend in electricity prices has been a steady gradual increase, flattening out in the past few years.

\section{Current Status}

Fuel price increases have slowed dramatically, and oil and electricity prices have actually dropped in real terms in the past few years. Decreasing oil prices reflect the glutted conditions in world markets. This glut developed largely due to unprecedented and unexpected conservation in response to rising prices rather than increased supplies of fuels, although fuel switching to coal and various renewables also relieved pressure on the oil market. World 
economic recession also has contributed to the recent decline in oil prices. End-use natural gas prices have continued to rise since 1970 reflecting the proportionately greater consumption of higher cost reserves.

\section{Future Prospects}

0il prices remain highly uncertain, but most longer term studies see considerably less upward pressure on prices over the next 10 to 15 years than was predicted even a few years ago. However, the 2005 to 2010 period may represent another point where new technologies must begin seriously replacing conventional oil. This could come from the supply side; oil-substitute liquid fuels can be generated from shale oil, coal, or biomass. Such developments could leave energy consuming equipment largely unchanged. Or, new technologies could evolve on the demand side--either providing dramatic conservation improvements or utilization of more abundant fuels (e.g., electric automobiles with a new cheap source of electricity). The cost of these substitute processes and products and the speed with which they penetrate will determine whether prices increase tremendously, increase only gradually, or remain flat overtime.

Exploitation of existing natural gas resources worldwide has lagged that of oil. Thus, resource limits may not provide as strong a force for price increases in the 2010 time horizon. The significant factor affecting U.S. prices in the longer term will be the probable need to import gas, particularly if it is necessary to import from areas requiring LNG transport. In the nearer term, the gradual decontrol of natural gas will also ultimately lead to higher end-use prices since gas will be produced from more expensive reserve areas.

Electricity prices ar also highly uncertain. The impacts of coal desulfurization equipment has not yet been fully reflected in rates. Many region's rates still reflect an averaging in of lower cost generating equipment exempt from the full effects of environmental regulation, having been built before the regulation took effect. The extent to which utilities will be able to pass on the costs of cancelled nuclear power plants is also unclear. Furthermore, in a climate of deregulation, utilities may return to using oil to generate electricity, especially if prices remain low. 
World oil prices were used to represent distillate prices in the scenarios. World oil prices were also used as a surrogate for natural gas prices since the panel felt that the two price series would move in the same direction. The reference price of natural gas used in this analysis is $\$ 7-\$ 9 / \mathrm{mmbtu}(1984 \$)$. The descriptor states and a priori probabilities reflecting those considerations are:

Descriptors

World Price of 0 il (1984\$)

Greater than $\$ 30 / \mathrm{bb} 1$

$\$ 20-30 /$ bb 1

Less than $\$ 20 / \mathrm{bbl}$

Price of Electricity (1984\$)

Greater than $\$ 20 / \mathrm{mmbtu}$

$\$ 17-20 /$ mmbtu

Less than $\$ 17 / \mathrm{mmbtu}$

\section{A Priori Probabilities}

.33

.33

.33

.35

.35

.30

\subsubsection{Interest Rates}

Interest rates are important factors, directly and indirectly, that affect the characteristics of buildings and the consequent impact on building energy consumption in the residential and commercial sectors. Interest rates are directly important because they influence the availability of financing for new home purchases, appliance purchases and residential building retrofits and because of the costs associated with lost opportunities can influence both attitudes toward energy conservation and the availability of conservation programs. Interest rates are equally important in the commercial sector because they influence the willingness of banks to float construction loans for new commercial buildings and because they weight heavily in the decision process regarding commercial building retrofits and equipment purchases.

They are indirectly important through their influence on both energy and non-energy prices and personal income. The indirect effects on energy efficiency and consumption in the residential and commercial sectors arise from the role of interest rates in general economic policy. Elementary textbook 
examples suggest that monetary authorities will intervene in financial markets to maintain interest rates or the money supply within a targeted range. These targets will be determined by the appropriate monetary policy for existing economic conditions--during periods of rising prices these targets will be restrictive to stifle inflation; during periods of low economic activity, the targets will be expansionary to promote growth. High interest rates, then, generally indicate a tightening of credit, lower rates a loosening of credit. If the monetary authorities are successful in "leaning against the wind," it is likely that high interest rates will be associated with high rates of inflation, while lower rates will be associated with periods of relative price stability. Abstracting from price changes, more rapid rates of growth in the economy would be associated with lower interest rates, while slower rates of economic growth would be associated with higher interest rates. (a) But textbook conditions rarely exist.

During recessions--real economic decline--one would expect the monetary authorities to ease credit conditions, the tightness of which might have been a partial cause of the decline. If so, there will be times when growth rates are high and interest rates are rising or vice-versa. Alternatively, during periods of "stagflation" (stagnant growth and inflation), the monetary authorities will be caught on the horns of a dilemma: slow growth suggests easing credit conditions while inflation suggests tightening credit. So in identifying the linkages, one must clearly differentiate between causal effect and coincident events. If monetary authorities respond to indications of adverse economic events, which is likely, interest rates will go up during periods of inflation and down during periods of low or negative economic growth. But what do the monetary authorities do when, as recently, the economy experiences both high inflation and low economic growth? Clearly the monetary authorities must choose. How they have reconciled these inconsistent objectives is an empirical matter; the results of these actions will be discussed in the next section.

The direct effects of interest rates on energy efficiency and use is less ambiguous. An indicator of the cost of borrowing, interest rates will influence

(a) For alternative theories of interest, see Rasche. 
the costs of purchases of home and commercial building appliances, the costs of retrofitting of all buildings to make them more energy efficient, the purchases of new homes, and the construction and rental costs of commercial floor space. The rate of additions to building stocks and the penetration of newer (and therefore more efficient) equipment both will clearly increase the efficiency of energy use in the residential and commercial sectors. Any additions to either building or equipment stocks will increase energy use; retrofits to existing stock or replacement of older stocks will decrease energy use. The cost of borrowing will also be a major factor in the decision to weatherize existing buildings since the costs of borrowing will determine the payback period for the retrofit.

\section{Historical Trends}

The prime rate over the period 1950 to 1984 is plotted as the solid line in Figure 4.4. Over the 35 years covered in the graph, what stands out most dramatically is the secular increase in the prime rate -- averaging about three percent after the Treasury Accord of 1952, with gradual rises through the mid-1960's, then increasing sharply to average about 13 percent during the early 1980's. One would have to go back before 1929 to see average interest rates that exceeded the prime rate in 1965. But relying on the trend over the past 35 years as a basis for projecting trends in interest rates into the future would be a mistake. A comparison of movements in the rate of inflation (plotted in Figure 4.4 with short dashes) and the prime rate since the Treasury Accord indicates that both of these variables move in much the same manner, with a historic differential of about 2-3 percent. This differential is a close approximation to a "real rate of interest"--the value of money adjusted for the losses that results from inflation.

This measure of the real rate of interest is only approximate because decisions are based on anticipated rates of inflation that can be foreseen only vaguely. Nonetheless, any trend in interest rates must take into account the likelihood that real rates of interest will reflect a more normal historic relationship between the prime rate and the rate of inflation. It is only during periods of sharp changes in the rate of inflation or economic recession that these historic relationships are badly disturbed. 


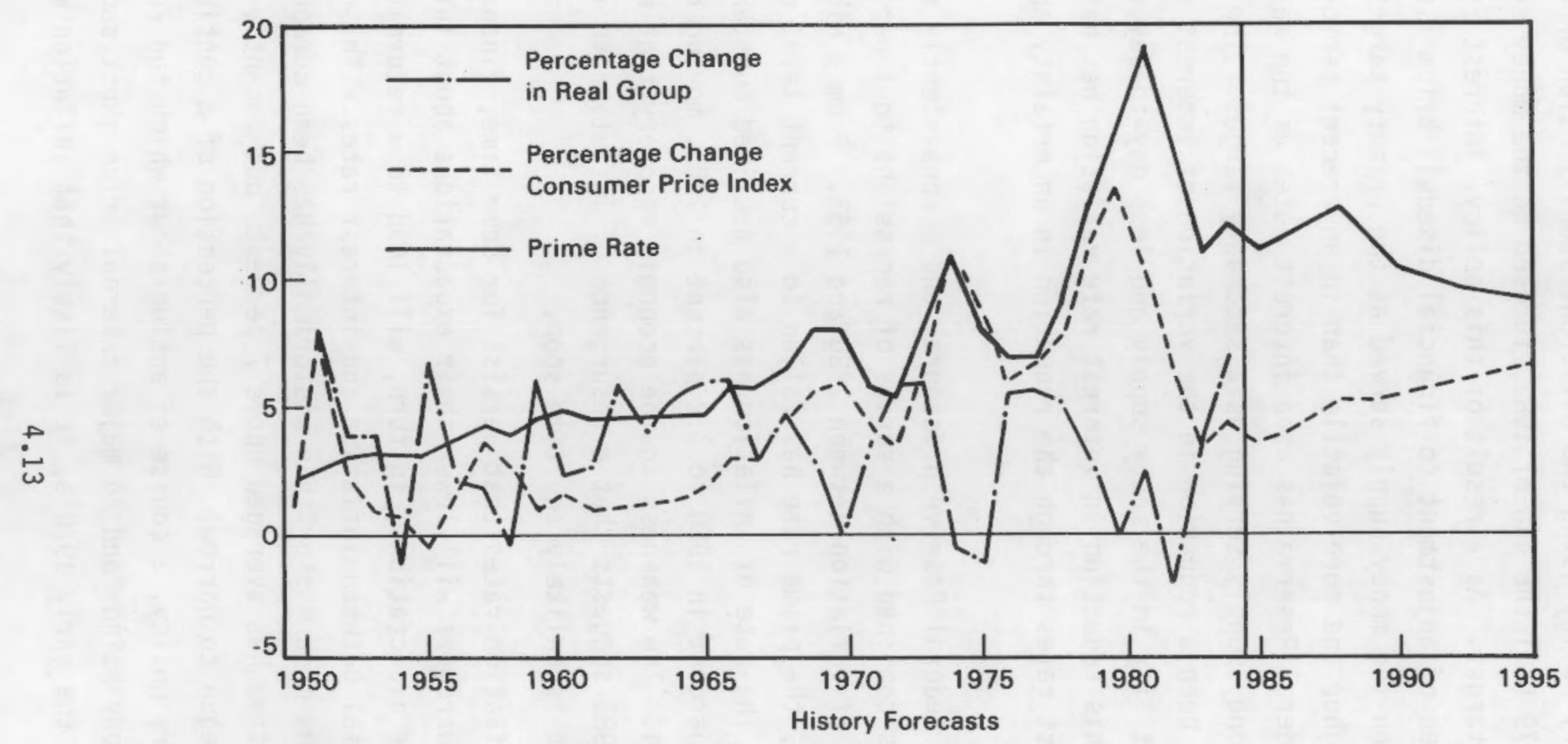

FIGURE 4.4. Prime Rate, Inflation and Real Growth in the U.S., 1950-1984, with Forecasts to 1995 


\section{Current Status}

Since October, 1979, the Federal Reserve System has pursued a generally restrictive monetary policy using two different stabilization procedures. The first, from 1979 till the end of 1982, focused on the money supply as the main intermediate target. As a result of this policy, interest rates bore the principal burden of adjustment to financial disequilibrium (Tobin 1985). Over the period when the money supply served as the primary target, interest rates were both higher and more volatile than in any recent period of history.

Since 1982, the Federal Reserve has used interest rates as the main intermediate target, with the money supply serving as a secondary target. The consequence of this change has been a reduction in the variation of interest rates with somewhat more volatility in the money supply and less day-to-day variation in interest rates. This reduction in interest rate variation has had the effect of lowering interest rates through the reduction in uncertainty about future interest rates.

This shift in Federal Reserve procedure, and a consistently restrictive monetary policy has combined with a series of recessions to lower both interest rates and the rate of inflation between 1980 and 1983. From a high of nearly 19 percent in 1980 , the prime rate has fallen to a current level of slightly about 10 percent. The rate of inflation has also declined substantially from a high of over 13 percent in 1980 to 3.2 percent in 1983, moving back up to 4.3 percent in 1984 . The weakness in the economic recovery that has become evident in early 1985 suggests that a resurgence of inflation to rates higher than 5 or 6 percent is unlikely any time soon.

With lower inflation rates that persist for some time, financial institutions and borrowers will lower their expectations about future rates of inflation; lower expectations, in turn, will lead to a return to a more historic differential between inflation and interest rates. The current differential remains much higher than historically has been common. Since 1981, the differential has averaged above 7 percent, but recently that differential has begun to narrow. With the perception of a continuing restrictive monetary policy, a course of action about which the Federal Reserve has been convincing, and no major external price shock such as the oil price shock of the early 1970's, it is likely that inflation will continue 
at reasonably low levels and that interest rates will gradually move back into historical relationship with inflation.

\section{Future Prospects}

If the rate of inflation returns to the more modest rates of the late 1960 's, which ranged from 2 to 6 percent, we could expect the prime rate to remain below double-digit rates. But if inflation persists at levels similar to the rates that have prevailed since the first OPEC price shock of 1973-74 (ranging from 6 to 13 percent), the prime rate would more likely stay within a range from 9 to 16 percent. The major area of uncertainty is how quickly the historical differentials between interest rates and inflation will return.

Figure 4.4 also plots forecasts of inflation and the prime interest rate for the period 1985-2010, based on the forecasts of Data Resources, Inc. (DRI) The DRI forecasts through 2010 predict inflation rates that climb annually to peak at slightly above 6 percent in the early 1990's, with a declining prime rate that drops below 9 percent in 1994. After 1994, both inflation and the prime rate decline very gradually until after 2005 , when they stabilize at 5.6 percent for inflation and about 8.25 percent for the prime rate. With a change in monetary policy back to interest rate targets and a sustained lower rate of inflation, our forecasts would have this historic differential achieved much sooner than the DRI forecast suggests. Accordingly, the descriptor states and a priori probabilities associated with then are as follows.

\begin{tabular}{lc} 
Descriptor States & A Priori Probability \\
\cline { 2 - 3 } Above 9 percent & .40 \\
From 6 to 9 percent & .35 \\
Descriptor States & A Priori Probability \\
Below 6 percent & .25
\end{tabular}

The probabilities associated with these descriptor states are contingent on the forecasts for the rate of inflation and assume a return to historic differentials between these two variables well before the 1995 period. At the same time, recent events have aptly demonstrated that this differential may deviate within wide limits, as may the forecasts (Bernstein and Silbert). 


\subsubsection{Technological Progress}

Technological progress is defined as an increase in output obtained without a commensurate increase in the factors of production: capital, labor, and natural resources. Technological progress has important implications for the relationship between building construction and energy use because technological progress affects how buildings are constructed, the materials used in their construction, and the energy efficiency of heating and cooling technologies. For the purposes of this exercise, however, the more important affects of technological progress occur at the aggregate level through increases in gross output (GNP) and income.

Technological progress necessarily implies greater aggregate income, more output for less input. It also has implications for the distribution of income, although this relationship is less well understood. Increases in aggregate income affect the amount of construction (residential and commercial), the type of buildings constructed (single versus multiple family dwellings), the types of appliances, the ability to retrofit, and the importance of changes in energy prices. Technological progress has both domestic and international implications. It reduces the cost of domestically produced goods or conversely expands consumers purchasing power. Technological progress also promotes the ability of the United States to compete in international markets and may therefore reinforce the growth in national income.

\section{Historical Trends}

The growth in output per hour of all persons in the private business sector from 1948 through 1981 is depicted in Figure 4.5. The productivity of labor, output per hour, has increases rapidly since the late 1940's. From 1948 to 1981 labor productivity has increased at an average rate of 2.4 percent annually. However, nearly ninety percent of the growth observed during this period occurred from 1948 to 1973. After 1973 output per hour increased only at an average annual rate of 0.8 percent. For three years during this period, 1974,1979 , and 1980, labor productivity decreased.

While short-term changes in total productivity over a year or two are generally caused by ups and downs in output and employment, the factors affecting long-term productivity are more fundamental and occur more slowly. In a general sense, these factors are the amount of capital equipment that 


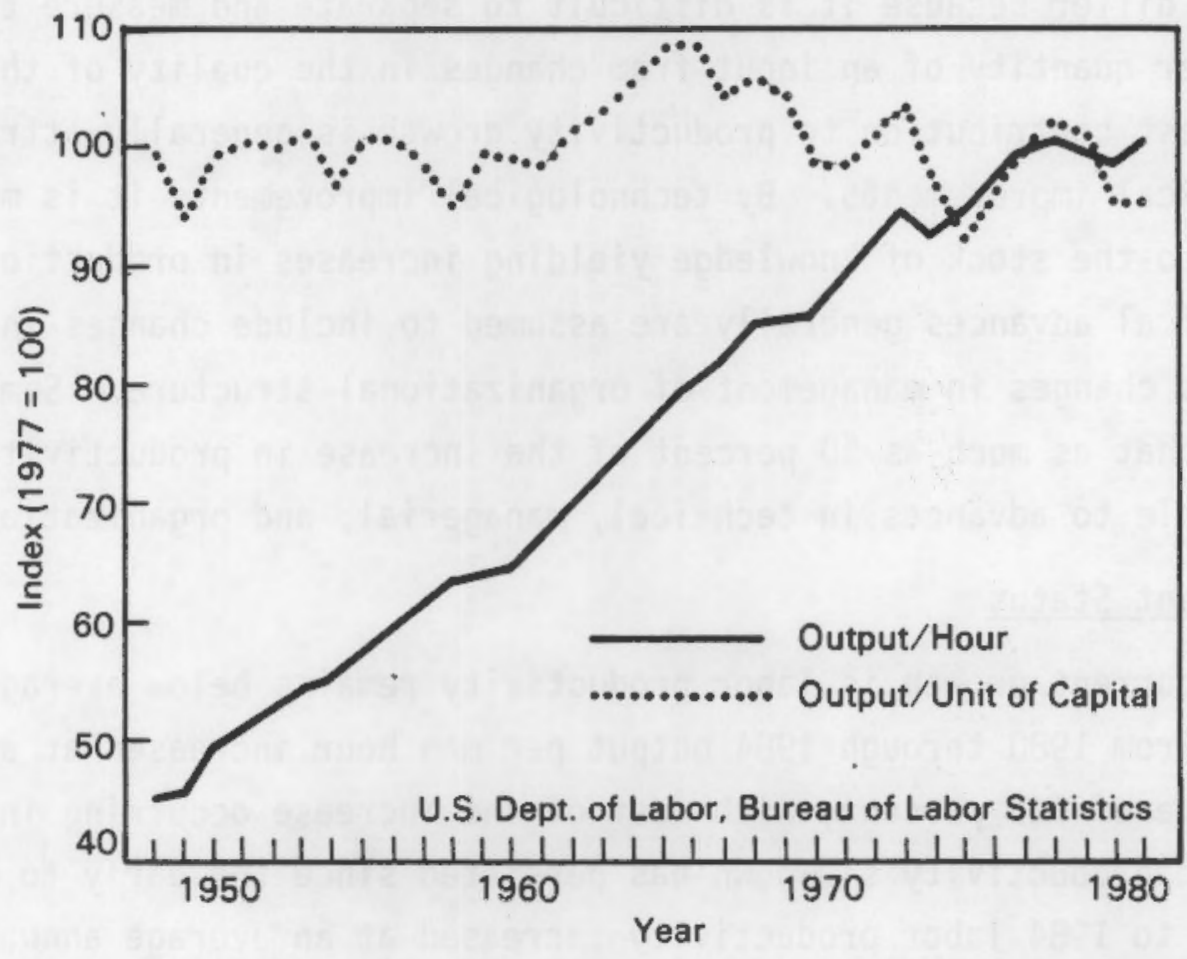

FIGURE 4.5. Productivity Measures for the Private Business Sector, 1948-1981 
can be used efficiently, the quality of the labor force using the equipment, and the efficiency with which production factors can be combined.

Researchers generally agree that during the postwar period more capital has contributed between 20 to 30 percent to growth in productivity and improvements in labor quality have accounted for between 10 to 30 percent. Estimates differ because it is difficult to separate and measure the effects of a larger quantity of an input from changes in the quality of the input. The greatest contribution to productivity growth is generally attributed to technological improvements. By technological improvements it is meant any addition to the stock of knowledge yielding increases in production. In fact, technological advances generally are assumed to include changes in equipment as well as changes in management of organizational structure. Some research suggests that as much as 50 percent of the increase in productivity is attributable to advances in technical, managerial, and organizational knowledge.

\section{Current Status}

The current growth in labor productivity remains below average historical levels. From 1980 through 1984 output per man hour increased at an average annual rate of 1.6 percent, with most of the increase occurring in 1983 and 1984. The productivity slowdown has persisted since the early to mid 1970's. From 1973 to 1984 labor productivity increased at an average annual rate slightly exceeding one percent. The slowdown in productivity growth has been identified as "one of the most significant economic problems in recent years." Although many hypotheses explaining the productivity slowdown abound, no satisfying explanation exists. Explanations run from a breakdown of the social contract between labor and management, resulting in worker dissatisfaction, work stoppages and declines in output, to inadequate funding of research and development.

\section{Future Prospects}

Near-term forecasts indicate a rebounding of productivity growth . Wharton Econometrics forecasts output per hour to increase from 1.7 percent in 1986 to 2.4 percent by 1988 . Their forecasts suggest rates of growth similar to those experienced from 1948 to 1981 . 
There remains substantial uncertainty regarding the long-term. Because of the complex nature of productivity growth, no definitive forecast of its long-term trajectory is possible. It is likely, however, that the seeds for productivity growth have already been planted in current research and development. It would appear that most of the sources of productivity growth, save technological change, are limited. The farm out migration has ceased, and large improvements in labor quality through improved education are unlikely. Far reaching improvements in technology and management will be necessary to achieve the rates of productivity increases observed during the 1950 's and 1960 's.

It seems likely, therefore, that increases in output per hour will be less than those observed during the period 1948 to 1973. However, the current forecasted rebounding of productivity growth suggests rates observed during the late 1970's will be exceeded. The descriptor states and a priori probabilities reflecting these considerations are:

\begin{tabular}{|c|c|c|}
\hline \multicolumn{2}{|c|}{ Descriptor States } & A Priori Probability \\
\hline Rate of & Very Rapid & .35 \\
\hline Technology : & Rapid & .40 \\
\hline Change & Slow & .25 \\
\hline
\end{tabular}

\subsubsection{Household Formation}

The rate at which members of the population form households clearly has important implications for the buildings sector. Implied in the number of households are characteristics relating to the size of the population and the average member of people living in a housing unit.

Current statistics indicate that even though the population continues to increase, the average number of people per household is declining. Based on these trends, it is not necessary to measure the countervailing effects of an increase in the size of the population coupled with a change in the number of people per household in order to determine household formation. The rate of household formation is directly related to the growth in the population and the change in the number of people per household. It is people per household that will serve as a proxy for this descriptor. 


\section{Historical Trends}

In 1930, 122.8 million people lived in the United States. At that time, there were, on average, over four people per household. By comparison, in 1984 , the population was 236.2 million and the number of people per household was 2.78. Between 1930 and 1984, the population increased by 1.2 percent per year and the number of people per household declined by 0.7 percent per year.

More recent trends are indicated in the data contained in Table 4.2. As shown in the Table, the population of the United States increased from 180.0 million in 1960 to 236.2 million in 1984. This was an annual growth rate of 1.1 percent. The population per household decreased by 0.8 percent per year since 1960. Brogue (1985) identifies the following factors as contributing causes of the downward trend:

- greater longevity combined with greater economic security for the aged thereby leading to an increasing share of a larger aged population living on their own;

- declines in fertility, thus fewer children at home;

- a tendency for young singles to move away from home;

- fewer young couples living with their parents;

- increased divorce and separation.

\section{Current Status}

Recent figures for 1985 taken from a U.S. Bureau of the Census document entitled, Households, Families, Marital Status, and Living Arrangements (1985(c)) show a sharp increase in the number of single people living alone. Between 1970 and 1985, the number of housing units occupied by a male living alone went from 3.5 million to 7.9 million, or from 5.6 percent of the total number of occupied housing units to 9.1 percent of the total. Women living alone in 1970 accounted for 7.3 million occupied housing units and 12.7 million units in 1985. This represented 11.5 percent of the total stock of occupied housing units in 1970 and 14.6 percent in 1985.

The increase in the number of people living alone in the last decade has reduced the average people per household and therefore contributed to an increase in the number of occupied housing units. The underlying reasons for 


\section{TABLE $\quad 4.2$}

Table 1 Population Per Household U.S. Total, 1960-1984

\begin{tabular}{|c|c|c|c|}
\hline Year & $\begin{array}{l}\text { Population } \\
\text { (Millions) }\end{array}$ & $\begin{array}{l}\text { Households (1) } \\
\text { (Million } \\
\text { Units) }\end{array}$ & $\begin{array}{l}\text { Population Per } \\
\text { Household }\end{array}$ \\
\hline $\begin{array}{l}1960 \\
1961 \\
1962 \\
1963 \\
1964 \\
1965 \\
1966 \\
1967 \\
1968 \\
1969 \\
1970 \\
1971 \\
1972 \\
1973 \\
1974 \\
1975 \\
1976 \\
1977 \\
1978 \\
1979 \\
1980 \\
1981 \\
1982 \\
1983 \\
1984\end{array}$ & $\begin{array}{l}180.0 \\
183.0 \\
185.8 \\
188.5 \\
191.1 \\
193.5 \\
195.6 \\
197.5 \\
199.4 \\
201.4 \\
204.0 \\
206.8 \\
209.3 \\
211.4 \\
213.3 \\
215.5 \\
217.5 \\
219.8 \\
222.1 \\
224.6 \\
227.2 \\
229.5 \\
231.8 \\
234.0 \\
236.2\end{array}$ & $\begin{array}{l}52.80 \\
53.56 \\
54.76 \\
55.27 \\
56.17 \\
57.44 \\
58.41 \\
59.24 \\
60.81 \\
62.21 \\
63.40 \\
64.78 \\
66.68 \\
68.25 \\
69.86 \\
71.12 \\
72.87 \\
74.14 \\
76.13 \\
77.33 \\
80.78 \\
82.37 \\
83.53 \\
83.92 \\
85.00\end{array}$ & $\begin{array}{l}3.41 \\
3.42 \\
3.39 \\
3.41 \\
3.40 \\
3.37 \\
3.35 \\
3.33 \\
3.28 \\
3.24 \\
3.22 \\
3.19 \\
3.14 \\
3.10 \\
3.05 \\
3.03 \\
2.98 \\
2.96 \\
2.92 \\
2.90 \\
2.81 \\
2.79 \\
2.78 \\
2.79 \\
2.78\end{array}$ \\
\hline
\end{tabular}

Source: U.S. Bureau of the Census, Current Population Series, $\mathrm{P}-20, \mathrm{U} . \mathrm{S}$. Bureau of the Census, various issues.

Note: (1) Number of occupied housing units. Excludes vacant and seasonal homes. 
the increase in the number of people living alone (U.S. Bureau of the Census, 1985) are similar to the reasons given by Brogue for the overall decline in the number of people per household:

- increase in divorce and separation,

- young adults living alone for a period after leaving their parents' home,

- women outliving men because of health care improvements. The median age for women living alone in March 1985 was 65.5. The median age for men living alone was 41.1 .

Although these trends are apparent, the effect on the number of people per household is less dramatic. As shown in Table 4.2, the number of people per household has remained relatively stable at about 2.8 since 1980 . Other tendencies such as young adults returning to the family home because of economic difficulties have also affected the data.

\section{Future Prospects}

Some of the factors driving the reduction in the number of people per household and the corresponding increase in the number of occupied housing units are expected to slow in the long run. The rate of divorce and separation may have already peaked. Increases in longevity have slowed from a .44 years per year increase from 1920 to 1950 to only .18 years per year increase between 1955 and 1983 (U.S. Bureau of the Census, 1984(b). Future increases are likely to be at this more moderate rate or slower. Cuts in Social Security and Medicare may contribute to a decline in the longevity rate.

The growth in the population is also expected to decline, thereby reducing the need for more housing units. This is based on the fact that young married couples are delaying child bearing. The immigration rate may also decrease as the tolerance of illegal aliens diminishes.

The descriptor states and associated a priori probabilities reflecting these considerations are:

\section{Descriptor State}

Increase: Greater than $2.8 \mathrm{PPH}$

Same: $2.7-2.8 \mathrm{PPH}$

Decline: Less than $2.7 \mathrm{PPH}$
A Priori Probability

.25

.40

.35 


\subsubsection{Geographic Distribution of the Population}

For the purposes of this analysis, the geographic distribution of the population is defined as the share of the population living in the Sunbelt. Although the Sunbelt is not an officially designated area, the states out lived in Figure 4.6 are defined as the Sunbelt in this study.

The proportion of the population living in the Sunbelt is important in terms of residential energy consumption because it affects the number of heating and cooling degree days a residence will typically face. The Sunbelt has been defined to include states with warm climates. As can be seen from Figure 4.6, the Sunbelt states include, for the most part, two climate zones: Zone 5 , which has low heating requirements (less than 4,000 HHD) and high cooling requirements (greater than 2,000 CDD), and Zone 4, which has low heating requirements (less than $4,000 \mathrm{HDD}$ ) and low cooling requirements (less than $2,000 \mathrm{CDD})$. Thus, the primary impact of shifts of population to the Sunbelt should be to reduce residential energy demand due to less need for heating. Secondary effects of a shift to the Sunbelt might be a change in seasonal demand (from winter to summer) and a change in fuel shares. Fuel oil is used for heating in the Northeast and is used only infrequently in the Sunbelt states. Electricity is the primary fuel for space cooling and more space cooling is obviously required in the Sunbelt. Natural gas is particularly dominant in the Midwest and is used less elsewhere. Heat pumps, using primarily electricity, are particularly cost effective where heating and cooling needs are more similar (making ideal capacity of the heat pump similar in both winter and summer) and where climates are milder; heat pumps become less efficient as the differential between desired indoor temperature and the outdoor temperature increases. Thus, a growing share of the population in the Sunbelt probably favors electricity over fuel oil and natural gas.

\section{Historical Trends}

Figure 4.7 gives the shares of the U.S. population in the Sunbelt from 1930 through 1982. The share has steadily increased, and has increased at a more rapid pace since 1970. Prior to 1970, Florida, Texas, California, and New Mexico showed large increases in population share whereas other southern 


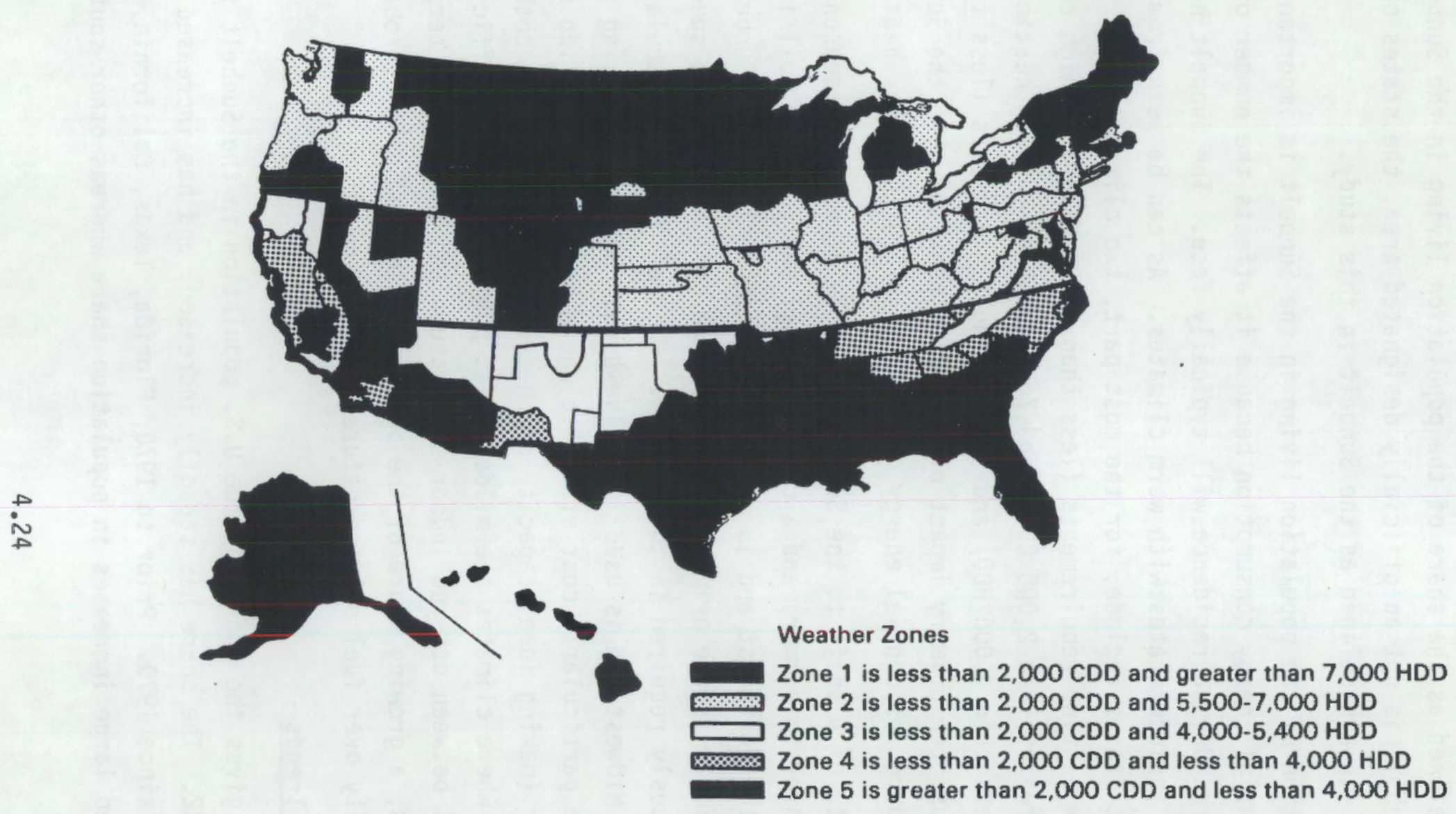

FIGURE 4.6. Sun Belt States and Heating and Cooling Degree Days

(Source: Energy Information Administration 1983) 


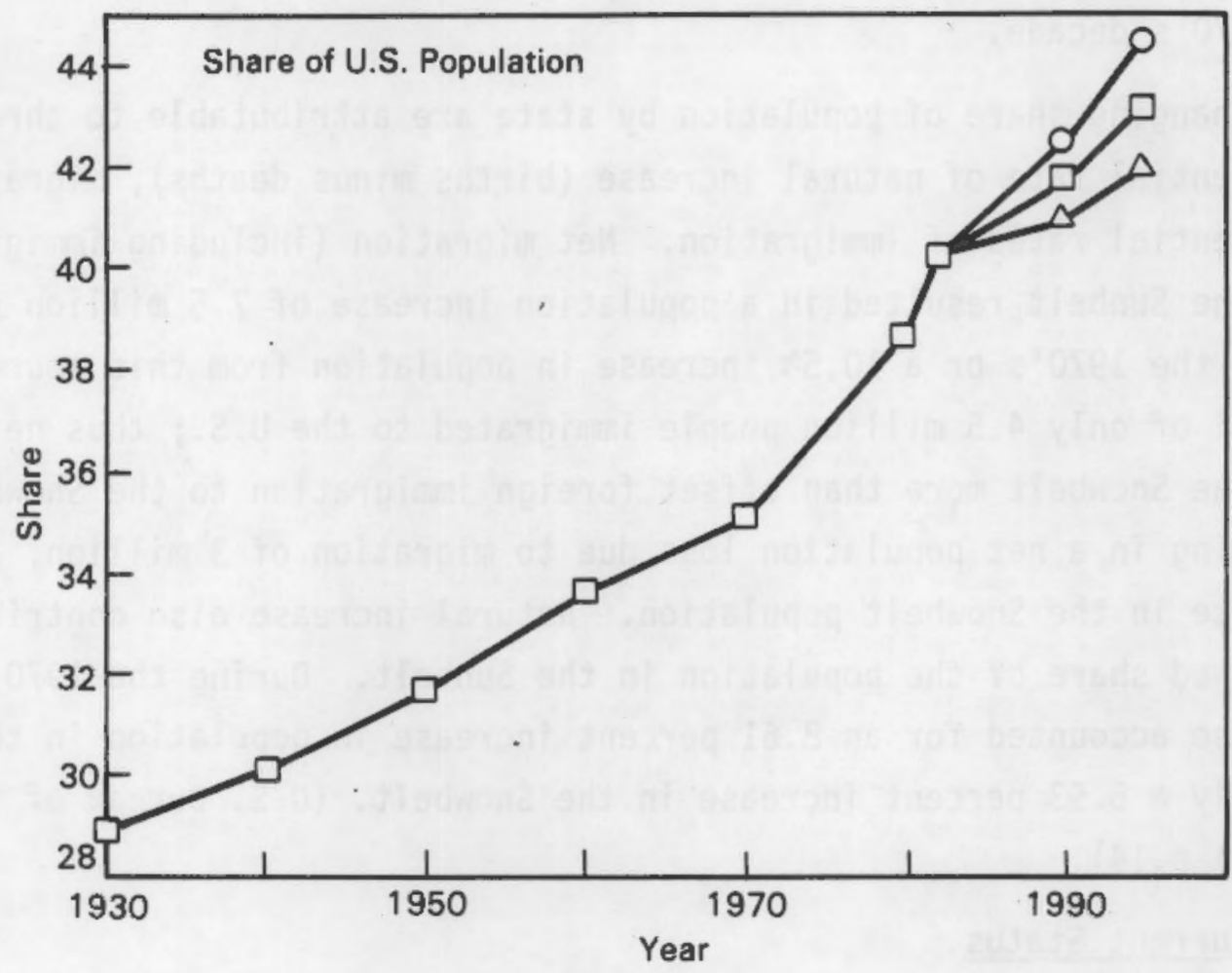

FIGURE 4.7. Sun Belt Population

(Historical data are from Donald J. Bogue. 1985. The Population of the United States: Historical Trends and Future Prospects.

The Free Press, New York. p.74.) 
states (e.g., Mississippi, Alabama) lost share. From 1970 to 1980, all of the states in the Sunbelt gained share (Bogue, 1985 p.74). This contributes to the large gains in share for the region as a whole after 1970 even though the gains in California (which alone accounts for over $10 \%$ of the U.S. population) slowed from a gain in share of 1.12 per decade from 1900 to 1970 to 0.63 for the 1970 's decade.

Changing share of population by state are attributable to three factors: differential rate of natural increase (births minus deaths), migration, and differential rates of immigration. Net migration (including immigration) into the Sunbelt resulted in a population increase of 7.5 million persons during the 1970 's or a $10.5 \%$ increase in population from this source alone. A total of only 4.5 million people immigrated to the U.S.; thus net migration from the Snowbelt more than offset foreign immigration to the Snowbelt, resulting in a net population loss due to migration of $3 \mathrm{million}$, a 2.28 percent decrease in the Snowbelt population. Natural increase also contributed an increased share of the population in the Sunbelt. During the 1970 's, natural increase accounted for an 8.61 percent increase in population in the Sunbelt but only a 5.93 percent increase in the Snowbelt. (U.S. Bureau of the Census, 1984(b) p.14).

\section{Current Status}

The current (1982) population share in the Sunbelt is just over 40 percent. Increases in share in the 1980 's appear to have accelerated even from the rapid pace of the past decade. The Sunbelt is popularly thought of as a "land of opportunity," drawing industry on the basis of low taxes, low wages, and less unionization, and drawing population on the basis of more jobs. The recession of the late 1970's and 1980's, hitting particularly hard in the Northeast and Midwest, may have temporarily accelerated migration to the Sunbelt over its longer term rate. Moreover, some of the advantages of the Sunbelt (low taxes, low land prices) are likely to erode as wages are bid up and as cities expand and require additions to and maintenance of infrastructure (e.g., schools, highways, mass transit, etc.). 


\section{Future Prospects}

The Census Bureau (1984(b), p.15) provides state level projections of population explicitly accounting for migration, immigration, and differential fertility rates. The projection shows a continuation of the general trend of an increasing share of the population in the Sunbelt. However, the rate of increases slows from the pace of the early 1980's. The Census Bureau's 1990 Sunbelt percentage is 41.8 , a gain in of 3.1 percentage points for the 1980 decade compared to a gain in share of 3.5 for the 1970's. The Census projections imply that the early $1980^{\prime}$ 's represent a temporary rapid increase in share to be balanced by slower rates of migration in the latter years of the 1980 's.

There remains considerable uncertainty regarding migration and it would seem that considerably more rapid migration then the Census projection is a possibility. It seems less likely that migration will reverse or slow significantly more $\tan$ the Census projection.

The descriptor states and a priori probabilities reflecting these considerations are:

Descriptor States

Greater than $44 \%$

Descriptor States

$42-44 \%$

Less than $42 \%$

\section{A Priori Probability}

.40

A Priori Probability

.25

\subsubsection{Percent Single Family Homes}

The percent of residences that are single family, detached homes is an important variable in any residential building conservation scenario and is closely linked with other considerations. Single family homes are more likely to be owner occupied and residents tend to have a higher income, on average, then residents of multi-family units or mobile homes. This point is substantiated by the fact that in 1981 the median income of owner occupied units was $\$ 21,800$ ( $\$ 1981$ ), for renter occupied units the median income was $\$ 11,400$ ( $\$$ $1981)$, and for mobile homes the median income was about $\$ 12,000$ 
(\$1981). (U.S. Bureau of the Census 1985(a)). Single family homes also tend to be larger in terms of square footage of floor space. In recently constructed housing units, single family homes averaged 1,025 square feet of floor space while multi-family units averaged 627 square feet. (U.S. Bureau of the Census, 1985(b), pp. 33,41). The necessarily larger number of external surfaces increases the need for insulation, has a tendency to increase window area and the number of doors opening to outside or unheated areas, and increases the potential for heat loss in general.

Since single family home ownership is generally associated with higher income, single family homes tend to have more convenience and luxury items such as fireplaces, greenhouses, and in-home washers and dryers and other appliances. Single family developments are less dense, creating a more sprawling urban environment with implications for commercial and industrial development, transportation alternatives, and work patterns. Resident ownership has implications for the type of energy conservation features the unit is likely to be built with initially and the conservation upgrades the resident is likely to undertake. Resident ownership leads to a greater likelihood that a single individual/family will bear the costs and feel the benefits of conservation measures. Lower fuel costs, greater comfort (i.e., fewer drafts), and higher resale value are all traded off against the cost of added insulation before a decision is made. Rental arrangements, whether the renter pays for fuel or not or controls the thermostat or not, scatters the benefits of conservation actions and thereby fails to provide full incentives for conservation to the relevant decision maker. At the same time, resident ownership of single family homes provides a very different target market for conservation equipment and services than commercial building owners or owner of large apartment buildings and complexes.

\section{Historical Trends}

Single family detached home form the largest share of residential units by far, accounting for 67.1 percent of all homes in 1983. This is down considerably since 1960 when 77.3 percent of homes were single family detached homes. The biggest decline in the share of single family homes occurred between 1960 and 1970; the percent fell to 69.1 in 1970 . This decline moderated during the 1970 's; in 1980, the single family share was 65.9 percent, a drop of just 
over three percentage points for the decade compared to a drop of over eight percentage points for the previous decade. (U.S. Bureau of the Census 1984(b), p. 731). This trend demonstrates an interesting point. While single family home ownership is associated with higher income, urbanization combined with a growing population and attendant increases in land prices made it less possible to realize the American dream of a single family home.

Demographic changes also played a role. Smaller households and a larger number of nontraditional household units (single-parent families and more single resident households due to later marriage and more divorce and separation) are more amenable to smaller, multi-family dwellings. There are, however, multiple causal links between demographic changes and changes in the proportion of single family homes running in both directions. On the one hand, later marriage has made apartment living more likely. On the other hand, the rising cost of a single family home, driven by increased demand brought on by an increasing population, has probably served as a deterrent to large families. The trend toward more women working outside the home (possibly-spurred on by . high housing costs) and more single parent families makes the low resident maintenance characteristics of condominiums/apartments desirable. Finally, the very fact that the baby boom generation was in the 20-30 year age bracket during the late 1960 's contributed to a bulge in demand for apartments vis-svis larger homes during that period.

\section{Current Status}

After declining steadily for a least the last two decades, the proportion of single family homes increased from 65.9 percent in 1980 to 67.1 percent in 1983. The aging of the baby boom and the increased birth rate (the echo boom) of the early 1980's is probably responsible.

\section{Future Prospects}

While population growth in the U.S. is likely to continue to slow over the next 25 years, growth will remain positive and there will be continued increases in income. This will combine to put pressure on land prices, particularly in and around major metropolitan areas. If the information revolution lives up to its promises of decentralizing the work environment through computer hook-ups and teleconferencing, this pressure may be averted 
via relocation of business to low density areas. Such relocation makes single family home ownership a real possibility for employees, whereas location in central cities forces employees to choose between commuting time and denser residences.

A major uncertainty in any buildings future is tax treatment of interest and property taxes. Current tax law is widely recognized as a major subsidy to home ownership and residential construction in general. Any tax reform that reduces this preferential treatment will make the real cost of housing higher. As a result, consumers will be able to afford less housing. This probably means a move toward more multi-family dwellings since they are less costly. However, the direction of tax treatment with regard to single family home ownership is anything but certain. The U.S. has a history of strong support for housing and most tax reform proposals continue to provide significant tax advantages for home owners. While the general direction of tax reform is probably to reduce tax subsidies to buildings, it may be the case that reforms end up tilting the balance further in favor of owner-occupancy by reducing the tax advantages of investor ownership. This tendency may or may not lead to more single family detached housing.

Overal1, the recent upturn in the percent single family most likely represents a temporary phenomenon brought on by the aging of the baby boom generation and the associated echo boom. Thus, we expect the most likely trend to be a continuing, modest drop in the percent of single family homes. The descriptor states and associated a priori probabilities reflecting these considerations are:

Descriptor State

Greater than $64 \%$

$60-64 \%$

Less than $60 \%$

\section{A Priori Probability}

.20

.40

.40

\subsubsection{Residential Energy Use Intensity}

Residential Energy Use Intensity (EUI) is defined as energy use per household. Energy use includes purchased fuels and electricity used in 
residences. It excludes fuels purchased for personal transportation. Households include all residences as usually defined.

The residential EUI times the number of households is an identity for total residential energy use. Thus, trends in the EUI are obviously important. Beyond this obvious importance, the Energy Use Intensity concept is a useful approach for controlling for activity level in the residential sector, with activity level defined as the number of households. It provides a concept comparable to energy intensity of output in the industrial sector. As such, it provides evidence on an aggregate basis as to whether residences are becoming more or less energy efficient.

\section{Historical Trends}

Figure 4.8 shows the historical EUI in the residential sector. As can be seen, the EUI showed a consistent upward trend during the 1960's and began an erratic downward trend starting in the early 1970's. From 1970 to 1981 the EUI decreased at a rate of 1.5 per year. Adams et al. (1984) explicitly treat five factors directly contributing to a declining EUI in the 1970's: geographical distribution of households (Snowbelt to Sunbelt migration), household size (number of persons per household), appliance efficiency, shell efficiency (insulation/weatherization of homes), and increased wood use. In addition, they suggest other factors not explicitly accounted for in the analys is including behavioral changes on the part of consumers (e.g., turning thermostats down) or switching to renewable energy sources like solar heat. Changes in these factors are likely to have been caused by underlying factors such as increasing energy prices, improved technology, consumer information programs, changing levels of income, changing interest rates, and other factors.

of the factors explicitly treated by Adams et al., improved thermal efficiency and changes in household size each were found to account for over 20 percent of the estimated savings. Improvement in appliance efficiency and wood use each accounted for 15 to 20 percent of estimated efficiency improvements. Geographical redistribution of the population was relatively unimportant, accounting for only 1.4 percent of savings. The unexplained or residual category accounted for 30 percent of estimated improvements. 


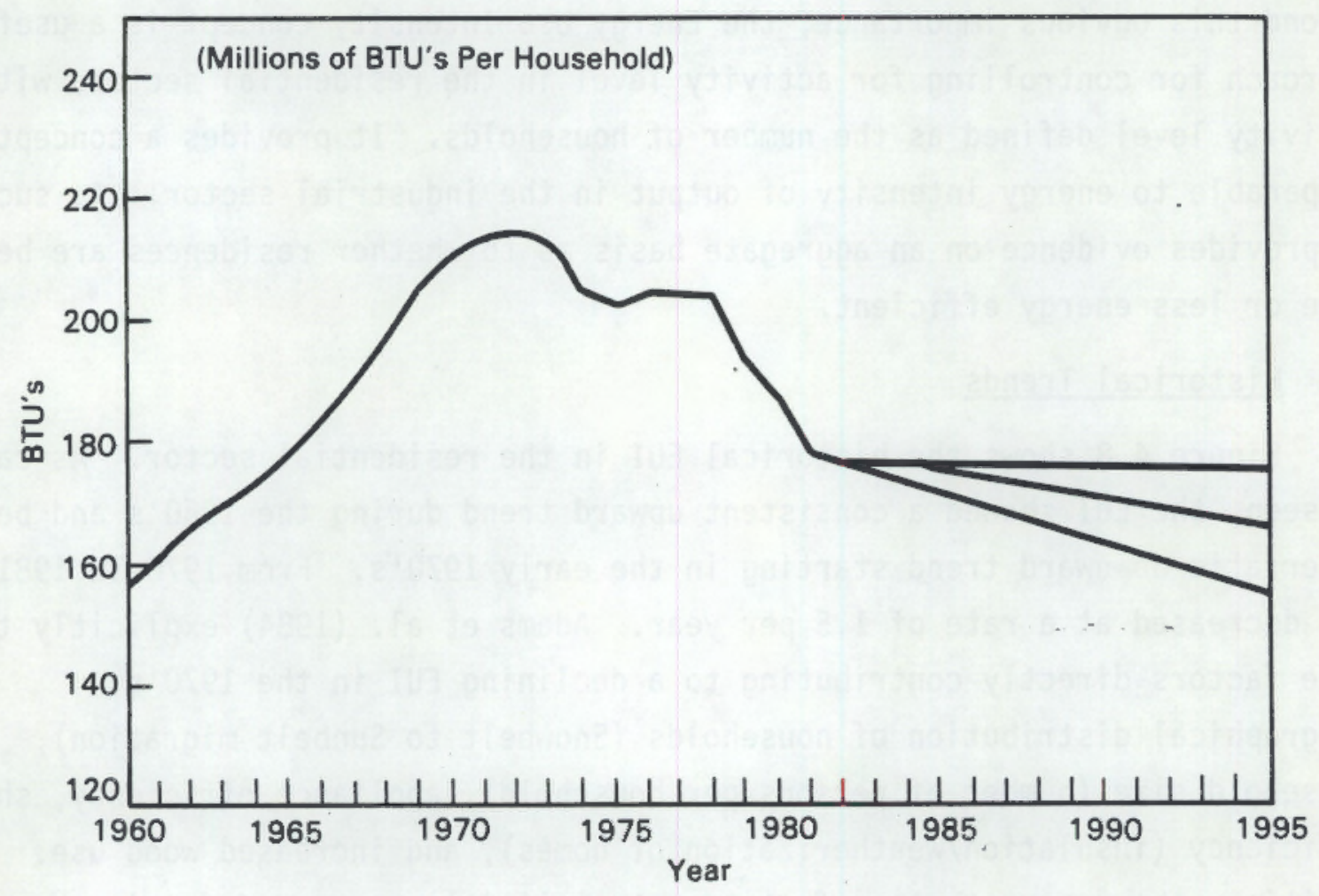

FIGURE 4.8. Residential Energy Use Intensity (EUI)

(Historical data are from R. C. Adams, et al. 1984. "A Retrospective Analysis of Energy Use and Conservation Trends: 1972-1982." Pacific Northwest Laboratory, Richland, Washington.) 
The particular pattern of changes in the EUI since 1973, sharp drops from 1973 to 1975 and from 1978 to 1981, strongly suggest the importance of energy prices as the underlying cause for decreases in the EUI since these periods correspond to sharp rises in oil prices with cross effects to other energy prices. These periods also correspond to economic recession; thus, falling income may have contributed to the EUI pattern of the $1970^{\prime} \mathrm{s}$. But changes in income have a mixed effect; higher incomes make it possible for extended family groups to split into separate households. Since smaller households reduce energy intensity per household, this part of the income effect would tend to reduce the EUI. Countering this tendency is the usual effect that higher incomes allow the purchase of more goods and services of all kinds including those that use energy in the household. Finally, some researchers have suggested that the inability of low income households to borrow prevents them from investing in energy efficiency; if true, changes in income would affect the rate of adoption of conservation technologies.

\section{Current Patterns}

Stabilization and, to some extent, declines in real energy prices since 1980 have resulted in a reduction in the rate of decline in the residential EUI to 0.5 percent for $1981 / 82$. Preliminary data show a slight increase in the residential EUI for 1983 and 1984.

\section{Future Prospects}

New homes are significantly more efficient than the existing stock and improved shell efficiency and passive energy design can be more easily incorporated in new construction than in retrofit of existing homes. This factor should contribute to a tendency for the EUI to continue to decline even if no further improvements in new homes occur.

Household size may have reached a lower limit. Therefore, income increases are more likely to increase the energy use intensity than in the past. Given that the residential sector has substituted away from oil, oil prices may have a less significant impact in the future, but oil prices will probably remain a barometer of energy prices in general.

If oil and energy prices remain at current levels or decline, it seems likely that the residential EUI may increase as energy conservation become 
Tess important to consumers. The current oil glut has led to falling prices but world economic expansion and increased oil consumption will probably tighten markets by 1990 . While a major price increase as markets tighten remains possible, built-in fuel switching capabilities, experience with shortages, and the existence of worldwide "strategic" oil stockpiles probably reduce the future change of price spirals like those of 1973-74 and 1979.

In terms of conservation technology itself, two different schools of thought appear to exist. Some energy analyses point to demonstration homes that use very little commercial energy as a indication that rates of decline exhibited during the 1970's can easily be duplicated or even exceeded in the future (e.g., see Lovins et al.).

A second school would argue that the commercial viability, general applicability, and consumer acceptance of many conservation technologies is yet to be demonstrated. Moreover, the price increases of the 1970's focused attention on energy conservation for the first time; this focused attention may have uncovered most of the easy, inexpensive, and acceptable conservation measures. Turning thermostats down from 70 or 75 to 60 or 65 may be acceptable, but much lower is not. Insulation and storm windows and doors may have been added on expectations that prices would continue rising, possibly doubling from 1979 levels. Thus, additional price increases may have been accounted for in past consumer decisions. Energy tax credits may also have moved conservation investments up in time. (For an examination of disaggregated factors affecting future residential energy use see Edmonds, et at. 1984).

In short, the historical trend shows considerable variability and there is little reason to be confident that variability will be less in the future. The descriptor states and a priori probabilities reflecting these consideration are:

\section{Descriptor State}

Upward trend (EUI G.T. 1.75)

Trend (EUI between 1.55 and 1.75)

Downward Trend (EUI L.T. 1.55)

\section{A Priori Probability}

\section{.25}

.50

.25 


\subsubsection{Commercial Floor Space}

The commercial floor space descriptor refers to the total floor space of occupied commercial buildings in the U.S. Square footage estimates for the commercial buildings were comprehensively surveyed by the Energy Information Administration for the first time in 1979. Based on this survey, the Nonresidential Building Energy Consumption Survey (NBECS), there was an estimated 43 billion square feet of occupied commercial space at the end of 1979 (EIA 1983(b)).

In nearly all analyses of commercial energy consumption, floor space is used as a proxy for the amount of energy-using capital. This relationship should be fairly accurate since most commercial end use systems are designed on the basis of floor space served. The three major commercial end uses, lighting, heating, and cooling, are all designed with total floor space in mind.

Other metrics associated with the commercial sector involve floor space. Building costs and rents are often denominated in dollars per square foot. Employment density, particularly for office buildings, is measured in square feet per employee.

In using total floor space to characterize the entire commercial sector, one must use caution as with any macroeconomic variable. Energy consumption per square foot varies considerably according to the size and type of building. Thus, to use floor space as a simple measure of energy using capital, one implicitly assumes that the composition of the building stock will remain relatively unchanged.

\section{Historical Trends}

The 1979 NBECS was a landmark survey in establishing the first statistically valid estimate of existing commercial floor space. Unfortunately, the floor space estimates apply to only a single point in time. The problem of establishing the trend rates of growth in floor space up to 1979 still remains.

Pacific Northwest Laboratory, as part of work on a commercial sector energy use model, has developed historical estimates of floor space benchmarked to the NBECS 1979 numbers. The methodology employed required a function to 
represent building demolitions as a function of time as historical data on newly constructed floor space from the F.W. Dodge Division of McGraw-Hill Corporation. The building demolition or decay function was based on aggregate data on building demolitions from the second NBECS conducted in 1983 (EIA 1985(a)). Based on this source, the overal1 decay rate between 1979 and 1983 was between 0.5 and 0.6 percent per year.

The development of floor space stocks for years prior to 1979 is based on a perpetual inventory methods that adds newly constructed space to the existing stocks and estimates building demolitions by means of a decay function. Floor space additions from 1925 to 1979 were used in the procedure. The earlier Dodge additions figures were adjusted to match the 1979 EIA information on existing stock by vintage.

Table 4.3 shows the amounts of floor space for four groups of commercial buildings in 1983 and the estimated growth rates since 1960.

TABLE 4.3. Estimated 1983 Stocks and Growth Rates by Building Type

$$
\begin{aligned}
& 1983 \text { stock } \\
& \text { billion sq. ft. }
\end{aligned}
$$

Commercial

Educationa 1

Health

other

Total
27.4

6.0

1.9

10.5

45.9

\author{
$1960-1983$ \\ growth rate $(p / y r)$
}

The commercial sector here is defined similarly to F.W. Dodge. It includes offices, stores, warehouses, and service establishments. The "other" category includes hotels and motels, assembly buildings, and other miscellaneous buildings.

\section{Future Prospects}

A number of energy models both inside and outside of DOE make forecasts of total commercial floor space. Since all do not employ the same definition of floor space, a more appropriate standard of comparison is in terms of percentage increase between 1983 and 2010. The growth in floor space forecasted from three of these models is shown in Table 4.4. 
TABLE 4.4. Percentage Increase in Floor Space

Source Period $\quad$ $/ \mathrm{yr}$.

EIA 1985 Annual Report

National Energy Policy Plan $1983-1995$

Gas Research Institute (Oct. 1984) $1983-2000 \quad 3.0$

The EIA forecast is based on regression analysis of the 1979 NBECS and estimates floor space from 1960-1979 on the basis of changes in population and disposable income. The methodologies used in the other sources are unknown.

An effort to provide a simple framework to generate an alternative projection was undertaken for this study. The approach uses a simple floor space-per-employee approach that has been used in a number of regional energy models. Since some types of buildings would not appear to be directly tied to employees, various components of population were substituted for these building types.

\section{Commercial}

Figure 4.9 shows the average floor space per employee for the "nonindustrial" sector over the period 1960-83. Using the floor space estimates shown in Table 4.3, floor space per employee appears to have actually declined over the past two decades. (The number of employees was defined as workers in trade, finance, services, and government.) Part of this may be due to compositional effects. The average space per worker in office buildings is significantly lower than in other building types; as the share of white collar office workers increases the average declines.

A forecast of space for this restricted commercial category - offices, stores, and warehouses - was made by 1) assuming a value for future floor space per employee and 2) utilizing a long-term forecast of employment growth in this category. The first assumption was to employ a constant 450 square foot per employee (see Figure 4.9). The second takes the 25-year forecast for service sector employment from DRI's Fall 1984 projection. On this basis, the estimates of total floor space were generated as shown in Figure 4.10. 


\section{Educational Buildings}

The demographic variable used to project educational floor space was population aged 5-15 (see Figure 4.11). Unfortunately, the floor space ratio has been rising primarily due to declining enrollments. As an alternative, floor space additions from F.W. Dodge were regressed upon a distributed lag of changes in the age 5-15 population. Additions are predicted to rise more than 50 percent from current levels, as the "second wave" baby boon reaches its peak in the late $1990^{\prime} s$. The predicted floor space additions were then used in a perpetual inventory procedure to generate floor space stocks out to 2010 (see Figure 4.12).

\section{Health}

The stock of health care facilities was related to a weighted population variable. This variable was constructed by giving a weight of three to the population aged 68 and over. As Figure 4.13 shows, the floor space of health care buildings rose rapidly throughout the sixties and first half of the seventies. More recently, the rate of increase has slowed, primarily due to declining federal support for new hospital construction.

Federal policy toward health care will likely become increasingly restrictive in the remainder of the $80^{\prime} \mathrm{s}$ and $90^{\prime} \mathrm{s}$ as more emphasis is placed on controlling medicare and medical costs. Currently, this has been a contributing factor in the present oversupply of hospital beds in many areas of the country. Reflecting this current situation and the likelihood of continuing restrictive government policy, the level of floor space per capita was held constant at roughly 10 per cent above the present level. (See Figure 4.13) Using the DRI projections of population by age group (and applying the 3 to 1 weight to population over age 65), the total floor space was projected as shown in Figure 4.14 .

Other Buildings

The other buildings category, consisting of motels/hotels, assembly buildings, and other miscellaneous buildings, was related to total population (Figure 4.15). A rising standard of living and increased leisure time suggests the floor space per capita should increase over time. To very simply model 


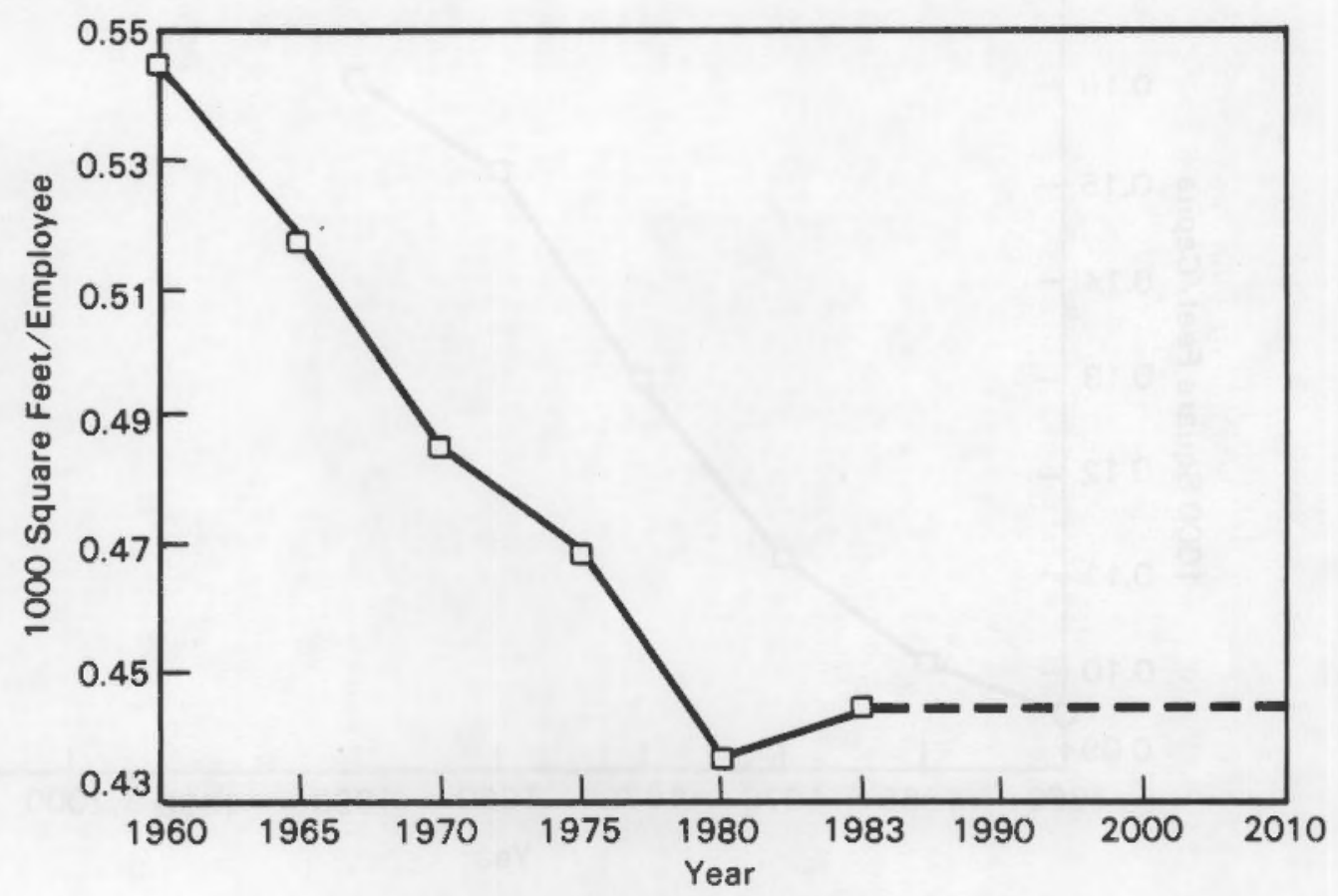

FIGURE 4.9. Floor Space Per Employee

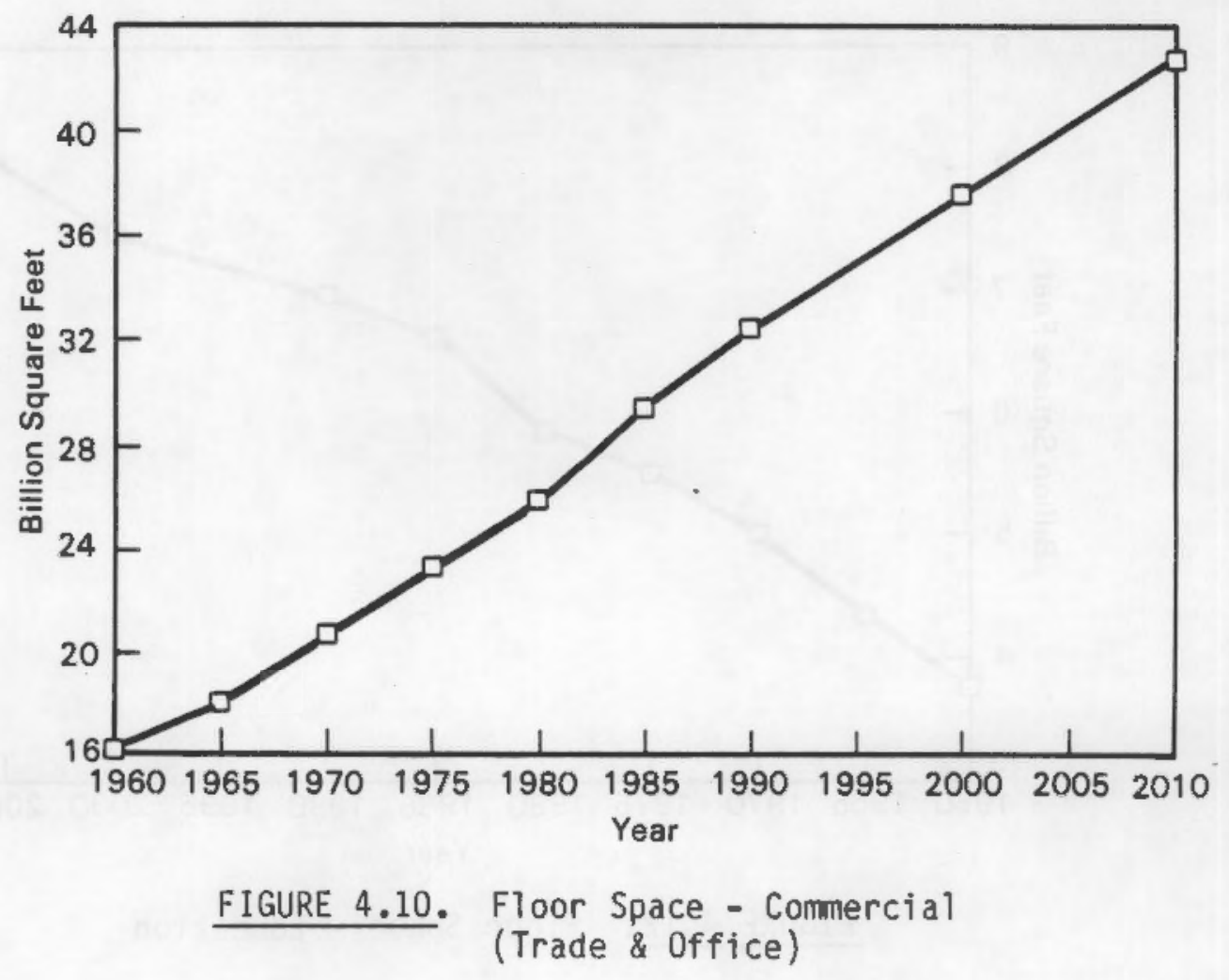




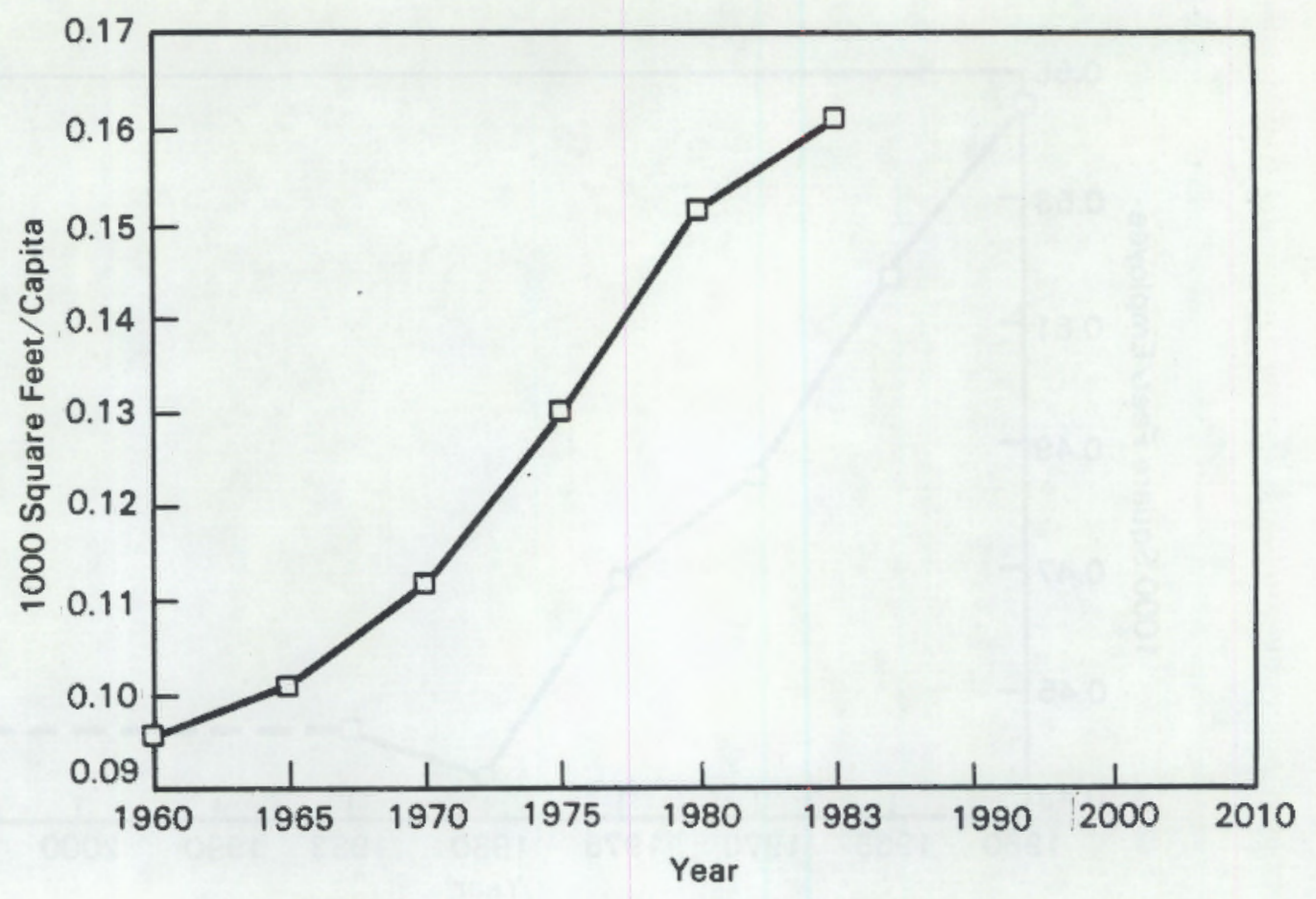

FIGURE 4.11. Floor Space Per Capita

(Population Age 5-15)

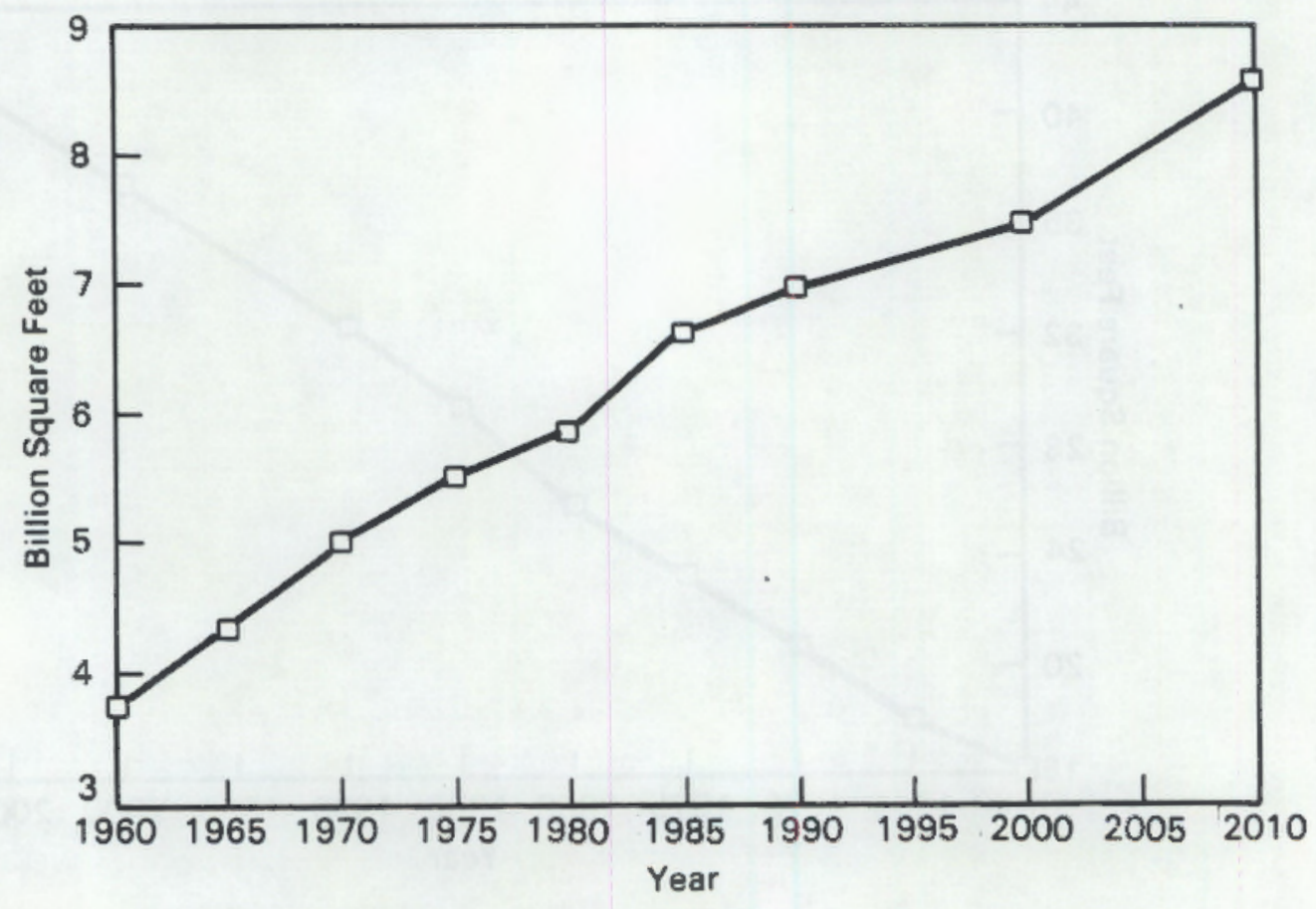

FIGURE 4.12. Floor Space - Education 


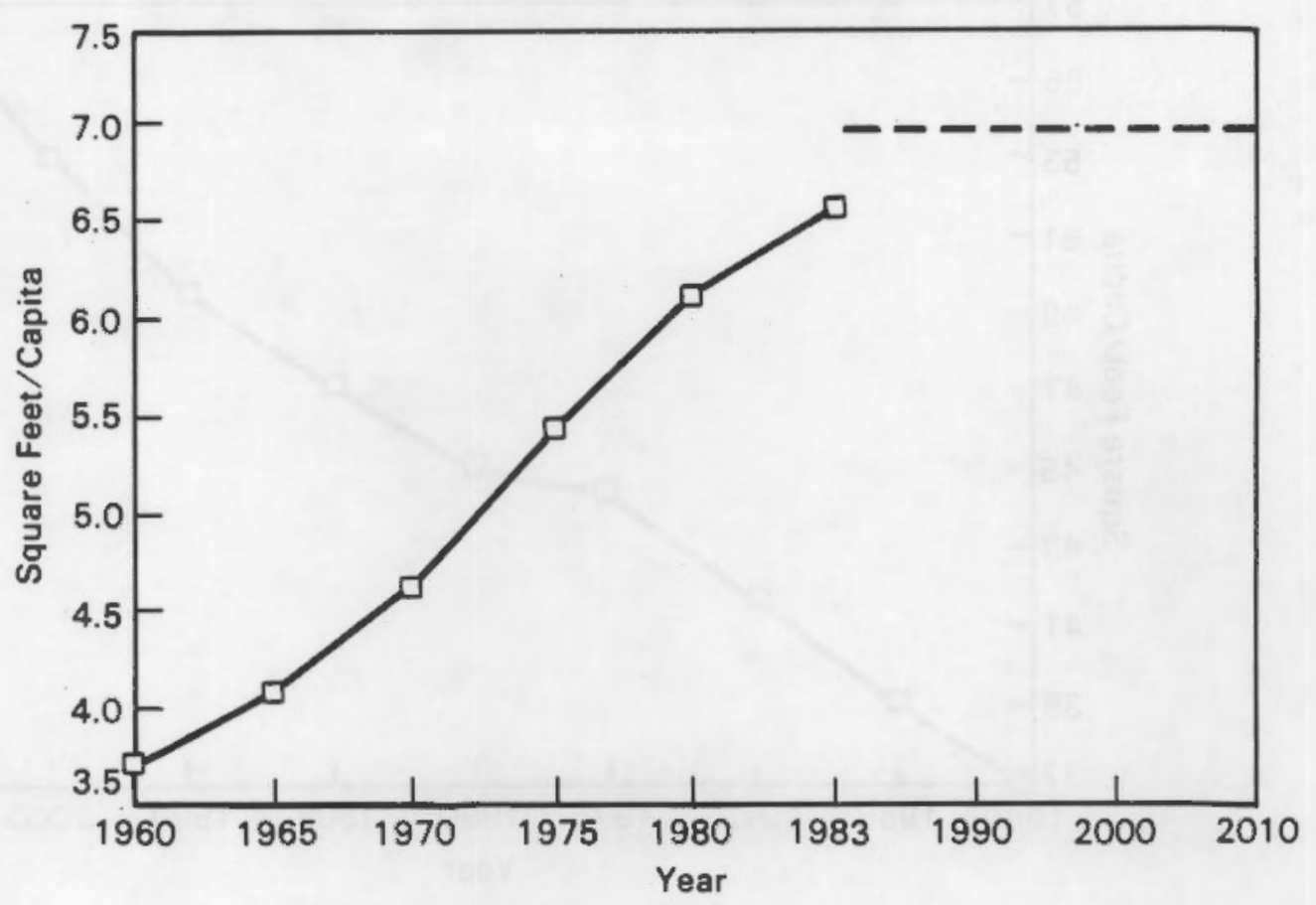

FIGURE 4.13. Floor Space Per Capita (Weighted Population)

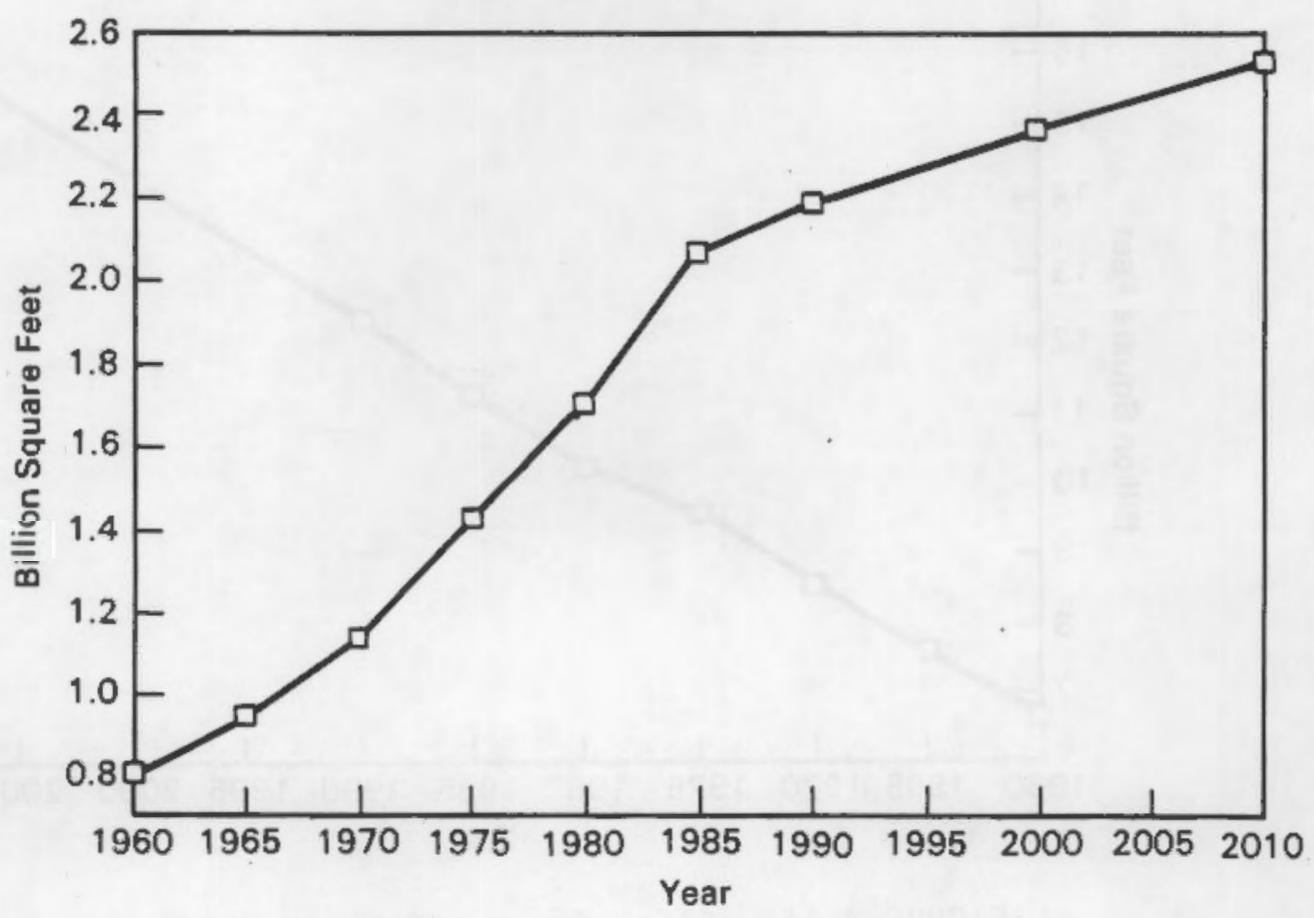

FIGURE 4.14. Floor Space - Health 


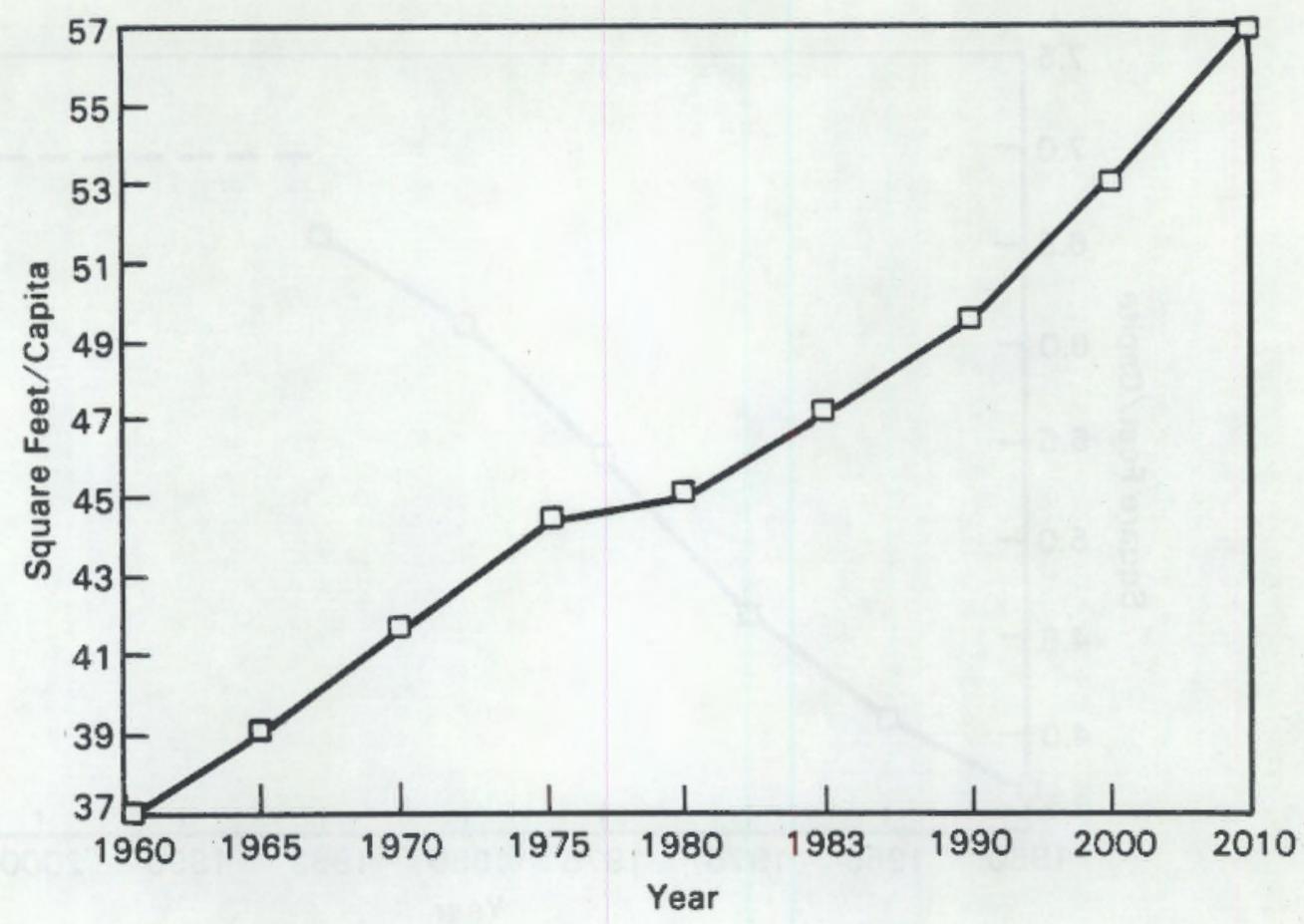

FIGURE 4.15. Floor Space Per Capita

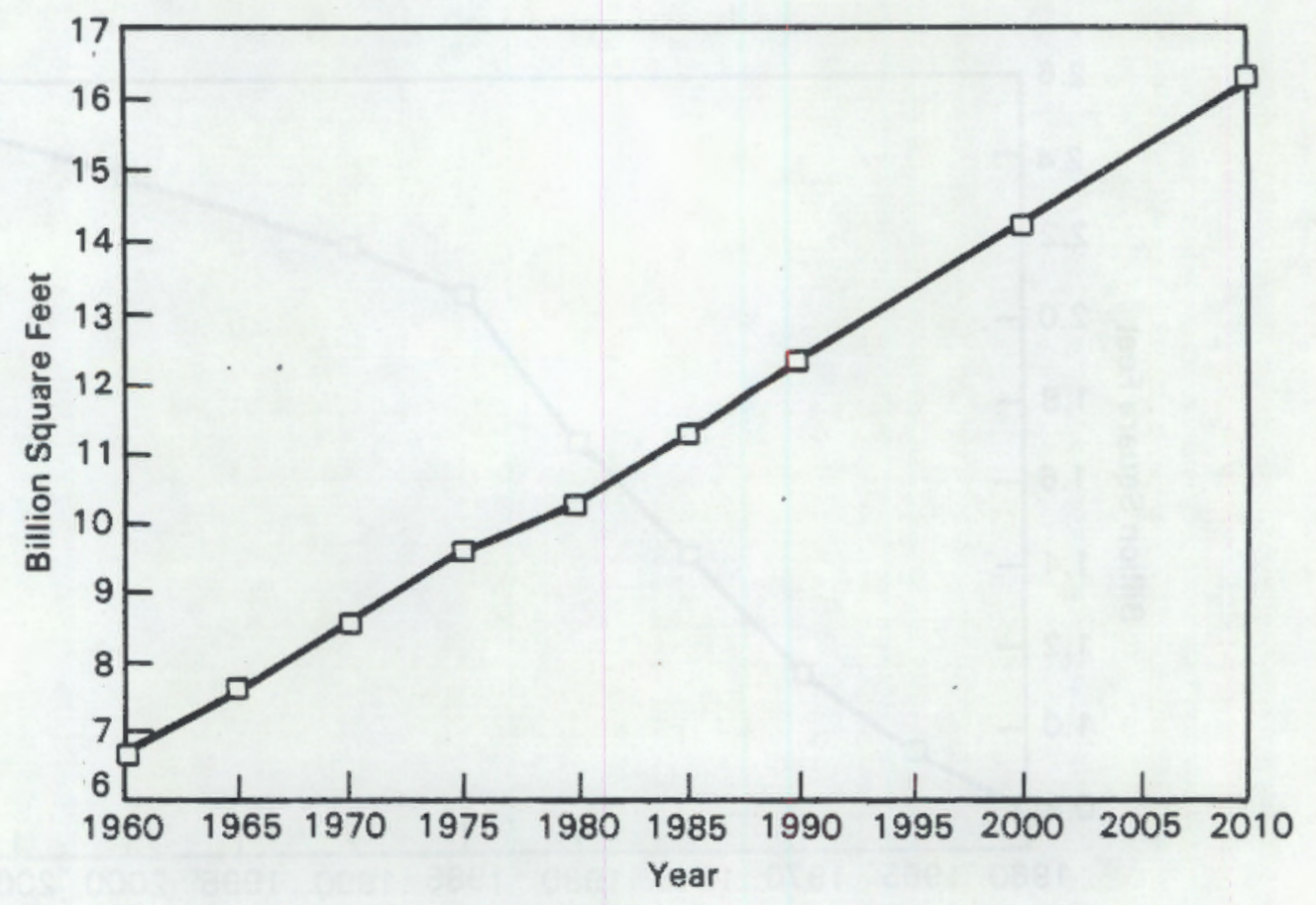

FIGURE 4.16. Floor Space - Other Buildings 
this relationship, a regression was performed with the following results:

$$
\log \text { (FS/capita) }=.44 \log \text { (GNP/capita) } 1960-1983
$$

Using this relationship and the Fall 1984 DRI forecast of GNP per capita, a forecast was made out to the year 2010. The results are plotted in Figure 4.16 .

\section{$\underline{\text { Summary Results }}$}

The results from the four building categories are shown in Table 4.5. Total floor space for 2010 is projected at just over 70 billion square feet using the approach described above. This translates into an average growth rate of approximately 1.6 percent per year.

TABLE 4.5. Projections of 2010 Floor Space

\begin{tabular}{lrcc} 
Building Category & $\begin{array}{c}\text { Floor space } \\
2010\end{array}$ & & $\begin{array}{c}\text { Increase } \\
\text { Space }\end{array}$ \\
\cline { 2 - 2 } Conmercial & & & \\
Education & 42.8 & 1.7 \\
Health & 8.6 & 1.3 \\
Other & 2.5 & 1.0 \\
Total & 16.2 & 1.6 \\
& 70.1 & 1.6
\end{tabular}

\section{Descriptor States}

The simple employee or population ratio approach provides significantly lower results than those generated in several of the published energy models. This suggests the following descriptor states with the associated probabilities.

\section{State}

Greater than $2.0 \%$ growth rate (greater than 80 billion sq. ft. in 2010)

$1.5-2.0 \%$ growth rate $(70-80$ billion sq. $\mathrm{ft}$. in 2010 Less than $1.5 \%$ growth rate (less than 70 billion sq. ft. in 2010)

\section{A Priori}

The first state corresponds to the growth rates in several published energy models. Growth rates over 2.0 percent would indicate that increasing 
disposable income translates directly into increased floor space per capita across the entire range of commercial buildings.

The second state is based principally on an assumed relationship that floor space will tend to follow service sector employment. With slower growth in employment over the next 25 years comes a corresponding decline in the growth rate of floor space. Based on the historical relationships derived from NBECS and other data sources, this state seems the more likely as compared to the first.

State 3 represents a low GNP case. In this case, growth in income does not appreciably increase the stock of assembly, lodging, and other buildings.

\subsubsection{Commercial Construction Cost}

Data from F.W. Dodge for 1983 indicates the average cost for all new commercial buildings was 62 dollars per square foot. Real cost is defined in terms of measuring the cost of new construction relative to the GNP deflator. Thus, if construction costs maintain, on average, the same rate of -growth of the general price level, real construction cost in the year 2010 would still be near the 1983 figure of 62 dollars per square foot.

Building space is just one of many factors in the production of service sector outputs. Other key factors include labor, energy, and equipment capital (e.g., office machinery). The economic theory of production posits that the desired level of floor space will be smaller the higher its cost relative to other factors.

Although a comprehensive study dictates the analysis of all factor inputs simultaneously, generally construction costs have been considered in two separate contexts for the commercial sector. First, the cost of new construction enters into the demand for new floor space as a component of the rental cost of capital. The second context in which the price of construction is relevant is in the area of energy conservation. Here, the cost of new construction serves as a proxy for the cost of specific energy conservation features (e.g., added insulation, treated windows, weatherstripping) that must be weighed against the savings in future energy costs. 


\section{Historical Trends}

As a measure of the trend in overall construction costs, the nonresidential structures deflator from the National Income and Product Accounts was utilized. This index is based on a simple average of three other indexes: 1) Census Bureau of new family houses, 2) Turner building cost index, and 3) Bureau of Public Roads highway structures index. The Census Bureau index is assumed to apply to small commercial buildings that require many of the same specifications and construction skills as residential buildings. The Turner index, developed by Turner Construction $\mathrm{Co}$. , is based on the estimated cost of constructing a hypothetical forty-story structural steel, finished office building of fixed specifications. For other structures, the judgment by the Commerce Department was that physical specifications were roughly comparable to those represented by the highway structures index of the Bureau of Public Roads.

Figure 4.17 shows the nonresidential structure deflator divided by the implicit GNP deflator since 1950. The real price of new construction rose sharply from 1965 through 1981; from 1981 to 1984, the price fell by nearly nine percent relative to the overall price level. A depressed construction market marked by both business recession and historically high interest rates is largely responsible. A contributing factor was probably increased competitiveness in the construction labor market, as more projects involved nonunion workers.

Prices of new structures depend primarily upon material costs, wage rates, and productivity changes in the construction industry. Construction materials by and large, are produced in mature industries that can be expected to exhibit constant real long-run costs. Construction wages in the past have been an important factor in pushing up construction costs, especially in the late 1960 's. Construction wage rates were one of the principal targets of the initial Nixon price and wage controls in 1971. By 1983, however, construction wages, relative to the rest of the private economy, had fallen back nearly to the level observed in 1960 .

The third component, productivity in construction industry, is difficult to analyze because of problems in measuring output. H. Kemble Stokes made a comprehensive study of productivity in the construction industry in 1981 (Stokes 1981). He documents that 1) between 1950 and 1968 labor productivity rose at 


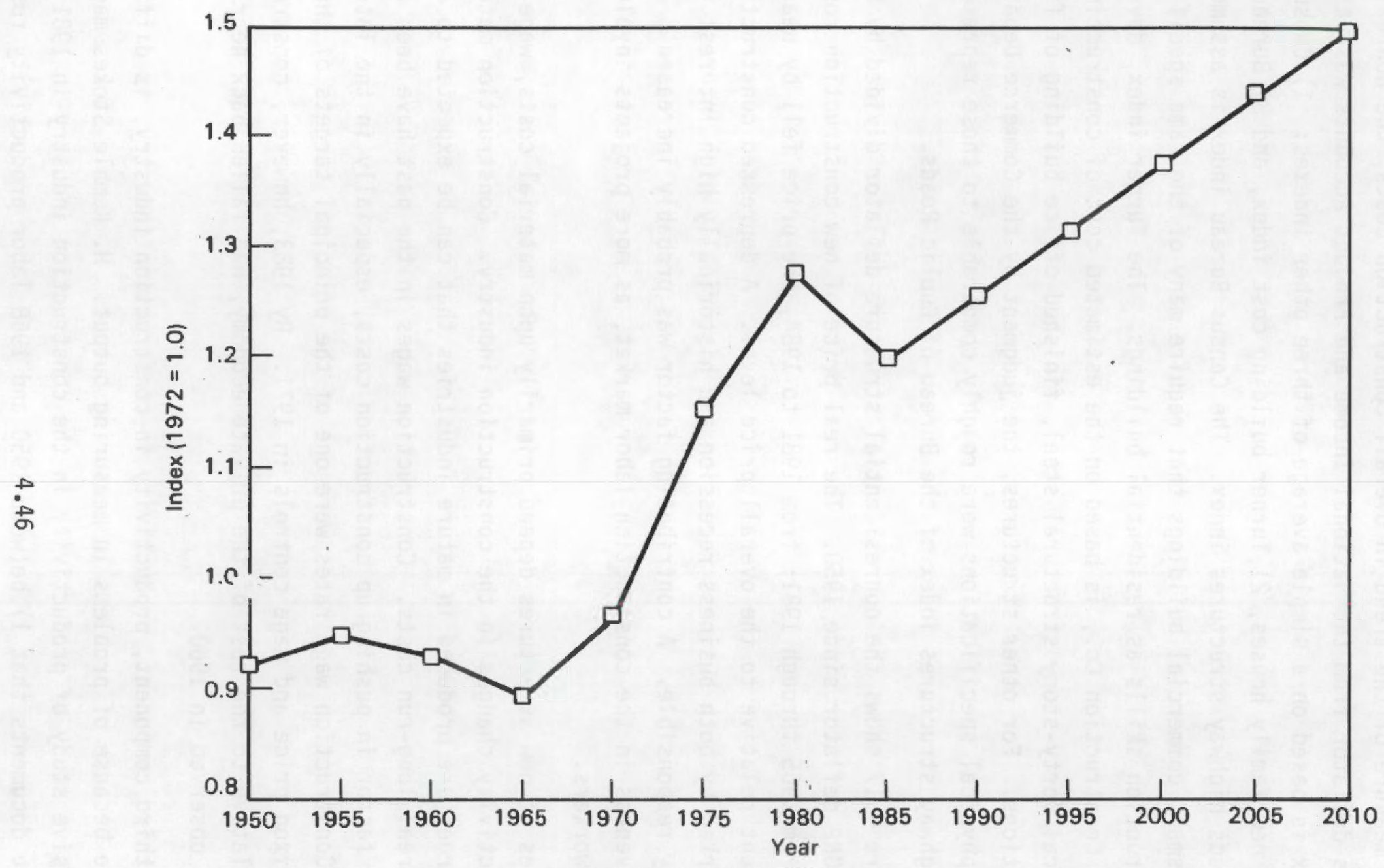

FIGURE 4.17. New Nonresidential Structures (Relative Price) 
an annual rate of $2.4 \%, 2$ ) between 1968 and 1978 labor productivity in construction declined at an annual rate of $2.8 \%$. This result is consistent with the overall pattern exhibited in Figure 4.17 .

\section{Future Prospects}

Given the competitive structure of the building materials industry, it is difficult to foresee significant escalation of real building costs for this source. The weakened position of construction unions, as well as increased construction activity in the South, should more than likely prevent relative construction wages from rising appreciably in the future. This leaves productivity, particularly labor productivity, as the key source of uncertainty for construction costs over the long run.

The descriptor states and a priori probabilities reflecting these considerations are:

\begin{tabular}{lc}
$\quad$ Descriptor States & A Priori Probability \\
\cline { 2 - 2 } Greater than $\$ 65 / \mathrm{sq}$. ft. & .20 \\
$\$ 60-\$ 65 / \mathrm{sq} . \mathrm{ft}$. & .45 \\
Less than $\$ 60 / \mathrm{sq} . \mathrm{ft}$. & .35
\end{tabular}

The middle state is essentially a construction of long term trends. The average rate of increase in real construction costs (estimated by regression) over the 1950 to 1983 period was about one percent per year. Using a one percent annual increase results in a value of real cost in 2010 very near DRI's (Fall 1984) forecast. This scenario essentially assumes little change in current construction practices. The bottom state applies to a situation in which new construction techniques are developed and employed and unproductive work rules relaxed. Construction wages on average increase no faster than wages in the rest of the economy.

\subsubsection{Building Type (Large Commercial Buildings)}

Large buildings require special types of equipment and control systems in their operation. Such buildings are highly affected by internal heat gains and are less affected by climatic variation. Any shift in the fraction of commercial floor space accounted by large buildings would have significant impact on the demand for certain types of equipment, as well as influencing 
utility peak loads. This descriptor is represented by the percentage of floor space in buildings containing over 100,000 square feet of floor space.

\section{Rationale}

The types and sizes of HVAC (heating, ventilating, air conditioning) equipment and distribution systems in commercial buildings vary over a wide range due to the variety of forms and uses for these buildings. Large buildings such as offices, hotels, and hospitals that have need for temperature control for a variety of indoor zones typically have centralized heating/cooling plants that produce and circulate heated and chilled water to air handling units in each zone. Smaller commercial buildings usually are heated and cooled by unitary equipment, mounted on the roof or on a wall, that produces and circulates chilled or heated air directly to the zones in the building.

There are significant differences in equipment capacity and distribution/ control system complexity between these two generic approaches to HVAC design. The centralized systems use larger equipment than is usually found in unitary. systems, and the distribution and control systems are much more complex. Therefore, economies of scale apply to centralized equipment to a higher degree than for unitary equipment, leading to a greater incentive for innovation in technology. Innovation in distribution and control for centralized systems is promoted by the large energy impacts and complexity of these subsystems.

Size of commercial buildings is used in this study as a proxy for building types that utilize central heating/cooling plants. While selection of a specific cutoff point is somewhat arbitrary, buildings over 100,000 square feet are large enough to warrant centralized systems, and this figure is used in this study. One notable exception to this is warehouses, which do not generally require precise temperature control.

\section{Historical Trends}

Two sources provide information on the size class of commercial buildings. The 1983 Nonresidential Energy Consumption Survey, NBECS II, (EIA 1985(a)) provides information on the size of buildings in the U.S. stock as of the end of 1983. The F.W. Dodge Division of McGraw-Hill Information Systems collects information on new building construction projects throughout the U.S. Although 
the Dodge information is limited in regard to building characteristics, data is collected on the size of the building.

Figure 4.18 shows the percentage of buildings larger than 100,000 square feet in the current stock. Although there is some evidence that larger figure buildings are demolished at a slower rate than smaller ones, (implying that for the earlier vintages, the percent of new floor space in buildings over 100,000 square feet was smaller than shown here) it appears that the percentage of floor space in these larger buildings has not increased appreciably since the beginning of this century. The period 1980-83 obviously requires some explanation. This data is based on the second NBECS, completed in 1983. The sample of post-1979 buildings was obtained by a different methodology than for the original NBECS; this sample was obtained from Dodge lists of new buildings. Dodge does not include projects valued at less than $\$ 25,000$ which will tend to increase the percentage of larger buildings. However, by itself, this cutoff could not be expected to significantly change the fraction of these very large buildings ( $>100,000 \mathrm{sq}$. ft.) since the amount of floor space: associated with $\$ 25,000$ projects is very small compared to total construction activity in the commercial sector Although there is some evidence of a boom of large office construction since 1981, it also appears that Dodge severely undercounts smaller buildings across a wide range of sizes. This is a severe problem which will require more analys is by researchers working with NBECS and by EIA staff. For now, the more reasonable case is.to treat the 1980-83 data as an outlier and exclude it from an historical analysis of overall trends.

As part of work in developing a regional model of the U.S., Pacific Northwest Laboratory extensively employed the primary Dodge data files. Summary statistics were developed on construction activity for 1985, 1979, 1975, and 1970. Table 4.6 shows the percentages for offices, stores, and the total commercial sector of floor space in buildings over 100,000 square feet. Looking over these particular years, there appears to be a fairly wide variation in the percentage of large buildings built from one year to the next. 


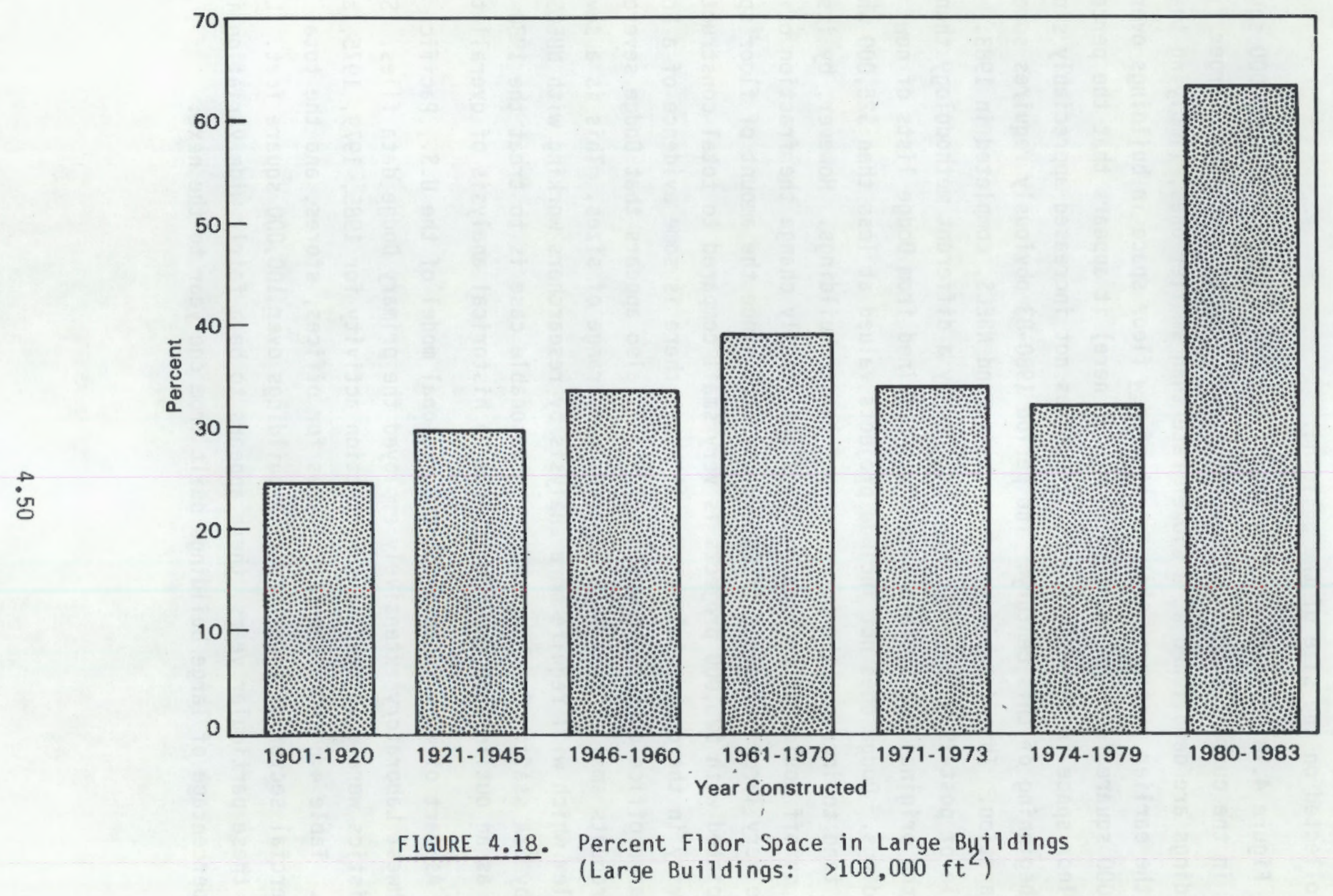


TABLE 4.6. Percent of Floor Space in New Buildings Over 100,000 Square Feet (million sq. ft.)

\begin{tabular}{|c|c|c|c|c|}
\hline & $\underline{1965}$ & $\underline{1970}$ & $\underline{1975}$ & $\underline{1980}$ \\
\hline $\begin{array}{l}\text { Commercial } \\
\text { Total new floor space } \\
>100,000 \mathrm{sq} \text { ft. } \\
\% \text { over } 100,000\end{array}$ & $\begin{array}{r}107.9 \\
40.1 \\
37\end{array}$ & $\begin{array}{c}170.4 \\
94.1 \\
55\end{array}$ & $\begin{array}{r}109.1 \\
39.9 \\
37\end{array}$ & $\begin{array}{c}243.9 \\
120.2 \\
49\end{array}$ \\
\hline $\begin{array}{l}\text { Retail } \\
\quad \text { Total new floor space }\end{array}$ & 108.2 & 192.1 & 155.2 & 183.6 \\
\hline $\begin{array}{l}>100,000 \mathrm{sq} . \mathrm{ft} . \\
\% \text { over } 100,000\end{array}$ & $\begin{array}{l}52.6 \\
29\end{array}$ & $\begin{array}{l}94.1 \\
49\end{array}$ & $\begin{array}{l}55.0 \\
35\end{array}$ & $\begin{array}{l}68.3 \\
37\end{array}$ \\
\hline $\begin{array}{l}\text { Total Commercial } \\
\text { Total new floor space } \\
>100,000 \mathrm{sq} \text { ft. } \\
\% \text { over } 100,000\end{array}$ & $\begin{array}{c}941.9 \\
281.9 \\
30\end{array}$ & $\begin{array}{c}961.8 \\
399.7 \\
42\end{array}$ & $\begin{array}{c}812.1 \\
262.5 \\
32\end{array}$ & $\begin{array}{l}990.4 \\
366.0 \\
37\end{array}$ \\
\hline
\end{tabular}

Source: F.W. Dodge

The size composition of buildings varies substantially by building type. To make any judgment as to whether the overall fraction of large buildings might increase in the future requires some perspective on the size characteristics of the existing stock. Table 4.7 is based on the 1983 NBECS and shows the percentage of floor space at the end of 1983 in buildings over 100,000 square feet. This data includes new stock constructed from 1979 to 1983, and thus includes the potential biases toward larger buildings discussed above. The average percentage in large buildings across all building types is 35.2 percent (from Figure 4.16 , this average jumped considerably with the addition of the $1980-83$ data; the average prior to 1980 was $31.7 \%$ ). Hospital and health care facilities have the greatest percentage of floor space in large buildings, over 75 percent. Offices rank third with almost 45 percent. Educational and lodging buildings are slightly above the average at 37 and 38 percent, respectively.

One final piece of evidence that may be pertinent is an assessment of very recent trends. Large office construction in city central cores appears to have increased substantially in the past three years. The Building Owners 
and Managers Association (BOMA) reports that occupancy rates for office space declined on average of nearly 10 percent nationwide from May 1981 through

IABLE 4.7. Percentage of Building Stock in Buildings Larger than 100,000 Square Feet

\begin{tabular}{|c|c|c|}
\hline Building Type & $\begin{array}{c}\text { Total Stock } \\
\text { (million sq. ft.) }\end{array}$ & $\begin{array}{c}\% \text { Larger } \\
100,000 \text { sq. ft. }\end{array}$ \\
\hline Assemb ly & 5483 & 21.1 \\
\hline Educational & 6044 & 37.2 \\
\hline Food Sales & 2051 & 5.7 \\
\hline Health Care & 2277 & 77.3 \\
\hline Lodging & 2241 & 38.2 \\
\hline Trade/Services & 10427 & 31.3 \\
\hline Office & 8454 & 44.4 \\
\hline Warehouse & 6791 & 33.8 \\
\hline Other & 2760 & 51.8 \\
\hline Vacant & 3342 & $31.5^{-}$ \\
\hline
\end{tabular}

Source: 1983 NBECS

october 1984. The principal reason has been construction rates exceeding absorption rates. This suggests that indeed the percentage of office space in new large buildings may have increased over the past few years. Unfortunately, we do not have access to the more recent Dodge data or NBECS II Survey tape to confim this presumption. However, even if all new offices in 1980-83 were larger than 100,000 square feet, this could only account for a portion of the abnomally high percentage of large buildings across the entire commercial sector reported by NBECS II.

\section{Future Prospects}

Based on the NBECS data, about 36 percent of the stock built in the period 1961-1979 was in buildings greater than 100,000 square feet. Given the uncertainty over the validity over the 1980-83 NBECS information, a continuation of existing patterns puts the percentage of new space in large buildings between 33 and 37 percent. This range would be consistent with the same trend toward urbanization that has been occurring over the post-war period. The lower percentage of large buildings in the 1970's (32 percent between 1974 and 1979) may be associated with a "ruralization" trend that was observed during this 
period, as rural communities and small towns grew faster than large metropolitan areas. The Census Bureau has just reported that this phenomenon appears to have stopped during the $1980^{\prime} \mathrm{s}$, as large cities have again started growing at a pace more in line with long term trends.

A percentage greater than 37 percent may reflect an even more accelerated trend toward urbanization and revitalization of large central core cities. Philip Chin, writing in BOMA's Skylines Newsletter (Chin 1985), reports, for example, that in the past few years over 8,000 residences have been added to the area around Chicago's Sears Tower. This influx of people moving back to the city would stimulate the construction of large office, trade, and health care buildings. The overall percentage of large buildings will also change due to higher average growth in the office and health care buildings, even if the average size of these buildings themselves remain constant.

The percentage of new large $(>100,000 \mathrm{sq}$. ft.) buildings less than 33 percent would essentially be related to the reverse of the influences discussed above. This may come about as growth in central cities reverts to its behavior in the 1970's and suburban lifestyles become more prevalent. Compositional effects on building types would be reflected in relatively more growth in assembly, trade, and food service buildings.

Given the above discussion, the following descriptor states and a priori probabilities are proposed:

New Floor space Bldqs $>100,000 \mathrm{sq}$. ft.

Greater than $37 \%$ 33-37\% Less than $33 \%$

A Priori Probability 


\section{REFERENCES}

Adams, R.C., et al. 1984. A Restrospective Analyses of Enerqy Use Conservation Trends 1972-1982. Pacific Northwest Laboratory, Richland, Washington.

American Gas Association. Gas Househeating Survey: 1983. American Gas Association, Arlington, VA.

Bernstein, P.L. and T.H. Silbert, 1984. "Are Economic Forecasts Worth Listening To?" Harvard Business Review, September/October, 1984.

Bogue, Donald J. 1985. The Population of the United States: Historical Trends and Future Prospects. The Free Press, New York, New York.

Business Week, February 10, 1986 and June 9, 1986. See the cover stories.

Chase Econometrics. Energy Analys is Quarterly: First Quarter 1985. Chase Econometrics, Bala Cynwyd, PA.

Chin, Philip. 1985. BOMA International Skylines. Vol. 10, No. 1, p.2.

Darmstadter, Joel, et. a1. 1983. Energy Today and Tomorrow: Living With Uncertainty. Prentice-Hall, Inc., Englewood Cliffs, New Jersey.

Data Resources, Inc., 1984. U.S. Long-Term Review. Data Resources, Inc., Lexington, MA.

Data Resources, Inc. Energy Review: Spring 1985. Data Resources, Inc., Lexington, MA.

Denison, Edward F. 1979. "Explanations of Declining Productivity Growth." Survey of Current Business. Vol. 59, No. 8, Part II: pp. 15-18.

Dornbusch, R, and S. Fischer. 1984. Macroeconomics. Third Edition, McGraw-Hil1 Book Co., New York, New York.

Downs, Anthony, Katherine Bradbury. 1984. Eneray Costs, Urban Development, and Housing. The Brookings Institution, Washington, D.C.

Ebinger, Charles K., et al. 1982. Energy and National Security in the 1980's. Bajlinger Publishing Co., Cambridge, Massachusetts.

Economic Report of the President, 1985. U.S. Government Printing Office, Washington D.C.

Edmonds, J.A., et a1. 1984. U.S. Energy and Economic Growth, 1980-2000. Institute for Energy Analysis, Oak Ridge, Tennessee.

Energy Information Administration. 1983(a). Energy Projections to the Year 2010. D0E/PE-0029/2, U.S. Department of Energy, washington, D.C. 
- 1983(b). Nonresidential Buildings Energy Consumption Survey: 1979 Consumption and Expenditures. DOE/EIA-0318 (79), U.S. Department of Energy, Washington, D.C.

- 1983(c). Residential Energy Consumption Survey: Consumption and Expenditures, April 1981 Through March 1982. DOE/EIA-0321/2 (81), U.S. Department of Energy, Washington, D.C.

- 1984. Energy Conservation Indicators, 1983 Annual Report. D0E/EIA-0441 (83), U.S. Department of Energy, Washington, D.C.

- 1985(a). Nonresidential Buildings Eneray Consumption Survey: Characteristics of Commercial Buildings, 1983. DOE/EIA-0246 (83), U.S. Department of Energy, Washington, D.C.

- 1985(b). State Energy Data Report: Consumption Estimates, 1960-1983. DOE/EIA-0214 (83), U.S. Department of Energy, Washington, D.C.

- 1985(c). State Energy Price and Expenditure Report, 1970-1982. DOE/EIA0376 (82), U.S. Department of Energy, Washington, D.C.

- 1986. Monthly Energy Review. D0E/EIA-0035 (86/02), U.S. Department of Energy, Washington, 0.C.

Jorgeson, D. and Z. Griliches. 1967. "The Explanation of Productivity Growth." Review of Economic Studies, 34(July 1967):214-31.

Lovins, A.B., et al. 1981. Energy Strateqies for Low Climate Risks. San Francisco International Project for Soft Energy Paths, San Francisco, California.

Mossavar-Rahmani, Bijan. 1986. "The OPEC Multiplier." Foreign Policy. No. 62, Spring, 1986: pp. 136-148.

Peterson, Paul E. 1984. The New Urban Reality. The Brookings Institution, Washington, D.C.

Rasche, Robert H. 1985. "Views on Deficits and Interest Rates." FRBSF Week]Y Letter. Federal Reserve Bank of San Francisco, Apri1 19, 1985.

Sant, Roger W., et. al. 1984. America's Least-Cost Energy Strategy: Creating Abundance. McGraw-Hill Book Co., New York, New York.

Stokes, H. Kemble. 1981. "An Examination of the Productivity Decline in the Construction Industry", Review of Economics and Statistics. No. 63, pp. 495-502.

Tatom, John A. 1982. "Potential Output and the Recent Productivity Decline." Federal Reserve Bank of St. Louis Review. 64(1):3-16.

Tobin, James. 1985. "Monetarism: An Ebbing Tide?" The Economist. Apri] 27, 1985, pp. 23-25. 
U.S. Bureau of the Census. 1984(a). Projections of the Population of the United States, by Age, Sex, and Race: 1983-2080. Current Population Reports, Series P-25, No. 952, U.S. Department of Commerce, Washington, D.C., 1984.

- 1984(b). Statistical Abstract of the United States: 1985. U.S. Department of Commerce, Washington D.C.

- 1985(a). Annual Housing Survey, Part A. Series H 150, U.S. Department of Commerce, Washington, D.C.

- 1985(b). Characteristics of New Housing: 1984. Construction Reports C2584-13, U.S. Department of Commerce, Washington D.C.

- 1985(c). Households, Families, Martial Status, and Living Arrangements: March 1985. Series P-20, No. 402, U.S. Department of Commerce, Washington, D.C.

U.S. Department of Labor. 1983. Trends in Multifactor Productivity, 19481981. Bureau of Labor Statistics, U.S. Government Printing Office, Washington, D.C. 
APPENDIX A

PANEL MEMBERS 
APPENDIX A

\section{PANEL MEMBERS}

\author{
Dr. Fred Abel, Senior Economist \\ Office of Buildings and Community \\ Systems \\ U.S. Department of Energy \\ Mr. Paul Holtberg, Manager \\ Economic Modeling \\ Gas Research Institute \\ Mr. Robert Hukill \\ Consultant To Business Roundtable \\ (Formerly Director of Engineering, \\ Sun $0 i 1$ ) \\ Mr. Stanley Pansky \\ Senior Research Scientist (Architect) \\ Pacific Northwest Laboratory
}

Mr. Ali Reza

Senior Planning Economist

Planning and Evaluation Division

Electric Power Research Institute

Mr. Gabriel L. Tincher, Manager

Corporate Technical Planning

Owens-Corning Fiberglass Corp.

Mr. Mike Warwick, Chief

Assessment and Evaluation Branch

Bonneville Power Administration 
APPENDIX B

PANEL MEMBERS 
APPENOIX B

\section{PANEL MEMBERS}

Dr. Fred Abel, Senior Economist Office of Buildings and Community Systems

U.S. Department of Energy

Dr. Reece Achenbach

Consultant

(Formerly Division Chief, Center for Building Technology, National Bureau of Standards)

Dr. Roger Carismith, Director

Conservation and Renewable Energy Programs

Oak Ridge National Laboratory

Mr. Howard Gaberson, Director

Mechanical Systems Division

Naval Civil Engineering Laboratory

Dr. Mark Hehnen, Manager

Technology Awareness R\&D

Weyerhaeuser Company

Mr. William Krauss, Director Heat Pump \& Appliance Research Gas Research Institute
Mr. John Millhone, Director

Office of Buildings and Community Systems

U.S. Department of Energy

Mr. Stanley Pansky Senior Research Scientist (Architect)

Pacific Northwest Laboratory

Mr. Donald Prowler

Assistant Professor

Department of Architecture

University of Pennsylvania

Mr. Ernesto Reyes

Information Systems Group

IBM

Mr. William Seaton

Manager of Research

ASHRAE

Or. Dan Turner, Department Head

Department of Mechanical Engineering

Texas A\&M University

Mr. Michael Warwick, Chief

Assessment and Evaluation Branch

Bonneville Power Administration 
APPENDIX C

METHODOLOGY AND COMPUTER RESULTS 
APPENDIX C

\section{METHODOLOGY AND COMPUTER RESULTS}

\section{C.1. Introduction}

The scenarios presented in this report were generated by a cross-impact computer program named BASICS (Battelle Scenario Inputs to Corporate Strategy). The overall procedure for using the BASICS program is to obtain and record a priori judgments $\left(^{\star}\right)$ about the future outcomes (states) of descriptors $\left(^{\star *}\right.$ ) and, using the computational algorithm, to adjust them based on the interaction of all the descriptor states. A priori probabilities are adjusted up or down as they are impacted by the occurrence of other events until the probabilities of all descriptor states are driven to one (occur) or zero (does not occur). when every descriptor state has a probability of one or zero, one simulation is complete. This procedure is completed once for each state of every descriptor, yielding a frequency distribution of results, or scenarios.

\section{C.2. Methodology}

\section{Inputs to the Model}

The three major inputs for the BASICS computer program are: 1) a definition of descriptor states, 2) a priori probabilities for those states, and 3) a cross-impact matrix. Each descriptor consists of one or more descriptor states that represent mutually exclusive alternative possible future outcomes for that descriptor. At the end of a simulation each descriptor is characterized by one of its states occurring and the other state(s) not occurring.

Judgments must be made regarding the a priori probability of occurrence of each of the descriptor states, independent of other external influences. A priori probabilities are established by combining trend analysis and expert

(*)A priori judgments are the best intuitive estimates of the likelihood of occurrences of alternative outcomes, or states, of specific descriptors before taking into account interactions of other descriptors.

$\left({ }^{*}\right)$ Descriptors are trends, events, developments, variables, or attributes that serve to describe the topic. 
opinion. One and only one of the states for a descriptor will ultimately occur at the end of one simulation, so the sum of the a priori probabilities for all states for a given descriptor will always equal 1.0. That is, descriptor states are defined to be both mutually exclusive and exhaustive of the range of possible outcomes for a descriptor.

Judgment must also be used to indicate how the occurrence of a descriptor state affects the probability of occurrence of all other states. Judgment about the effect is recorded in a cross-impact matrix using an index number. Working on one column at a time, the indices are used to record judgment on the following question: "If the jth descriptor state were to occur, how would this affect the probability that the ith descriptor state will occur?". The $j$ 's refer to column states and i's refer to row states. All descriptors and states are assigned to both columns and rows. The index values are:

Index Value

$-3$

$-2$

$-1$

0

1

3
Meaning

Significantly decreases the probability Decreases the probability Slightly decreases the probability No effect on the probability Slightly increases the probability Increases the probability

Significantly increases the probability

Judgment must be similarly used to indicate how the non-occurrence of a descriptor state affects the probability of occurrence of all other states. This is done in the same manner as for the occurrence matrix, using the same index values. In practice, the non-occurrence matrix is generated by the computer software based on the information contained in the occurrence matrix.

\section{C.3. Computational Procedure}

The purpose of the computational procedure is to adjust the a priori probabilities based on the occurrence or non-occurrence of events until each descriptor state is driven to occur or not occur. To start the procedure, one state is initialized to one (occur) or zero (does not occur). The next step is to calculate new values for the a priori probabilities of every other descriptor state by using the cross-impact index values recorded in the occurrence matrix.

The probability adjustment is performed using the following algorithm. 
First the index value in the matrix is converted into a coefficient value (CV) according to:

$$
\begin{array}{lll}
\mathrm{CV} & =\text { IMPACT }+1 & \text { for IMPACT } \geq 0 \\
\text { and } & \mathrm{CV}= & \text { for IMPACT } \leq 0
\end{array}
$$

Using equations (1) and (2), the coefficient values for the integers between -3 and 3 can be calculated as:

\section{Cross-Impact \\ Index Value}

$-3$

$-2$

$-1$

0

1

3
Coefficient value (CV)

$$
\begin{gathered}
1 / 4 \\
1 / 3 \\
1 / 2 \\
1 \\
2 \\
3 \\
4
\end{gathered}
$$

Next, the coefficient value is used in the following formula:

$$
N P_{i}=\frac{P_{i} \star C V}{1-P_{i}+\left(P_{i} \star C V\right)}
$$

where $\quad N P_{j}=$ the new (adjusted) probability of descriptor state $i$

$$
\begin{aligned}
C V= & \text { coefficient value } \\
P_{i}= & \underset{1 d}{ }(i=1,2,3, \ldots N \text { descriptor states in the matrix) }
\end{aligned}
$$

The derivation of this formula is based on the fact that in general the odds of an event happening are given by the formula:

$$
\text { OODS }=\frac{P_{i}}{1-P_{i}}
$$

which also can be written as:

$$
P_{i}=\frac{\text { ODDS }}{1+\text { ODDS }}
$$


In the BASICS program the probability adjustment principle is that new odds can be used to calculate the new probability. New odds are first calculated by adjusting the current odds by the coefficient value:

$$
\text { NEW ODDS }=\text { ODDS * CV }
$$

There is a similar adjustment to probabilities for the non-occurrence of a state. When a given descriptor state does not occur the relevant column of cross-impact index values from the non-occurrence matrix is used with equations (1), (2), and (3) to determine the probability adjustinent. The only difference is that indices from the occurrence matrix are used when a descriptor state occurs and indices from the non-occurrence matrix are used when a descriptor state does not occur.

One more computation takes place before the new probabilities are completely calculated. The sum of probabilities for all states of a given descriptor must sum to one (mutually exclusive and exhaustive states are defined for each descriptor). Therefore, after all the probabilities have been adjusted in a given step, the computational program normalizes the probabilities of each set of descriptor states so they sum to one. Normalization is performed immediately following the probability adjustment during each step of the simulation.

After making all adjustments and normalizing all sets of the descriptor state probabilities, one step in the simulation is complete. The BASICS program continues this computation once for every descriptor state in the cross-impact matrix. At the end of each step, one more descriptor state is set to occur or not occur and the current probabilities of all remaining descriptor states are adjusted.

The descriptor states are set to occur or not occur based on the distance between each descriptor state's current probability and zero or one:

and

$$
\begin{aligned}
& \text { Distance }=0.0+P \text { if } P<.5 \\
& \text { Distance }=1.0-P \text { if } P \geq 0.5
\end{aligned}
$$

The probability with the smallest distance is set either to occur if it is greater than or equal to 0.5 or to not occur if it is less than 0.5 . 


\title{
C.4. BASICS Computer Results
}

This section presents the BASICS computer results for the Macro-Environment (Table C.1), the Buildings Base Run (Table C.2), the Buildings "A" Scenario (Table C.3), and the Buildings "B" Scenario (Table C.4). There are 19 descriptors with 55 descriptor states in the Macro-Envirnoment matrix, for a total of 110 simulations. The three buildings matrices consist of 24 descriptors with 70 descriptor states for a total of 140 simulations each.

The four tables are interpreted in the same way. Each column represents a particular realization of the simulation, with a 1 indicating which descriptor state occured for that realization. The frequency of occurrence of each realization is given at the top of the column, while outcome type is just a count of the total simulations - 110 for the Macro-Environment and 140 for the buildings matrices. (In the interest of saving space, only the first 25 outcome types are shown in each of the four tables since the frequency for each column remains 1 ).

Reading all the way across a row for a descriptor state shows how many times that state occured out of the total of simulations. Dividing the number of occurrences by the total yields the posterior probability for the descriptor state. The posterior probabilities show the adjustment to the a priori probabilities after the interaction of all the descriptor states has been taken into account in the simulations.

The three buildings simulations were conditioned on the results from the Macro-Environment. Nine descriptors in the Macro-Environment matrix provided the linkage:

Descr

\author{
Descriptor \\ Price of $0 i 1$ \\ Price of Electricity \\ Immigration \\ Population Growth \\ Geographic Shift to the Sunbelt \\ Affordability of Buildings \\ Residential Housing Cost \\ Comnercial Building Cost \\ Investment Horizon
}

The Base Scenario was defined by those descriptor states in the MacroEnvironment that had the highest frequency of occurrence, or the largest 
posterior probability. The descriptor states with the highest frequency of occurrence for each of the nine descriptors listed above were then set to occur (i.e., set to 1 ) in the buildings matrix to provide the Buildings Base Run, completing the buildings portion of the Base Scenario.

The "A" Scenario was determined from the Macro-Environment by outcome type 1, the column realization that had the highest frequency of occurrence. Again, the descriptor state that occurred for each of the nine linking variables in column 1 was set to occur in the buildings matrix, providing the Buildings "A" Scenario.

The same procedure was carried out for the "B" Scenario. Outcome type 12 from the Macro-Environment was chosen because it provided the largest. contrast across the key variables. The descriptor states that occurred in column 12 for the nine linking variables were set to occur in the buildings matrix, providing the Buildings "B" Scenarios. 
TABEL C.1. Macro-Environment

Building Scenarias to 2010:Macro Envir

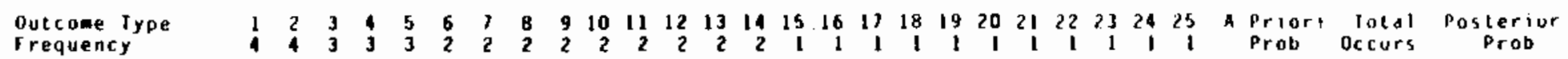

1.

rinsptation cost
Higher

$\begin{array}{lllllllllllllllllllllllllllllll}\text { Higher } & 1 & 0 & 1 & 0 & 0 & 0 & 0 & 0 & 0 & 1 & 1 & 0 & 0 & 0 & 1 & 1 & 1 & 0 & 0 & 0 & 0 & 0 & 1 & 0 & 0 & 0.40 & 28 & 0.25 & \text { H1gher } \\ \text { Same- } & 0 & 1 & 0 & 1 & 1 & 1 & 1 & 1 & 1 & 0 & 0 & 1 & 1 & 1 & 0 & 0 & 0 & 1 & 1 & 1 & 1 & 0 & 0 & 1 & 1 & 0.35 & 19 & 0.72 & 5.45\end{array}$

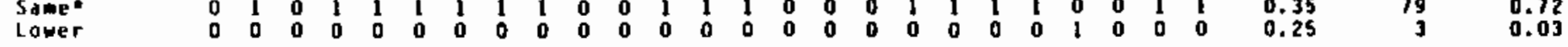

Price

ce of 0 il

$3 \$ 30 / 00 !$

$\begin{array}{llllllllllllllllllllllllll}1 & 0 & 1 & 1 & 1 & 0 & 1 & 1 & 1 & 1 & 1 & 0 & 1 & 0 & 0 & 0 & 0 & 0 & 1 & 0 & 1 & 1 & 0 & 1 & 0 & 0 \\ 0 & 0 & 0 & 0 & 0 & 0 & 0 & 0 & 0 & 0 & 0 & 1 & 0 & 1 & 0 & 0 & 1 & 1 & 0 & 1 & 0 & 0 & 0 & 0 & 0\end{array}$

$\begin{array}{lll}0.33 & 15 \\ 0.33 & 26\end{array}$

$\begin{array}{lll}15 & 0.11 & 2830 / 601 \\ 26 & 0.24 & \$ 20-30 \%\end{array}$

Price of Ele 848

$>\$ 20$ mint
$317-20=$
317 mant

$\begin{array}{llllllllllllllllllllllllll}1 & 0 & 0 & 0 & 0 & 0 & 0 & 0 & 0 & 1 & 0 & 0 & 0 & 0 & 0 & 0 & 0 & 0 & 0 & 0 & 0 & 0 & 1 & 0 & 0 & 0.35\end{array}$

0.35
0.35
0.30

13
25

0.35

$\$ 20 / \mathrm{bbl}$

4.

herest Rates

$$
\begin{aligned}
& 298 \\
& 6-921 * \\
& 642
\end{aligned}
$$

$\begin{array}{llllllllllllllllllllllllll}1 & 0 & 0 & 0 & 0 & 0 & 0 & 0 & 0 & 1 & 0 & 0 & 0 & 0 & 0 & 0 & 0 & 1 & 1 & 0 & 0 & 0 & 0 & 0 & 0 & 0.40 \\ 0 & 1 & 1 & 1 & 1 & 1 & 1 & 1 & 1 & 0 & 0 & 1 & 1 & 1 & 1 & 1 & 1 & 0 & 0 & 1 & 1 & 1 & 0 & 1 & 1 & 0.35\end{array}$

Immigration Higher"
=lower

1

6. lotion Groth

High Ser

to Law Ser $\begin{array}{llllllllllllllllllllllllll}1 & 1 & 1 & 0 & 0 & 0 & 1 & 1 & 0 & 0 & 0 & 0 & 1 & 1 & 1 & 1 & 1 & 0 & 0 & 1 & 1 & 1 & 1 & 1 & 1 & 0.30 \\ 0 & 0 & 0 & 0 & 0 & 1 & 0 & 0 & 0 & 1 & 0 & 0 & 0 & 0 & 0 & 0 & 0 & 0 & 0 & 0 & 0 & 0 & 0 & 0 & 0 & 0.40 \\ 0 & 0 & 0 & 1 & 1 & 0 & 0 & 0 & 1 & 0 & 1 & 1 & 0 & 0 & 0 & 0 & 0 & 1 & 1 & 0 & 0 & 0 & 0 & 0 & 0 & 0.30\end{array}$

16
83
11

16

$0.12320 \mathrm{mbt}$

0.65 (\$17)

7.

te Tech change

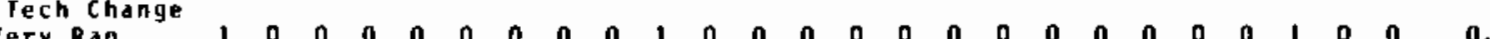

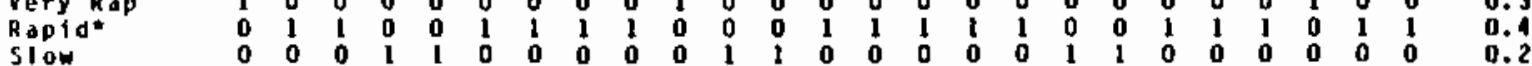

0.35
0.10
0.25

1

8.

Growth

$2 \pi$
$2-4 x$
$>4 x$

$\begin{array}{llllll}0 & 0 & 0 & 1 & 1 & 0 \\ 0 & 1 & 1 & 0 & 0 & 1 \\ 1 & 0 & 0 & 0 & 0 & 0\end{array}$

$\begin{array}{lll}0 & 0 & 1 \\ 1 & 1 & 0\end{array}$

$\begin{array}{lllllll}0 & 1 & 1 & 0 & 0 & 0 & 0 \\ 0 & 0 & 0 & 1 & 1 & 1 & 1 \\ 1 & 0 & 0 & 0 & 0 & 0 & 0\end{array}$

Geoshift: Sunoelt $\begin{array}{lllllllllllllllllllllllllll}344 x & 1 & 0 & 0 & 0 & 0 & 0 & 0 & 0 & 0 & 1 & 1 & 0 & 1 & 0 & 0 & 0 & 1 & 0 & 0 & 1 & 0 & 0 & 1 & 0 & 0 & 0.40 \\ 42-44 x & 0 & 1 & 1 & 1 & 0 & 1 & 1 & 0 & 1 & 0 & 0 & 0 & 0 & 1 & 1 & 1 & 0 & 0 & 0 & 0 & 1 & 1 & 0 & 1 & 1 & 0.35\end{array}$

0.30

0.10

11
19

0.15

791

$0.10<61$

$\begin{array}{lll}67 & 0.61 & \begin{array}{l}\text { N1gher } \\ \text {-Lover }\end{array}\end{array}$

$\begin{array}{lll}56 & 0.51 & \text { High Ser } \\ 12 & 0.11 & \text { Hid ser }\end{array}$

\begin{abstract}
$\begin{array}{llll}0 & 0 & 0 & 0\end{array}$
\end{abstract}

\begin{abstract}
(2)
\end{abstract}


IABEL C.1. Macro-Environment, cont.

10 .

Hhold Foimation

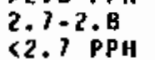

1

11.

Infiation

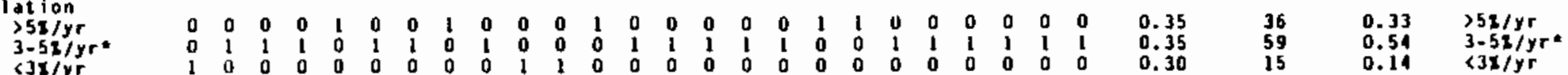

12.

Econoetc seruct

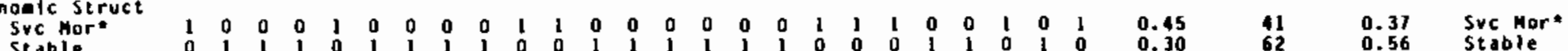
$\begin{array}{lllllllllllllllllllllllllllllll}\text { Stable } & 0 & 1 & 1 & 1 & 0 & 1 & 1 & 1 & 1 & 0 & 0 & 1 & 1 & 1 & 1 & 1 & 1 & 0 & 0 & 0 & 1 & 1 & 0 & 1 & 0 & 0.30 & 62 & 0.56 & 5 t a b l e \\ \text { Mfg Mor } & 0 & 0 & 0 & 0 & 0 & 0 & 0 & 0 & 0 & 0 & 0 & 0 & 0 & 0 & 0 & 0 & 0 & 0 & 0 & 0 & 0 & 0 & 0 & 0 & 0 & 0.25 & j & 0.06 & M f g\end{array}$

13.

Urbon/Suburd Patt

$\begin{array}{llllllllllllllllllllllllllllll}\text { Cnt city } & 0 & 0 & 0 & 1 & 1 & 0 & 0 & 1 & 1 & 0 & 0 & 1 & 0 & 0 & 0 & 1 & 0 & 1 & 1 & 0 & 1 & 0 & 0 & 1 & 1 & 0.50 & 61 & 0.55 & \text { Cnt City } \\ \text { Suburbn* } & 1 & 1 & 1 & 0 & 0 & 1 & 1 & 0 & 0 & 1 & 1 & 0 & 1 & 1 & 1 & 0 & 1 & 0 & 0 & 1 & 0 & 1 & 1 & 0 & 0 & 0.50 & 49 & 0.45 & \text { Suburbn* }\end{array}$

14.

Tax Policy

Mare Far
Sane fas far

$\begin{array}{llllllllllllllllllllllllll}1 & 0 & 0 & 0 & 1 & 0 & 0 & 1 & 0 & 1 & 0 & 0 & 0 & 0 & 0 & 0 & 0 & 1 & 1 & 0 & 0 & 0 & 0 & 0 & 0 & 0.25 \\ 0 & 1 & 1 & 1 & 0 & 1 & 1 & 0 & 1 & 0 & 0 & 1 & 1 & 1 & 1 & 1 & 1 & 0 & 0 & 1 & 1 & 1 & 1 & 1 & 1 & 0.40 \\ 0 & 0 & 0 & 0 & 0 & 0 & 0 & 0 & 0 & 0 & 1 & 0 & 0 & 0 & 0 & 0 & 0 & 0 & 0 & 0 & 0 & 0 & 0 & 0 & 0 & 0.35\end{array}$

ardability

nore.
Same"
Less

$\begin{array}{lllll}0 & 0 & 0 & 0 & 0\end{array}$

$\begin{array}{lllll}0 & 0 & 0 & 0 & 0 \\ 1 & 1 & 1 & 1 & 0 \\ 0 & 0 & 0 & 0 & 1\end{array}$

$\begin{array}{lll}0 & & \\ 0 & 0 & 0 \\ 0 & 1 & 1 \\ 1 & 0 & 0\end{array}$

16.

Housg Costs

$3340 \%$ sf

$330-40 /$
$430 / \mathrm{sf}$

10

1.

160-65t

$$
\begin{aligned}
& \mathbf{0} \\
& \mathbf{0} \\
& \mathbf{1}
\end{aligned}
$$

18.

triscal Resp

Ctrcyci
Contract 1
$\mathbf{0}$
0 19.

Invest Horizon

shorcer
sabie.
longer

$\begin{array}{lllllllllllllllllllllllll}1 & 0 & 0 & 0 & 0 & 0 & 0 & 0 & 0 & 1 & 1 & 0 & 0 & 0 & 0 & 0 & 0 & 0 & 0 & 0 & 0 & 0 & 0 & 0 & 0 \\ 0 & 1 & 1 & 1 & 1 & 1 & 1 & 1 & 1 & 0 & 0 & 1 & 1 & 1 & 1 & 1 & 1 & 1 & 1 & 1 & 1 & 1 & 1 & 1 & 1 \\ 0 & 0 & 0 & 0 & 0 & 0 & 0 & 0 & 0 & 0 & 0 & 0 & 0 & 0 & 0 & 0 & 0 & 0 & 0 & 0 & 0 & 0 & 0 & 0 & 0\end{array}$

0.30
0.35
0.35

0.25
0.40
0.35

76
10

0.22
0.69
0.09

More fay

Less $f a v$

$\begin{array}{lllllllllllllllllllllllll}1 & 0 & 0 & 0 & 1 & 0 & 0 & 1 & 0 & 1 & 0 & 0 & 0 & 0 & 0 & 0 & 0 & 0 & 1 & 0 & 0 & 0 & 0 & 0 & 1 \\ 0 & 1 & 1 & 1 & 0 & 1 & 1 & 0 & 1 & 0 & 0 & 1 & 1 & 1 & 1 & 0 & 1 & 1 & 0 & 1 & 1 & 1 & 1 & 0 & 0 \\ 0 & 0 & 0 & 0 & 0 & 0 & 0 & 0 & 0 & 0 & 1 & 0 & 0 & 0 & 0 & 1 & 0 & 0 & 0 & 0 & 0 & 0 & 0 & 1 & 0\end{array}$

0.10

2

0.04

0.71

More.

less

$\begin{array}{llllllllllllllllllllllllllll}0 & 0 & 0 & 0 & 1 & 0 & 0 & 1 & 0 & 0 & 0 & 1 & 0 & 0 & 0 & 0 & 0 & 1 & 1 & 0 & 0 & 0 & 0 & 0 & 0 & 0.20 & 2 \\ 0 & 1 & 1 & 1 & 0 & 1 & 1 & 0 & 1 & 0 & 0 & 0 & 1 & 1 & 1 & 1 & 1 & 0 & 0 & 0 & 1 & 1 & 0 & 1 & 1 & 0.45 & & 6 \\ 1 & 0 & 0 & 0 & 0 & 0 & 0 & 0 & 0 & 1 & 1 & 0 & 0 & 0 & 0 & 0 & 0 & 0 & 0 & 1 & 0 & 0 & 1 & 0 & 0 & 0.35 & & 2\end{array}$

$25 \quad 0.23$

$3840 / 5 f$

$330-40 /$
$\$ 330 / \mathrm{sf}$

$\begin{array}{ll}0.20 & 2865 / 5 f \\ 0.55 & \$ 60-65 / \\ 0.25 & \$ 360 / 5 f\end{array}$

$\begin{array}{llllllllllllllllllllllll}0 & 0 & 0 & 1 & 0 & 0 & 1 & 0 & 1 & 0 & 0 & 0 & 0 & 0 & 0 & 0 & 1 & 1 & 0 & 0 & 0 & 0 & 0 & 0\end{array}$

$0.30 \quad 29 \quad 0.25 \quad$ Expansn

0.05 cantract

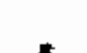


Quilaing scendrios to 20i0:0109 Oase Run

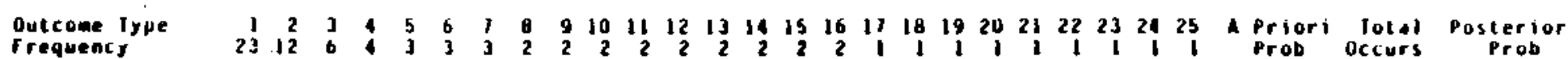

1. of ketrofit

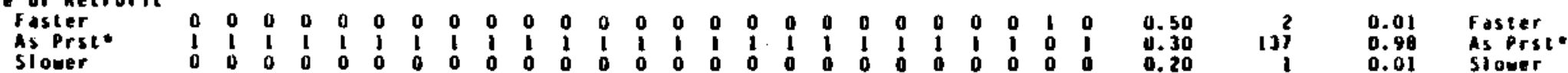

2.

Res Units

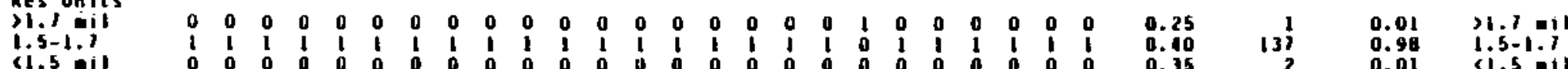

3ingle faeily

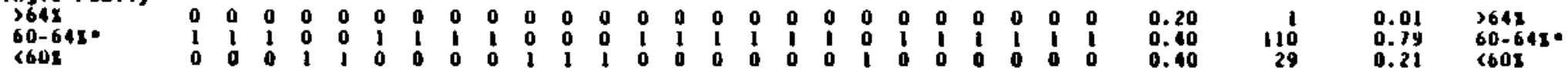

1.

Manufterd housg

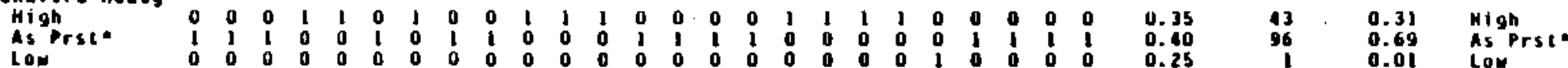

5.

Hsing Uait size

$>1500$ s.

$\begin{array}{lllllllllllllllllllllllll}0 & 0 & 0 & 0 & 0 & 0 & 0 & 0 & 0 & 0 & 0 & 0 & 0 & 0 & 0 & 0 & 0 & 0 & 0 & 0 & 0 & 1 & 0 & 0 & 0 \\ 1 & 1 & 1 & 0 & 0 & 0 & 1 & 1 & 1 & 0 & 0 & 0 & 1 & 1 & 1 & 1 & 0 & 0 & 0 & 1 & 1 & 0 & 0 & 1 & 1\end{array}$

0.:35

6.

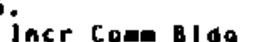

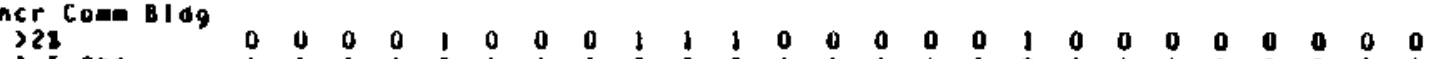

$323-28 *$

$\begin{array}{llllllllllllllllllllllll}0 & 0 & 0 & 1 & 0 & 0 & 0 & 1 & 1 & 1 & 0 & 0 & 0 & 0 & 0 & 1 & 0 & 0 & 0 & 0 & 0 & 0 & 0 & 0 \\ 1 & 1 & 1 & 0 & 1 & 1 & 1 & 0 & 0 & 0 & 1 & 1 & 1 & 1 & 1 & 0 & 1 & 1 & 1 & 1 & 1 & 1 & 1 & 1 \\ 0 & 0 & 0 & 0 & 0 & 0 & 0 & 0 & 0 & 0 & 0 & 0 & 0 & 0 & 0 & 0 & 0 & 0 & 0 & 0 & 0 & 0 & 0 & 0\end{array}$

0.35

$0.50 \quad 108$

$31 \quad 0.22 \quad 223.28 *$

Very log bidg

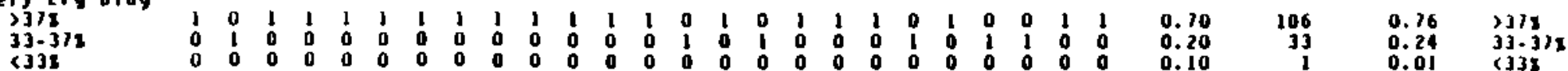

a.

\begin{tabular}{|c|c|c|c|c|c|c|c|c|c|c|c|c|c|c|c|c|c|c|c|c|c|c|c|c|c|c|c|c|c|}
\hline $\begin{array}{l}\text { Hsng Costs } \\
2 \$ 40, f \\
130-10 \text { st } \\
<\$ 30 \text { sf }\end{array}$ & $\begin{array}{l}0 \\
1 \\
0\end{array}$ & $\begin{array}{l}0 \\
1 \\
0\end{array}$ & $\begin{array}{l}0 \\
1 \\
0\end{array}$ & $\begin{array}{l}0 \\
1 \\
0\end{array}$ & $\begin{array}{l}0 \\
1 \\
0\end{array}$ & $\begin{array}{l}0 \\
1 \\
0\end{array}$ & $\begin{array}{l}\mathbf{0} \\
\mathbf{1} \\
\mathbf{0}\end{array}$ & $\begin{array}{l}0 \\
1 \\
0\end{array}$ & $\begin{array}{l}0 \\
1 \\
0\end{array}$ & $\begin{array}{l}0 \\
1 \\
0\end{array}$ & $\begin{array}{l}0 \\
1 \\
0\end{array}$ & $\begin{array}{l}0 \\
\mathbf{1} \\
0\end{array}$ & $\begin{array}{l}0 \\
\text { I } \\
0\end{array}$ & $\begin{array}{l}0 \\
1 \\
0\end{array}$ & $\begin{array}{l}0 \\
1 \\
0\end{array}$ & $\begin{array}{l}0 \\
1 \\
0\end{array}$ & $\begin{array}{l}0 \\
1 \\
0\end{array}$ & $\begin{array}{l}0 \\
1 \\
0\end{array}$ & $\begin{array}{l}0 \\
1 \\
0\end{array}$ & $\begin{array}{l}0 \\
\mathbf{1}\end{array}$ & $\begin{array}{l}0 \\
1 \\
0\end{array}$ & $\begin{array}{l}0 \\
1\end{array}$ & $\begin{array}{l}0 \\
1 \\
0\end{array}$ & $\begin{array}{l}0 \\
1 \\
0\end{array}$ & $\begin{array}{l}0 \\
1 \\
0\end{array}$ & $\begin{array}{l}0.01 \\
0.99 \\
0.01\end{array}$ & 137 & $\begin{array}{l}0.01 \\
0.98 \\
0.01\end{array}$ & $\begin{array}{l}\$ \$ 40 s f \\
\$ 30-40 s f \\
\$ \$ 30 s t\end{array}$ \\
\hline $\begin{array}{l}010 y \text { casts } \\
>50351 \\
560-6351 \\
1500>1\end{array}$ & $\begin{array}{l}0 \\
1 \\
0\end{array}$ & $\begin{array}{l}0 \\
1 \\
0\end{array}$ & $\begin{array}{l}0 \\
1 \\
0\end{array}$ & $\begin{array}{l}0 \\
1 \\
0\end{array}$ & $\begin{array}{l}0 \\
1 \\
0\end{array}$ & $\begin{array}{l}0 \\
1 \\
0\end{array}$ & $\begin{array}{l}0 \\
1 \\
0\end{array}$ & $\begin{array}{l}0 \\
1 \\
0\end{array}$ & $\begin{array}{l}0 \\
\mathbf{1} \\
\mathbf{0}\end{array}$ & $\begin{array}{l}0 \\
1 \\
0\end{array}$ & $\begin{array}{l}0 \\
1 \\
0\end{array}$ & $\begin{array}{l}0 \\
1 \\
0\end{array}$ & $\begin{array}{l}0 \\
1 \\
0\end{array}$ & $\begin{array}{l}\mathbf{0} \\
\mathbf{1} \\
\mathbf{0}\end{array}$ & $\begin{array}{l}0 \\
1 \\
0\end{array}$ & $\begin{array}{l}0 \\
1 \\
0\end{array}$ & $\begin{array}{l}0 \\
1 \\
0\end{array}$ & $\begin{array}{l}0 \\
1 \\
0\end{array}$ & $\begin{array}{l}0 \\
\mathbf{1} \\
0\end{array}$ & $\begin{array}{l}0 \\
\mathbf{i}\end{array}$ & $\begin{array}{l}0 \\
\mathbf{1}\end{array}$ & $\begin{array}{l}0 \\
1 \\
0\end{array}$ & $\begin{array}{l}0 \\
1 \\
0\end{array}$ & $\begin{array}{l}0 \\
1\end{array}$ & $\begin{array}{l}0 \\
1 \\
0\end{array}$ & $\begin{array}{l}0.01 \\
0.98 \\
0.01\end{array}$ & $\begin{array}{r}137 \\
2\end{array}$ & $\begin{array}{l}0.01 \\
0.98 \\
0.01\end{array}$ & $\begin{array}{l}2365 s f \\
\$ 60-65 s f \\
<\$ 60 s f\end{array}$ \\
\hline
\end{tabular}


IABLE C.2. Buildings Base Run, cont.

${ }_{H / C}^{10:}$

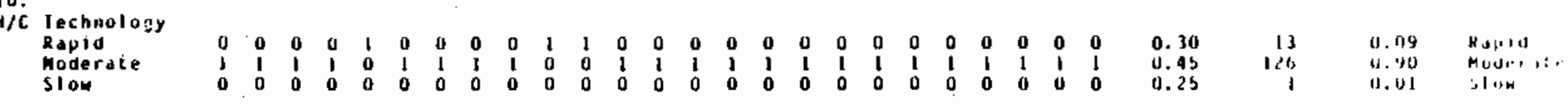

11.

Materials rechn

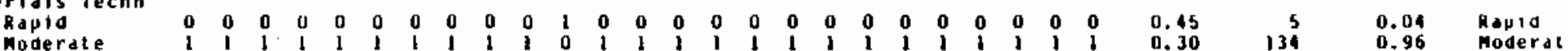

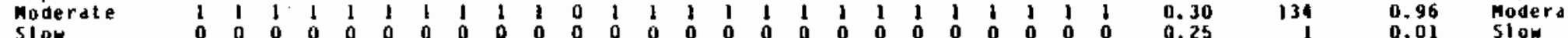

12.

code cororc

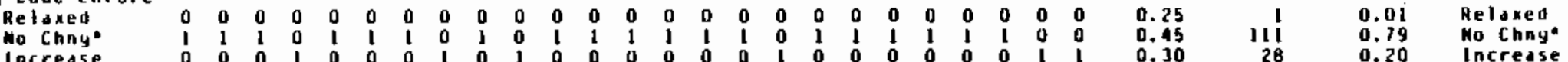

13.

Enrgy fific Bloy

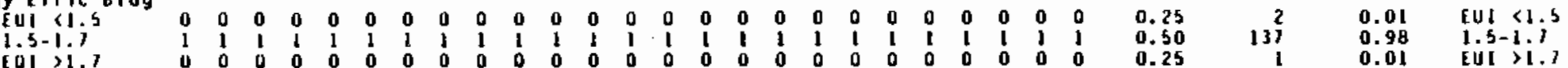

14.

larst Horizon

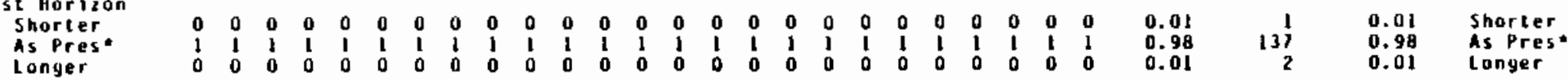

15

Wiility Role

$\begin{array}{llllllllllllllllllllllllllllll}\text { MareAct: } & 0 & 0 & 0 & 0 & 0 & 0 & 0 & 0 & 0 & 0 & 0 & 0 & 0 & 0 & 0 & 0 & 0 & 0 & 0 & 0 & 0 & 0 & 0 & 0 & 0 & 0.15 & 1 & 0.01 & \text { MoreActy } \\ \text { As Prst: } & 1 & 1 & 1 & 1 & 1 & 1 & 1 & 1 & 1 & 1 & 1 & 1 & 1 & 1 & 1 & 1 & 1 & 1 & 1 & 1 & 1 & 1 & 1 & 1 & 1 & 0.45 & 13 & 0.95 & \text { As Prst: }\end{array}$

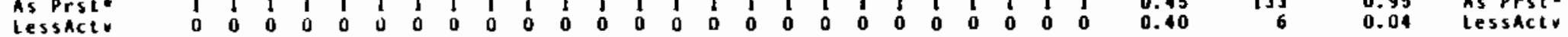

16.

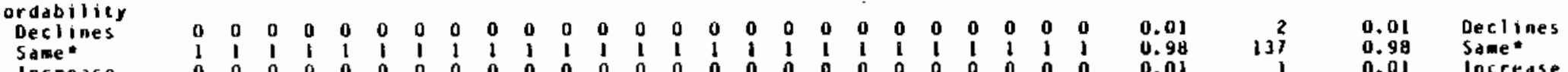

17 .

Geographic shet

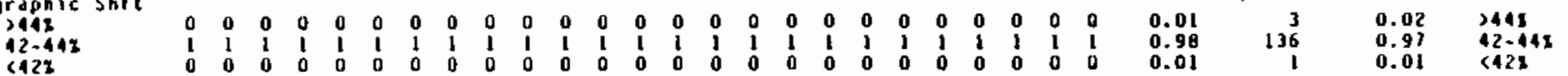

18.

log Density

Higher

Salae *
cover

$\begin{array}{lllllllllllllllllllllllll}1 & 0 & 0 & 1 & 1 & 1 & 1 & 1 & 1 & 1 & 1 & 1 & 1 & 0 & 0 & 0 & 1 & 1 & 1 & 0 & 1 & 0 & 0 & 1 & 1\end{array}$

0.40

(20)

a.

Pret for convent

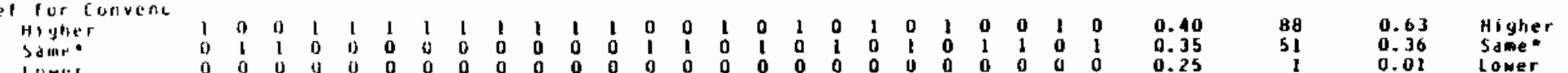


IABLE C.2. Buildings Base Run, cont.

20.

\begin{tabular}{|c|c|c|c|c|c|c|c|c|c|c|c|c|c|c|c|c|c|c|c|c|c|c|c|c|c|c|c|c|c|}
\hline $\begin{array}{l}\text { Higher } \\
\text { Baselina } \\
\text { Lower }\end{array}$ & $\begin{array}{l}1 \\
0 \\
i\end{array}$ & $\begin{array}{l}\text { I } \\
\text { u } \\
0\end{array}$ & $\begin{array}{l}1 \\
0 \\
0\end{array}$ & $\begin{array}{l}1 \\
0 \\
0\end{array}$ & $\begin{array}{l}1 \\
u \\
D\end{array}$ & $\begin{array}{l}\text { l } \\
0 \\
0\end{array}$ & $\begin{array}{l}1 \\
0 \\
0\end{array}$ & $\begin{array}{l}1 \\
0 \\
0\end{array}$ & $\begin{array}{l}1 \\
0 \\
0\end{array}$ & $\begin{array}{l}1 \\
0 \\
0\end{array}$ & $\begin{array}{l}1 \\
0 \\
0\end{array}$ & $\begin{array}{l}1 \\
0 \\
0\end{array}$ & $\begin{array}{l}1 \\
0 \\
0\end{array}$ & 0 & $\begin{array}{l}\text { l } \\
0 \\
0\end{array}$ & $\begin{array}{l}1 \\
0 \\
0\end{array}$ & $\begin{array}{l}\text { b } \\
\text { a } \\
a\end{array}$ & $\begin{array}{l}\mathbf{l} \\
\mathbf{0} \\
\mathbf{u}\end{array}$ & $\begin{array}{l}1 \\
0 \\
0\end{array}$ & $\begin{array}{l}\mathbf{1} \\
\mathbf{0} \\
\mathbf{0}\end{array}$ & $\begin{array}{l}1 \\
0 \\
0\end{array}$ & $\begin{array}{l}1 \\
a \\
0\end{array}$ & u & & $\begin{array}{l}1 \\
a \\
0\end{array}$ & $\begin{array}{l}10.98 \\
0.01 \\
0.01\end{array}$ & $\begin{array}{r}137 \\
2 \\
1\end{array}$ & $\begin{array}{l}0.98 \\
1.01 \\
11.01 \\
11.1\end{array}$ & 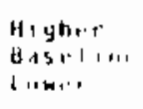 \\
\hline $\begin{array}{l}\text { ciricty Price } \\
\text { "igner } \\
\text { Haseline } \\
\text { Lomer }\end{array}$ & $\begin{array}{l}0 \\
1 \\
0\end{array}$ & $\begin{array}{l}0 \\
1 \\
0\end{array}$ & $\begin{array}{l}1 \\
1 \\
0\end{array}$ & $\begin{array}{l}0 \\
1 \\
0\end{array}$ & $\begin{array}{l}0 \\
1 \\
0\end{array}$ & $\begin{array}{l}0 \\
1 \\
0\end{array}$ & $\begin{array}{l}0 \\
1 \\
0\end{array}$ & $\begin{array}{l}0 \\
1 \\
0\end{array}$ & $\begin{array}{l}0 \\
1 \\
0\end{array}$ & $\begin{array}{l}u \\
1 \\
0\end{array}$ & $\begin{array}{l}0 \\
1 \\
0\end{array}$ & $\begin{array}{l}0 \\
\mathbf{1} \\
0\end{array}$ & $\begin{array}{l}0 \\
1 \\
0\end{array}$ & $\begin{array}{l}0 \\
1 \\
0\end{array}$ & $\begin{array}{l}0 \\
1 \\
0\end{array}$ & $\begin{array}{l}0 \\
1 \\
0\end{array}$ & $\begin{array}{l}0 \\
1 \\
0\end{array}$ & $\begin{array}{l}0 \\
1 \\
0\end{array}$ & $\begin{array}{l}0 \\
1 \\
0\end{array}$ & $\begin{array}{l}0 \\
1 \\
0\end{array}$ & $\begin{array}{l}0 \\
1 \\
0\end{array}$ & $\begin{array}{l}0 \\
1 \\
0\end{array}$ & $\begin{array}{l}0 \\
1 \\
0\end{array}$ & $\begin{array}{l}0 \\
1 \\
0\end{array}$ & $\begin{array}{l}0 \\
1 \\
0\end{array}$ & $\begin{array}{l}0.01 \\
0.98 \\
0.01\end{array}$ & 133 & $\begin{array}{l}0.01 \\
0.98 \\
0.01\end{array}$ & $\begin{array}{l}\text { Hygher } \\
\text { Baseline } \\
\text { lower }\end{array}$ \\
\hline $\begin{array}{l}\text { Migration } \\
\text { Higher } \\
\text { =flower }\end{array}$ & $\begin{array}{l}1 \\
0\end{array}$ & $\begin{array}{l}1 \\
0\end{array}$ & $\begin{array}{l}1 \\
0\end{array}$ & $\begin{array}{l}1 \\
0\end{array}$ & $\begin{array}{l}1 \\
0\end{array}$ & $\begin{array}{l}1 \\
0\end{array}$ & $\begin{array}{l}1 \\
0\end{array}$ & $\begin{array}{l}1 \\
0\end{array}$ & $\begin{array}{l}1 \\
0\end{array}$ & $\begin{array}{l}1 \\
0\end{array}$ & $\frac{1}{0}$ & 0 & $\begin{array}{l}1 \\
0\end{array}$ & $\begin{array}{l}1 \\
0\end{array}$ & $\begin{array}{l}0 \\
1\end{array}$ & $\begin{array}{l}1 \\
0\end{array}$ & $\begin{array}{l}1 \\
0\end{array}$ & $\begin{array}{l}1 \\
0\end{array}$ & ! & $\begin{array}{l}\mathbf{l} \\
\mathbf{0}\end{array}$ & $\begin{array}{l}1 \\
0\end{array}$ & $\begin{array}{l}i \\
0\end{array}$ & I & $\begin{array}{l}1 \\
0\end{array}$ & $\begin{array}{l}1 \\
0\end{array}$ & $\begin{array}{l}0.99 \\
0.01\end{array}$ & $\begin{array}{r}138 \\
2\end{array}$ & $\begin{array}{l}0.99 \\
0.01\end{array}$ & $\begin{array}{l}\text { Hiyher } \\
\text { = liower }\end{array}$ \\
\hline $\begin{array}{l}\text { iira Pref Hous } \\
\text { >mult } \\
\text { carsable }\end{array}$ & $\frac{1}{0}$ & ! & ! & $\begin{array}{l}1 \\
0\end{array}$ & l & ! & $\begin{array}{l}1 \\
0\end{array}$ & $\begin{array}{l}1 \\
0\end{array}$ & ! & l & $\begin{array}{l}1 \\
0\end{array}$ & b & $\begin{array}{l}1 \\
0\end{array}$ & a & $\begin{array}{l}1 \\
0\end{array}$ & $\begin{array}{l}0 \\
1\end{array}$ & $\frac{1}{0}$ & $!$ & ! & l & l & $\begin{array}{l}1 \\
0\end{array}$ & $\begin{array}{l}1 \\
0\end{array}$ & $\stackrel{1}{0}$ & $\begin{array}{l}1 \\
0\end{array}$ & $\begin{array}{l}0.60 \\
0.40\end{array}$ & 136 & $\begin{array}{l}0.97 \\
0.03\end{array}$ & $\begin{array}{l}\text { renulti } \\
\text { corsoline }\end{array}$ \\
\hline $\begin{array}{l}\text { wlation Grwth } \\
\text { High } \\
\text { Hidde. } \\
\text { low }\end{array}$ & $\begin{array}{l}1 \\
0 \\
0\end{array}$ & $\begin{array}{l}1 \\
0 \\
0\end{array}$ & $\begin{array}{l}1 \\
0 \\
0\end{array}$ & $\begin{array}{l}1 \\
0 \\
0\end{array}$ & $\begin{array}{l}1 \\
0 \\
0\end{array}$ & $\begin{array}{l}1 \\
0 \\
0\end{array}$ & $\begin{array}{l}1 \\
0 \\
0\end{array}$ & $\begin{array}{l}1 \\
0 \\
0\end{array}$ & $\begin{array}{l}! \\
0 \\
0\end{array}$ & $\begin{array}{l}1 \\
0 \\
0\end{array}$ & $\begin{array}{l}1 \\
0 \\
0\end{array}$ & $\begin{array}{l}1 \\
0 \\
0\end{array}$ & $\begin{array}{l}\text { l } \\
0 \\
0\end{array}$ & $\begin{array}{l}1 \\
0 \\
0\end{array}$ & $\begin{array}{l}1 \\
0 \\
0\end{array}$ & $\begin{array}{l}\text { l } \\
0 \\
0\end{array}$ & $\begin{array}{l}1 \\
0 \\
0\end{array}$ & $\begin{array}{l}\text { l } \\
\mathbf{0} \\
0\end{array}$ & $\begin{array}{l}1 \\
0 \\
0\end{array}$ & $\begin{array}{l}l \\
0 \\
0\end{array}$ & $\begin{array}{l}1 \\
0 \\
0\end{array}$ & $\begin{array}{l}1 \\
0 \\
0\end{array}$ & $\begin{array}{l}1 \\
0 \\
0\end{array}$ & $\begin{array}{l}1 \\
0 \\
0\end{array}$ & $\begin{array}{l}1 \\
0 \\
0\end{array}$ & $\begin{array}{l}0.98 \\
0.01 \\
0.01\end{array}$ & $\begin{array}{r}137 \\
2 \\
1\end{array}$ & $\begin{array}{l}0.98 \\
0.01 \\
0.01\end{array}$ & $\begin{array}{l}\text { Migh } \\
\text { Middle. } \\
\text { Low }\end{array}$ \\
\hline
\end{tabular}


Building scendrios to 2010 :Buildinys "A"

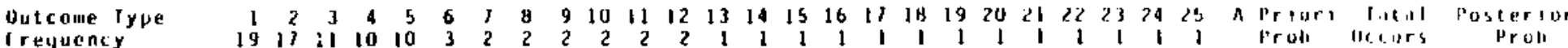

Rate of Retrofit o $\begin{array}{llllllllllllllllllllllllll}1 & 1 & 1 & 1 & 1 & 0 & 1 & 1 & 1 & 1 & 0 & 1 & 1 & 1 & 1 & 1 & 1 & 1 & 1 & 1 & 1 & 1 & 1 & 1 & 0.50\end{array}$ $\begin{array}{rrrr}0.50 & 131 & 0.94 & \text { Faster } \\ 0.30 & 6 & 0.04 & \text { As Prst }\end{array}$ $\begin{array}{llllllllllllllllllllllllllllll}\text { as Prst } & 0 & 0 & 0 & 0 & 0 & 0 & 1 & 0 & 0 & 0 & 0 & 0 & 0 & 0 & 0 & 0 & 0 & 0 & 0 & 0 & 0 & 0 & 0 & 0 & 0 & 0.30 & 0 & 0.02 & 510 n e r\end{array}$

$\begin{array}{lll}1 & 0.01 & 2648 \\ 2 & 0.01 & 60-642= \\ 137 & 0.98 & <605\end{array}$

$\begin{array}{lrll}0.35 & 137 & 0.98 & \text { High } \\ 0.40 & 2 & 0.01 & \text { As Prst* }\end{array}$

$\begin{array}{llll}0.25 & 0.01 & >1500 \mathrm{~s} f\end{array}$ $\begin{array}{lll}2 & 0.01 & 1-1500 s f \\ 137 & 0.98 & 21000 s f\end{array}$

$\begin{array}{rll}134 & 0.96 & >25 \\ 5 & 0.04 & 1.5-2 x * \\ 1 & 0.01 & >1.53\end{array}$

$\begin{array}{lrrr}0.70 & 135 & 0.96 & 3378 \\ 0.20 & 4 & 0.03 & 33-318\end{array}$

$0.01<33$

131 $0.94 \quad 3405 f$

$\begin{array}{ll}0.94 & 3505 f \\ 0.01 & \$ 30-40 s t\end{array}$

0.01286558 $0.01 \quad 360-65 s$ 
TABLE C.3. Buildings "A" Scenario, cont.

10.

ic Technoloyy
Rapid

Rapidite

S) ow

II.

Moterials Jechn

Rapid
Moderale
Slou

12.

Hlay code infare

$\begin{array}{llllllllllllllllllllllllll}\text { Meldaxed } & 0 & 0 & 0 & 0 & 0 & 0 & 0 & 0 & 0 & 0 & 0 & 0 & 0 & 0 & 0 & 0 & 0 & 0 & 0 & 0 & 0 & 0 & 0 & 0 & 0 \\ \text { Mochny* } & 0 & 0 & 0 & 0 & 0 & 0 & 0 & 0 & 0 & 0 & 0 & 0 & 0 & 0 & 0 & 0 & 0 & 0 & 0 & 0 & 0 & 0 & 0 & 0 & 0 \\ \text { Increase } & 1 & 1 & 1 & 1 & 1 & 1 & 1 & 1 & 1 & 1 & 1 & 1 & 1 & 1 & 1 & 1 & 1 & 1 & 1 & 1 & 1 & 1 & 1 & 1 & 1\end{array}$

Mo Chny"
Incredse

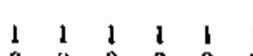

Enryy fricic alda

\{ul $\{1,5$
luiti.i. 0
1
0

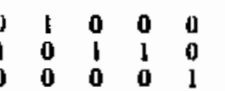

14.

Inust Harizon

sharter.
As Pres.

1 Lonyer

15.

Ifility Role

MoreAcly:

As Prst.

0
1
0

16.

$$
\begin{aligned}
& \text { ordability } \\
& \text { Declines } \\
& \text { Samed } \\
& \text { Increase }
\end{aligned}
$$

1
0
0

$\begin{array}{lllllll}1 & 1 & 1 & 1 & 1 & 1 & 1\end{array}$

$1 \%$.

Geographic Sinte

$214 x$
$2-443$
$42 x$

\section{!}

$\begin{array}{lllllll}1 & 1 & 1 & 1 & 1 & 1\end{array}$

H.

Higner

Hi yher
Same*

1
0
0

1
0
0

liget fou lanertine

thind

1

$\begin{array}{llllll}1 & 1 & 1 & b & 0 & 1\end{array}$

$\begin{array}{lll}0 & 1 & 1 \\ 1 & 0 & 0 \\ 0 & 0 & 0\end{array}$

$\begin{array}{ll}0 & 0 \\ 1 & 1 \\ 0 & 0\end{array}$

$\begin{array}{lllll}1 & 0 & 0 & 0 & 0 \\ 0 & 0 & 1 & 0 & 1\end{array}$

$\begin{array}{lllllllllll}0 & 0 & 0 & 0 & 0 & 0 & 0 & 0 & 0 & 0 & 0\end{array}$

$\begin{array}{lllll}1 & 1 & 1 & 1 & 1 \\ 0 & 0 & 0 & 0 & 0 \\ 0 & 0 & 0 & 0 & 0\end{array}$

$1+1$

$\begin{array}{lllllllllll}1 & 0 & 0 & 0 & 0 & 0 & 0 & 0 & 0 & 0 & 1\end{array}$

0.25

0.30
0.45
0.25

129

1

0.92 Rabla

II. M7 Mande.".

0.35

0.30
0.25

ii

$\begin{array}{ll}0.91 & \text { Kapiu } \\ 0.49 & \text { Hoderate } \\ 0.01 & \text { S10ur }\end{array}$

0.25
0.45
0.30

10.01 Relaxed

360.97 increase

I.....

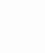

\begin{abstract}
$\begin{array}{llllllllllllllllllllllll}1 & 1 & 1 & 1 & 1 & 1 & 1 & 0 & 1 & 1 & 1 & 1 & 1 & 1 & 1 & 1 & 1 & 1 & 1 & 1 & 1 & 1 & 1 & 1 \\ 0 & 0 & 0 & 0 & 0 & 0 & 0 & 0 & 0 & 0 & 0 & 0 & 0 & 0 & 0 & 0 & 0 & 0 & 0 & 0 & 0 & 0 & 0 & 0 \\ 0 & 0 & 0 & 0 & 0 & 0 & 0 & 1 & 0 & 0 & 0 & 0 & 0 & 0 & 0 & 0 & 0 & 0 & 0 & 0 & 0 & 0 & 0 & 0\end{array}$
$\begin{array}{llllllllllllllllllllllll}1 & 1 & 1 & 1 & 1 & 1 & 1 & 0 & 1 & 1 & 1 & 1 & 1 & 1 & 1 & 1 & 1 & 1 & 1 & 1 & 1 & 1 & 1 & 1 \\ 0 & 0 & 0 & 0 & 0 & 0 & 0 & 0 & 0 & 0 & 0 & 0 & 0 & 0 & 0 & 0 & 0 & 0 & 0 & 0 & 0 & 0 & 0 & 0 \\ 0 & 0 & 0 & 0 & 0 & 0 & 0 & 1 & 0 & 0 & 0 & 0 & 0 & 0 & 0 & 0 & 0 & 0 & 0 & 0 & 0 & 0 & 0 & 0\end{array}$
\end{abstract}

$\begin{array}{llllllllllllllllllllllll}0 & 0 & 0 & 0 & 0 & 0 & 0 & 0 & 0 & 0 & 1 & 0 & 0 & 0 & 0 & 0 & 0 & 0 & 0 & 0 & 0 & 0 & 0 & 0 \\ 0 & 0 & 1 & 0 & 0 & 1 & 1 & 0 & 1 & 1 & 0 & 0 & 1 & 0 & 0 & 1 & 0 & 1 & 1 & 1 & 1 & 1 & 1 & 0 \\ 1 & 1 & 0 & 1 & 1 & 0 & 0 & 1 & 0 & 0 & 0 & 1 & 0 & 1 & 1 & 0 & 1 & 0 & 0 & 0 & 0 & 0 & 0 & 1\end{array}$

0.15
0.45
0.40

0.98

$\begin{array}{lll}39 & 0.28 & \{01<1.5 \\ 83 & 0.59 & 1.5-1.7 \\ 18 & 0.13 & \text { Evi }>1.1\end{array}$

37

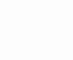


IABLE C.3. Buildings "A" Scenario, cont.

tarla price 13 il

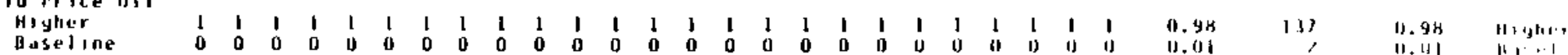

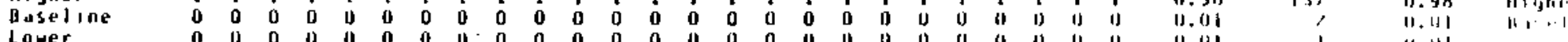

21.

Electricty Price

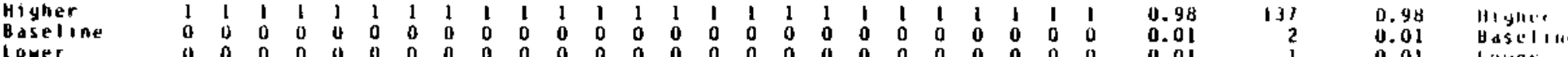

0.99

Laner. 23. Reli ird Pref Hous corsana 0 24. Populdition Grwth Hi yh Hid 
IABLE C.4. Buildings "B" Scenario

Huilding Scendrios to 2010:0uildings"a"

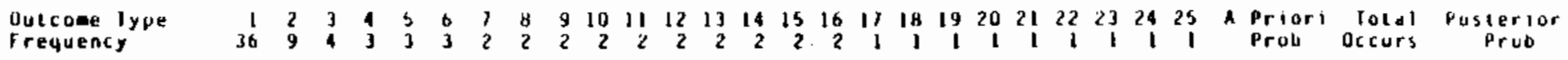

1.

Rate of ketruf

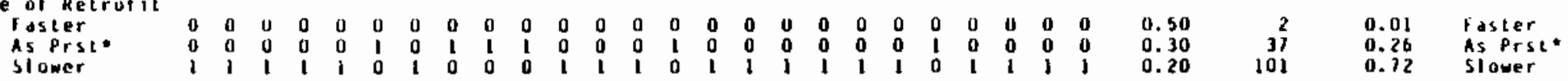

2.

New unes unts

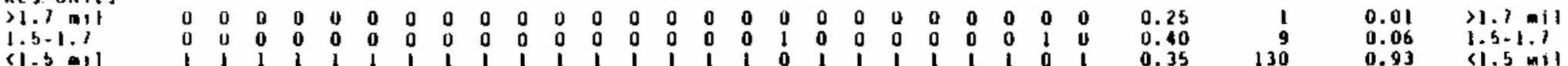

3. Single fanily $\begin{array}{llllllllllllllllllllllllllllllllllll}7645 & 1 & 1 & 1 & 1 & 1 & 1 & 0 & 0 & 1 & 1 & 1 & 1 & 1 & 1 & 0 & 1 & 0 & 1 & 1 & 1 & 1 & 1 & 1 & 1 & 1 & 0.20 & 108 & 0.71 & 2648 \\ 60.642 & 0 & 0 & 0 & 0 & 0 & 0 & 1 & 1 & 0 & 0 & 0 & 0 & 0 & 0 & 0 & 0 & 1 & 0 & 0 & 0 & 0 & 0 & 0 & 0 & 0 & 0.40 & 14 & 0.10 & 60.643\end{array}$

o.

$21500 \mathrm{sf}$ cloovst

$$
\text { I incr coom Bldy }
$$

0.08

'Very trg Bidg $33 / 2$
$33-3 / 2$
$<338$ Iisny Costs

\begin{tabular}{|c|c|c|c|c|c|c|c|c|c|c|c|c|c|c|c|c|c|c|c|c|c|c|c|c|c|c|c|c|}
\hline 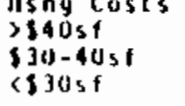 & $\begin{array}{l}0 \\
0 \\
1\end{array}$ & $\begin{array}{l}0 \\
0 \\
1\end{array}$ & $\begin{array}{l}0 \\
0 \\
1\end{array}$ & $\begin{array}{l}0 \\
0 \\
1\end{array}$ & $\begin{array}{l}0 \\
0 \\
1\end{array}$ & $\begin{array}{l}0 \\
0 \\
1\end{array}$ & $\begin{array}{l}\mathbf{l} \\
0 \\
0\end{array}$ & $\begin{array}{l}1 \\
0 \\
0\end{array}$ & $\begin{array}{l}0 \\
0 \\
\mathbf{1}\end{array}$ & $\begin{array}{l}0 \\
0 \\
1\end{array}$ & $\begin{array}{l}1 \\
0 \\
0\end{array}$ & $\begin{array}{l}\mathbf{0} \\
\mathbf{0} \\
1\end{array}$ & $\begin{array}{l}\mathbf{0} \\
\mathbf{0} \\
\mathbf{l}\end{array}$ & $\begin{array}{l}0 \\
0 \\
1\end{array}$ & $\begin{array}{l}\mathbf{l} \\
\mathbf{0} \\
\mathbf{0}\end{array}$ & $\begin{array}{l}0 \\
0 \\
1\end{array}$ & $\begin{array}{l}1 \\
0 \\
0\end{array}$ & $\begin{array}{l}0 \\
0 \\
1\end{array}$ & $\begin{array}{l}0 \\
0 \\
1\end{array}$ & $\begin{array}{l}0 \\
0 \\
\mathbf{J}\end{array}$ & $\begin{array}{l}1 \\
0 \\
0\end{array}$ & $\begin{array}{ll}0 & 1 \\
0 & 0 \\
1 & 1\end{array}$ & $\begin{array}{ll}0 & 0 \\
0 & 0 \\
1 & 1\end{array}$ & $\begin{array}{ll}0 & 0 \\
0 & 0 \\
1 & 1\end{array}$ & $\begin{array}{l}0.98 \\
0.01 \\
0.01\end{array}$ & $\begin{array}{r}32 \\
1 \\
107\end{array}$ & $\begin{array}{l}0.23 \\
0.01 \\
0.76\end{array}$ & $\begin{array}{l}2 \$ 405 f \\
\$ 30-10 s f \\
<\$ 30 s f\end{array}$ \\
\hline & & & & & & & & & & & & & & & & & & & & & & & & & & & & \\
\hline 3.1, & u & u & u & u & u & u & 0 & 0 & 0 & 0 & 0 & 0 & 0 & 0 & 0 & 0 & 0 & 0 & 0 & 0 & 0 & 00 & 0 & 0 & 0.01 & i & $0.0 !$ & $\begin{array}{l}250551 \\
\$ 60-6551\end{array}$ \\
\hline
\end{tabular}


JABLE C.4. Buildings "B" Scenario, cont.

10.

H/C Iechnolusy

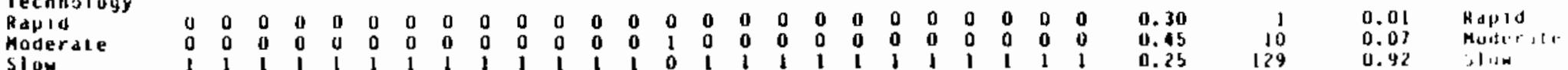

11.

Materials lechn Kajia $\begin{array}{lllllllllllllllllllllllllll}\text { Haderate } & 0 & 0 & 0 & 0 & 0 & 0 & 0 & 0 & 0 & 0 & 0 & 0 & 0 & 0 & 0 & 0 & 1 & 0 & 0 & 0 & 0 & 0 & 0 & 0 & 0 & 0.45 \\ \text { Slaw } & 1 & 1 & 1 & 1 & 1 & 1 & 1 & 1 & 1 & 1 & 1 & 1 & 1 & 1 & 1 & 1 & 0 & 1 & 1 & 1 & 1 & 1 & 1 & 1 & 1 & 0 .\end{array}$

12. My Code Inforc

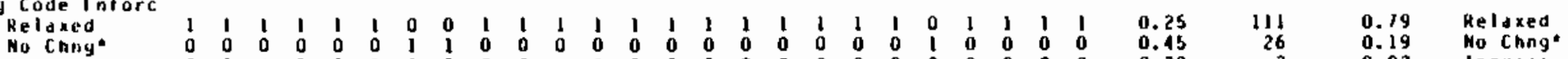

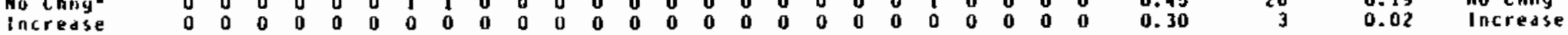

13.

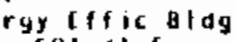

E01 11.5 a

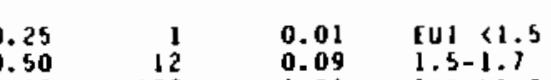

14.

Invst Horizon $\begin{array}{lllllllllllllllllllllllll}0 & 0 & 0 & 0 & 0 & 0 & 1 & 0 & 0 & 0 & 0 & 1 & 0 & 0 & 1 & 0 & 0 & 0 & 0 & 0 & 0 & 0 & 0 & 0 & 0\end{array}$ $\begin{array}{lllllllllllllllllllllllllll}\begin{array}{l}\text { Shiorter } \\ \text { As Pres. }\end{array} & 1 & 0 & 0 & 0 & 0 & 0 & 1 & 0 & 0 & 0 & 0 & 1 & 0 & 0 & 1 & 0 & 0 & 0 & 0 & 0 & 0 & 0 & 0 & 0 & 0 & 0.01 \\ \text { Lonyer } & 0 & 0 & 0 & 0 & 1 & 1 & 0 & 1 & 1 & 1 & 1 & 0 & 1 & 1 & 0 & 1 & 1 & 1 & 1 & 1 & 1 & 1 & 1 & 1 & 1 & 0.9 \\ \end{array}$

15.

Qility Role Mareact $\begin{array}{lllllll}0 & 0 & 1 & 0 & 0 & 0 & 0 \\ 0 & 1 & 0 & 0 & 0 & 1 & 0 \\ 0 & 0 & 0 & 0 & 0 & 0\end{array}$ As Prst* $\begin{array}{lllllllllllllllllllllllll}0 & 0 & 0 & 0 & 0 & 1 & 0 & 0 & 0 & 0 & 1 & 0 & 0 & 0 & 0 & 0 & 0 & 0 & 0 & 0 & 0 & 0 & 0 & 0 & 0 \\ 1 & 0 & 0 & 1 & 1 & 0 & 1 & 1 & 1 & 0 & 0 & 0 & 1 & 1 & 0 & 0 & 1 & 1 & 1 & 1 & 1 & 1 & 0 & 1 & 1 \\ 1 & 1 & 0 & 0 & 1 & 1 & 0 & 0 & 0 & 0 & 0 & 0 & 1 & 0 & 0\end{array}$

0.15 01

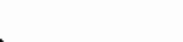
$\begin{array}{llllllllllllllllllllllllll}\text { Declines } & 1 & 1 & 1 & 1 & 1 & 1 & 1 & 1 & 1 & 1 & 1 & 1 & 1 & 1 & 1 & 1 & 1 & 1 & 1 & 1 & 1 & 1 & 1 & 1 & 1\end{array}$

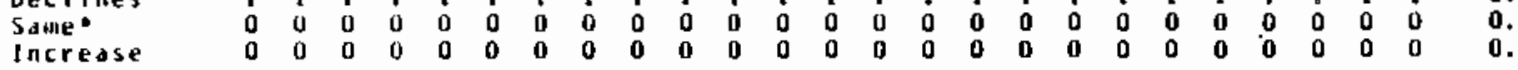
17.

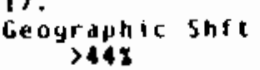
$>448$
$42-442$
$<42 \pi$

$\begin{array}{llllllllll}0 & 0 & 0 & 0 & 0 & 0 & 0 & 0 & 0 & 0 \\ 1 & 1 & 1 & 0 & 0 & 0 & 0 & 0 & 0 & 0\end{array}$

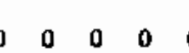

$\begin{array}{llllllllll}0 & 0 & 0 & 0 & 0 & 0 & 0 & 0 & 0 & 0 \\ 0 & 0 & 0 & 0 & 0 & 0 & 0 & 0 & 0 & 0 \\ 1 & 1 & 0 & 1 & 1 & 1 & 1 & 1 & 1 & 1\end{array}$

0.01

0.01
0.01
0.98

.08 I

1.0.1.

18 . $\begin{array}{llllllllllllllllllllllllllllll}\text { Higher } & 0 & 0 & 0 & 0 & 0 & 0 & 0 & 0 & 0 & 0 & 0 & 0 & 0 & 0 & 1 & 0 & 0 & 0 & 0 & 0 & 0 & 0 & 0 & 0 & 0 & 0.40 & 16 & 0.11 & \text { Higher } \\ \text { Saget } & 0 & 0 & 0 & 0 & 0 & 0 & 0 & 1 & 0 & 0 & 0 & 0 & 0 & 0 & 0 & 0 & 0 & 0 & 0 & 0 & 0 & 0 & 0 & 0 & 0 & 0.35 & 7 & 0.05 & 509 e^{2}\end{array}$

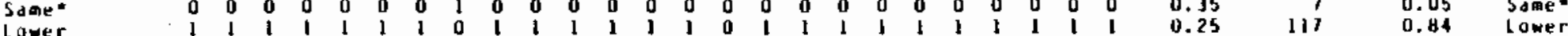
19.

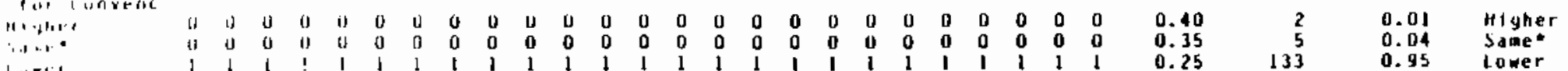


TABLE C.4. Buildings "B" Scenario, cont.

20.

Worta Price oil

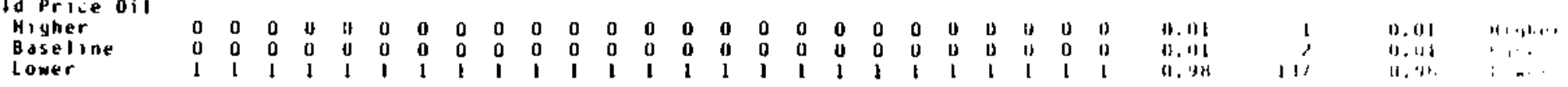

21.

Electricty Price

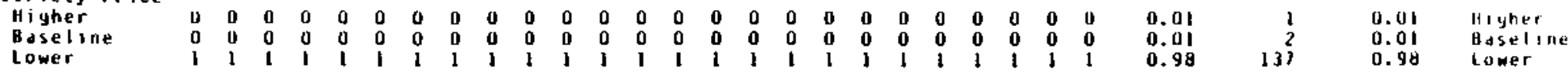
22.

mi i yratiun

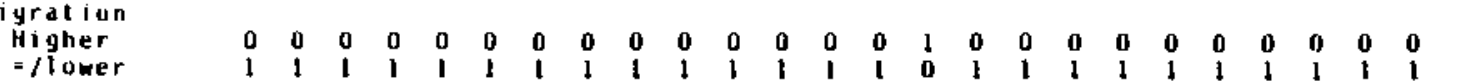

23. ird Pret Hows 24. Pigliden Grweh
Hiddie* $\begin{array}{lllllllllllllllllllllllll}0 & 0 & 0 & 0 & 0 & 0 & 0 & 0 & 0 & 0 & 0 & 0 & 0 & 0 & 0 & 0 & 0 & 0 & 0 & 0 & 0 & 0 & 0 & 0 & 0 \\ 0 & 0 & 0 & \mathbf{1} & 0 & 0 & \mathbf{0} & 0 & 0 & 0 & \mathbf{0} & \mathbf{0} & 0 & 0 & \mathbf{0} & 0 & 0 & \mathbf{0} & \mathbf{0} & \mathbf{0} & 0 & \mathbf{0} & \mathbf{0} & \mathbf{0} & 0\end{array}$ Low 


\section{DISTRIBUTION}

No. of

Copies

OFFSITE

Mr. Fred Abe]

U.S. Department of Energy

Office of Building and Community Systems

Forrestal Building

1000 Independence Avenue SW

Washington, DC 20585

30 DOE Technical Information Center

Dr. Reece Achenbach

Consultant Center for Building

Technology

National Bureau of Standards

Gaithersburg, MD 20899

Dr. Roger Carlsmith, Director

Conservation and Renewable Energy

Oak Ridge National Laboratory

P.0. Box $X$

Oak Ridge, TN 37830

$\mathrm{Mr}$. Howard Gaberson, Director

Mechanical Systems Division

Nava] Civit Engineering Laboratory

Port Hueheme, CA 93403

Dr. Mark Hehnen, Manager

Technology Awarness R \& D

Weyerhaeuser Company

Techology Center

Tacoma, WA 98477

Mr. John Milithone

U.S. Department of Energy

Office of Building \&

Community Systems

Forrestal Building

1000 Independence Avenue SW

Washington, DC 20585
No. of

Copies

OFFSITE

Mr. Stanley Pansky

Architect

$2647 \mathrm{SW}$

Portland, OR 97201

Mr. Donald Prowler

Assistant Professor

Department of Architecture

University of Pennsylvania

34 \& Spruce Street

Philadelphia, PA 19104

Mr. William Seaton

Manager of Research

ASHRAE, Inc.

1791 Tulie Circle

At lanta, GA 30329

Mr. Gary Stacy

505 King Avenue

Columbus, $\mathrm{OH} 43201$

Dr. Dan Turner, Dept. Head

Department of Mechanical

Engineering

Texas A \& M University

College Station, TX 77843

Mr. William Krauss, Director

Heat Pump \& Appliance Research

Gas Research Institute

8600 West Bryan Mawr Avenue

Chicago, IL 60631

Mr. Michael Warwick, Chief

Assessment and Evaluation Branch

Bonneville Power Administration

P.0. Box 3621

Portland, OR 97208 
No. of

Copies

ONSITE

DOE Richland Operations Office

J.J. Sutey

21 Pacific Northwest Laboratory

R.C. Adams

W. B. Ashton

W.T. Flynn (2)

C.A. Geffen

J.P. Kohlman

R.W. Reilly

R.G. Rivera

R.M. Scheer

T.J. Secrest

Publishing Coordination (2)

Technicat Library (5) 